\title{
CIÊNCIAS DA SAÚDE E SUAS CONTRIBUIÇÕES SOCIAIS
}
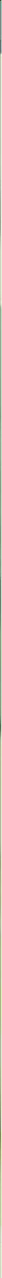

DEWSON ROCHA PEREIRA MARIA LUIZA DA CUNHA REGO RICARDO SÉRGIO DA SILVA 
Dados Internacionais de Catalogação na Publicação (CIP) (Câmara Brasileira do Livro, SP, Brasil)

Ciências da saúde e suas contribuições sociais [livro eletrônico] / [organização] Dewson Rocha Pereira, Maria Luiza da Cunha Rego, Ricardo

Sérgio da Silva. -- 1. ed. -- Recife, PE :

Instituto Internacional Despertando Vocações, 2020.

PDF

Bibliografia.

ISBN 978-65-991061-9-4

1. Ciências da saúde 2. Ciências da saúde Pesquisa 3. Contribuições sociais I. Pereira, Dewson Rocha. II. Rego, Maria Luiza da Cunha. III. Silva, Ricardo Sérgio da. CDD-610

Índices para catálogo sistemático:

1. Ciências da saúde 610

Cibele Maria Dias - Bibliotecária - CRB-8/9427 


\title{
CIÊNCIAS DA SAÚDE E SUAS CONTRIBUIÇÕES SOCIAIS
}

\author{
1 a Edição
}

Recife - PE - Brasil

INSTITUTO INTERNACIONAL DESPERTANDO VOCAÇÕES

2020

[iii] 


\section{LIVRO DOS TRABALHOS PREMIADOS NO I CONGRESSO \\ INTERNACIONAL DAS CIÊNCIAS DA SAÚDE - I COINTER PDVS 2019}

ORGANIZADORES: Dewson Rocha Pereira

Maria Luiza Da Cunha Rego

Ricardo Sérgio Da Silva

EDITOR: Ayrton Matheus da Silva Nascimento

DIAGRAMAÇÃO: Anderson Soares da Silva / Mariana Almeida Ferreira de Lima

ISBN: 978-65-991061-9-4

DOI: $\underline{10.31692 / 978-65-991061-9-4}$

EDITORA: Instituto Internacional Despertando Vocações (IIDV)

Edição Digital 2019. Direitos exclusivos reservados para todos os países. Proibida sua reprodução total ou parcial, para uso privado ou coletivo, em qualquer meio impresso ou eletrônico de acordo com as leis de Propriedade Intelectual.

Digitalizado no Brasil / Digitalizado en Brasil/ Digitized in Brazil. 


\section{PREFÁCIO}

Este livro faz parte dos trabalhos aprovados, apresentados e premiados do I Congresso Internacional da Saúde - I COINTER PDVS foi uma realização do Instituto Internacional Despertando Vocações (IIDV), que teve o compromisso com a democratização do conhecimento e com uma Educação de qualidade e teve como objetivos: discutir os caminhos e perspectivas dos estudos na área; divulgar os conteúdos e resultados de pesquisas; estabelecer trocas de experiências entre docentes investigadores do Brasil e do exterior, contribuir na formação dos estudantes e estimular a geração de novas redes de cooperação multicêntricas.

A intenção é, dessa forma, foi estimular, numa perspectiva plural, conversações e reflexões sobre a área, em diversos âmbitos. A importância do I COINTER-PDVS, foi a necessidade de ofertar aos estudantes e docentes, maior possibilidade de participação em eventos internacionais, que permitiram a troca de saberes e fazeres entre instituições parceiras e potenciais parceiras. Foram convidados pesquisadores do Brasil e do exterior com ampla experiência e produção em seus campos de estudo, onde apresentaram em conferências e mesas redondas os resultados de suas pesquisas. Todas as sessões foram seguidas de debates, possibilitando maior interface entre pesquisadores, estudantes de pós-graduação e graduação, professores universitários, de Educação Básica, além de pessoas da comunidade interessadas no tema.

Destacamos que as discussões contemplaram as seguintes áreas das Ciências da Saúde: Biomedicina; Educação Física; Enfermagem; Farmácia; Fisioterapia; Medicina; Nutrição; Psicologia; Fonoaudiologia; Odontologia. Eixos Temáticos: Aplicações clínicas; Biomateriais; Práticas Educacionais em Saúde; Ciências básicas; Educação em saúde; Ensino Comunitário; Promoção à Saúde; Educação Popular; Tecnologias Educacionais; Epidemiologia; Gestão; Outra; Saúde pública; Segurança do paciente e bioética.

Dr. Dewson Rocha Pereira (Coordenador do COINTER PDVS 2019)

MSc. Ricardo Sérgio Da Silva (Coordenador do COINTER PDVS 2019) MSc. Maria Luiza Da Cunha Rego (Coordenadora do COINTER PDVS 2019)

I Congresso Internacional das Ciências da Saúde 


\section{PRESIDENTE DO IIDV 2019}

$\mathrm{Dr}^{\mathrm{a}}$. Kilma da Silva Lima Viana

COORDENADOR GERAL DO PDV 2019

MSc. Erick da Silva Lima Viana

COORDENADORA GERAL DO PDVS 2019

MSc. Maria Luiza da Cunha Rego

COORDENADOR EXECUTIVO DO COINTER PDV 2019

Esp. Ayrton Matheus da Silva Nascimento

PRESIDENTE DA COMISSÃO CIENTÍFICA DO COINTER PDVS 2019

Dr. Dewson Rocha Pereira

PRESIDENTE DA COMISSÃO CIENTÍFICA DO COINTER PDVS 2019

MSc. Maria Luiza da Cunha Rego

PRESIDENTE DA COMISSÃO CIENTÍFICA DO COINTER PDVS 2019

MSc. Ricardo Sérgio da Silva

MEMBROS DA COMISSÃO CIENTÍFICA DO I CONGRESSO INTERNACIONAL DAS CIÊNCIAS DA SAÚDE - COINTER PDVS 2019

\begin{tabular}{|c|c|c|}
\hline NOME & ÁREA & TEMA \\
\hline ADAUTO GOMES BARBOSA NETO & Ciências Biológicas & Biotecnologia \\
\hline ANNELIESE GONÇALVES COSTA MARINHO & Saúde Coletiva & Saúde pública \\
\hline BÁRBARA RAFAELA DA SILVA BARROS & Ciências Biológicas & Biotecnologia \\
\hline BRUNO OLIVEIRA DE VERAS & $\begin{array}{c}\text { Ciências Biológicas } \\
\text { (Lic) }\end{array}$ & Biotecnologia \\
\hline CARMEM SARA PINHEIRO DE OLIVEIRA & Nutrição & $\begin{array}{c}\text { Práticas Educacionais } \\
\text { em Saúde }\end{array}$ \\
\hline DAYANE KELLY DIAS DO NASCIMENTO SANTOS & Biomedicina & Produtos naturais \\
\hline EDSON FRANCISCO DO CARMO NETO & $\begin{array}{c}\text { Ciências Biológicas } \\
\text { (Lic) }\end{array}$ & Genética Ambiental \\
\hline GRAZIELA CLAUDIA DA SILVA & Ciências Biológicas & Biotecnologia \\
\hline JOSÉ JAILSON LIMA BEZERRA & Ciências Biológicas & Aplicações clínicas \\
\hline KARLA REGINA FREITAS E SILVA & Enfermagem & Educação em saúde \\
\hline MARIA GISLAINE PEREIRA & Ciências Biológicas & Genética Ambiental \\
\hline NATÁLIA ALMEIDA ONOFRE CORDEIRO & Biomedicina & Biotecnologia \\
\hline PAULO EUZÉBIO CABRAL FILHO & Biomedicina & Biotecnologia \\
\hline PENHA PATRÍCIA CABRAL RIBEIRO & Nutrição & Promoção à Saúde \\
\hline RAFAELA ALVES DE OLIVEIRA & $\begin{array}{c}\text { Ciências Biológicas } \\
\text { (Lic) }\end{array}$ & Genética Ambiental \\
\hline RICARDO SÉRGIO DA SILVA & Ciências Biológicas & Biotecnologia \\
\hline SAMUEL LIMA DE SANTANA & $\begin{array}{c}\text { Ciências Biológicas } \\
\text { (Lic) }\end{array}$ & Genética Ambiental \\
\hline WELTON AARON DE ALMEIDA & $\begin{array}{c}\text { Ciências Biológicas } \\
\text { (Lic) }\end{array}$ & Biotecnologia \\
\hline
\end{tabular}




\section{SUMÁRIO}

INTER-RELAÇÃO OU COEXISTÊNCIA: POSSÍVEIS (DES)ARTICULAÇÕES ENTRE A FIBROMIALGIA E A DEPRESSÃO

Karoliny Paula da Silva; Higor Bezerra Lima; André Cabral

DOI: https://doi.org/10.31692/978-65-991061-9-4.1-13

MECANISMOS DE EMPODERAMENTO: O QUE DIZEM OS AGENTES COMUNITÁRIOS DE SAÚdE (ACS) A RESPEITO DA SAÚdE SEXUAL NA ATENÇÃO BÁSICA

Thiago Rubens da Silva; Paulo Marcelo Freitas de Barros

DOI: https://doi.org/10.31692/978-65-991061-9-4.14-28

MECANISMOS DE EMPODERAMENTO: O QUE DIZEM OS ENFERMEIROS A RESPEITO DA SAÚDE SEXUAL NA ATENÇÃO BÁSICA

Alexsandra Aderita da Silva; Paulo Marcelo Freitas de Barros

DOI: https://doi.org/10.31692/978-65-991061-9-4.29-43

PROPRIEDADES MEDICINAIS DE PLANTAS DO MANGUE DO ESTADO DE PERNAMBUCO

Ricardo Sérgio da Silva; Zion Nascimento de Souza; Rayza Helen Graciano dos Santos; Elielma Josefa de Moura; Isabelly Fernanda Santos Barbosa.

DOI: $\underline{\text { https://doi.org/10.31692/978-65-991061-9-4.44-55 }}$

UM OLHAR SOB A PERSPECTIVA DA OFICINA "EU RECONHEÇO SINAIS DE ALERTA NO PRÉ-NATAL E PUERPÉRIO” - DISTRITO SANITÁRIO VII RECIFE - PE

Ariosto Afonso de Morais; Thâmara Onofre de Melo; Fernanda Evelyn Silva; Eliane Barbosa da Silva; Christiane Walburga Ferreira de Azevedo.

DOI: $\underline{\text { https://doi.org/10.31692/978-65-991061-9-4.56-61 }}$

AÇÃO COMPORTAMENTAL RELACIONADA À ANSIEDADE E ASPECTOS ELETROFISIOLÓGICOS CEREBRAIS DA CAFEÍNA: ANÁLISE EM RATOS ALBINOS EM DESENVOLVIMENTO

Maria Luísa Figueira de Oliveira; Camila Lima Chagas; Regina de Deus Lira Benevides; Fernanda das Chagas Angelo Mendes Tenório

DOI: https://doi.org/10.31692/978-65-991061-9-4.62-67

POTENCIAL ANTIMICROBIANO DE ÓLEOS ESSENCIAIS ENCAPSULADOS EM LIPOSSOMAS

Jaqueline Barbosa de Souza; Maria Anndressa Alves Agreles; Davi de Lacerda Coriolano; Sandrelli Meridiana de Fátima Ramos do Santos Medeiros; Isabella Macário Ferro Cavalcanti

DOI: https://doi.org/10.31692/978-65-991061-9-4.68-74

RELAÇÃO DA QUALIDADE DO SONO E DESEMPENHO ACADÊMICO DE JOVENS UNIVERSITÁRIOS

Jamilly Henrique Costa da Silva; Jadna Emille da Silva Arruda; Natália de Castro e Silva Martins; Luciana Moraes Studart Pereira

DOI: https://doi.org/10.31692/978-65-991061-9-4.75-80

ASSOCIAÇÃO ENTRE RESISTÊNCIA À INSULINA E SÍNDROME METABÓLICA X EM INDIVÍDUOS DO MUNICÍPIO DE CARUARU-PE

Jeaninne Alexandra de Azevedo Silva; Layse Ciane Silveira Cirino de Britto Galvão; Antônio Lopes Ferreira Neto; Iasmine Andreza Basilio dos Santos Alves; Bianka Santana dos Santos

DOI: https://doi.org/10.31692/978-65-991061-9-4.81-86 
TOXICOLOGICAL EFFECTS OF THALLIUM IN THE EXPERIMENTAL MODEL CAERNOHABDITIS ELEGANS

Amanda Onduras de Andrade; Larissa Pereira Dantas; Leandro de Oliveira Amaral; Alexandre Varão de Moura; Priscila Gulbert

DOI: https://doi.org/10.31692/978-65-991061-9-4.87-93

EFEITO DO NÚMERO CUMULATIVO DE CIGARROS FUMADOS SOBRE O PERFIL LIPÍDICO E CLASSES DE FOSFOLIPÍDIOS DE UMA POPULAÇÃO DE CARUARU-PERNAMBUCO

Antonio Lopes Ferreira Neto; Isabela Simões Alves; Jeaninne Alexandra de Azevedo Silva; Ana Carolina Bezerra Paz; Bianka Santana dos Santos

DOI: https://doi.org/10.31692/978-65-991061-9-4.94-99

CONTRIBUIÇÕES DAS AÇÕES DE DESPERTAR VOCAÇÕES: O CASO DA VISITA GUIADA A UM CAMPUS AGRÍCOLA.

Karoliny Paula da Silva; Erick Viana da Silva

DOI: https://doi.org/10.31692/978-65-991061-9-4.100-103

A IMPORTÂNCIA DO TESTE DA LINGUINHA E DA INTERVENÇÃO DE UMA EQUIPE MULTIPROFISSIONAL EM CRIANÇAS COM ANQUILOGLOSSIA POR MEIO DO PROTOCOLO DE MARTINELLI

Danielle Pereira de Lima; Alana Tainá Rodrigues Barbosa; Eduardo Ramos da Silva; Vytor Paulo Conserva Silva; Artemísia Ruth Arruda Lucena Veras

DOI: $\underline{\text { https://doi.org/10.31692/978-65-991061-1-8.104-106 }}$

SERVIÇO DE ATENDIMENTO INTERDISCIPLINAR A PACIENTES COM ALTERAÇÕES CRANIOMANDIBULARES

Natália de Castro e Silva Martins; Clarissa Evelyn Bandeira Paulino; Giovanna Siqueira Faustino da Silva; Camilla Thalya da Silva Batista; Luciana Moraes Studart Pereira

DOI: https://doi.org/10.31692/978-65-991061-9-4.107-110

USO DE DROGAS LÍCITAS E ILÍCITAS NA GRAVIDEZ: A IMPORTÂNCIA DOS ESCLARECIMENTOS DOS RISCOS AS GESTANTES

Larissa Tainá; Deyse Aíla; Alessandra Alves; Laniedja Jacó; Robervam Pedroza

DOI: https://doi.org/10.31692/978-65-991061-9-4.111-114

PLANTAS MEDICINAIS UTILIZADAS NO NORDESTE DO BRASIL: UMA REVISÃO DE LITERATURA

Zion Nascimento de Souza, Bárbara Rafaela da Silva Barros, Kaline Soares da Silva, Ricardo Sérgio da Silva, Cristiane Moutinho Lagos de Melo.

DOI: https://doi.org/10.31692/978-65-991061-9-4.115-132 


\title{
INTER-RELAÇÃO OU COEXISTÊNCIA: POSSÍVEIS (DES)ARTICULAÇÕES ENTRE A FIBROMIALGIA E A DEPRESSÃO
}

\section{INTER-RELACIÓN O COEXISTENCIA: POSIBLE (DES) ARTICULACIÓN ENTRE FIBROMIALGIA Y DEPRESIÓN}

\section{INTERRELATIONSHIP OR COEXISTENCE: POSSIBLE (DIS) ARTICULATIONS BETWEEN FIBROMYALGY AND DEPRESSION}

\author{
Karoliny Paula da Silva ${ }^{1}$; Higor Bezerra Lima²; André Cabral ${ }^{3}$
}

DOI: $\underline{\text { https://doi.org/10.31692/978-65-991061-9-4.1-13 }}$

\begin{abstract}
RESUMO
O escopo deste artigo é analisar como é estabelecida a relação entre a Síndrome de Fibromialgia e a depressão, vista a alta demanda de pacientes acometidos pelas enfermidades. Para nos fundamentar teoricamente, partimos da concepção de Mello-Filho et al (2010) sobre fibromialgia, Dalgalarrondo (2008) sobre depressão, Lipp (2001) e Homann et al (2012) para elucidar conceitos de estresse, todos fundantes para o processo de sistematização de informações e escrita deste trabalho. Para realizar a presente análise, partimos da metodologia de revisão bibliográfica integrativa, a partir da qual analisamos 4 artigos científicos coletados das plataformas digitais: Google Scholar, SciELO e PePsic. Para isto, partimos da seguinte pergunta norteadora: "qual a relação entre a fibromialgia e a depressão denotada nas pesquisas mais recentes?" Enquanto resultados, pudemos perceber a escassez de pesquisas recentes na área, principalmente na Psicologia, além de todas as pesquisas serem realizadas com o público feminino, por esse ser mais afetado pelo transtorno fibromiálgico. Além disso, é perceptível uma forma reducionista de lançar luz sobre a depressão, como se esta fosse apenas um sintoma da fibromialgia que pode ser desenvolvido ou não, negando o caráter individual da doença. Não se verificou uma abordagem sobre o ponto de vista psicopatológico e nem mesmo uma causa bem definida para o surgimento da doença em questão. A partir disso, pôde-se concluir a necessidade de uma maior investigação sobre os casos de fibromialgia e seu surgimento, qual a sua relação com as condições socioeconômicas, educacionais e de gênero. Além disso, é necessária uma fomentação nas pesquisas científicas acerca do tema.
\end{abstract}

Palavras-Chave: Depressão, Fibromialgia, Psicologia.

\section{RESUMEN}

El alcance de este artículo es analizar cómo se establece la relación entre el Síndrome de Fibromialgia y la depresión, teniendo en cuenta la gran demanda de pacientes afectados por las enfermedades. Para apoyarnos teóricamente, partimos de la concepción de Mello-Filho et al (2010) sobre la fibromialgia, Dalgalarrondo (2008) sobre la depresión, Lipp (2001) y Homann et al (2012) para dilucidar los conceptos de estrés, todos fundamentales para el proceso de sistematización de la información y redacción de este trabajo. Para realizar este análisis, partimos de la metodología integradora de revisión de literatura, a partir de la cual analizamos 4 artículos científicos recopilados de plataformas digitales: Google Scholar, SciELO y PePsic. Para esto, partimos de la siguiente pregunta orientadora: "¿cuál es la relación entre la fibromialgia y la depresión denotada en la investigación más reciente?" Como resultado, pudimos ver la escasez de investigación reciente en el área, especialmente en psicología,

\footnotetext{
${ }^{1}$ Graduanda em Psicologia, Centro Universitário Guararapes (UNIFG), karolinypaula.pt@gmail.com

${ }^{2}$ Técnico em Segurança do Trabalho, Instituto Federal de Pernambuco (IFPE), higorbezerralima2003@gmail.com

${ }^{3}$ Mestre em Gerontologia, Professor do Centro Universitário Guararapes (UNIFG), andre.cabral@unifg.com.br
} 
además de toda la investigación que se realiza. con el público femenino, ya que esto se ve más afectado por el trastorno de fibromialgia. Además, se nota una forma reduccionista de arrojar luz sobre la depresión, como si fuera solo un síntoma de fibromialgia que puede desarrollarse o no, negando el carácter individual de la enfermedad. No hubo un enfoque psicopatológico y ni siquiera una causa bien definida para el inicio de la enfermedad en cuestión. A partir de esto, se concluyó que existe la necesidad de una mayor investigación sobre los casos de fibromialgia y su aparición, cuál es su relación con las condiciones socioeconómicas, educativas y de género. Además, se requiere fomentar la investigación científica sobre el tema.

Palabras Clave: Depresión, Fibromialgia, Psicología.

\section{Abstract}

The scope of this article is to analyze how the relationship between Fibromyalgia Syndrome and depression occurs, given the high demand of patients affected by the diseases. To support ourselves theoretically, we start from the conception of Mello-Filho et al (2010) about fibromyalgia, Dalgalarrondo (2008) about depression, Lipp (2001) and Homann et al (2012) to elucidate concepts of stress, all key to the process. systematization of information and writing of the work. To perform this analysis, we started from the integrative literature review methodology, with which we analyzed 4 scientific articles collected from digital platforms: Google Scholar, SciELO and PePsic. For this, we start from the following guiding question: "What is the relationship between fibromyalgia and depression denoted in the most recent research?". As results, we could see the scarcity of recent research in the area, especially in Psychology, and all research is conducted with the female public, as this is more affected by fibromyalgia disorder. Moreover, a reductionist way of shedding light on depression is noticeable, as if it were just a symptom of fibromyalgia that may or may not develop, denying the individual character of the disease. There was no psychopathological approach and not even a well-defined cause for the onset of the disease in question. From this, it was concluded that there is a need for further investigation into the cases of fibromyalgia and its emergence, what is its relationship with socioeconomic, educational and gender conditions. In addition, a fostering of scientific research on the subject.

Keywords: Depression, Fibromyalgia, Psychology.

\section{INTRODUÇÃO}

O presente artigo busca verificar o que há na literatura especializada atual sobre a ocorrência da Fibromialgia (FM) em pacientes portadores de depressão. A FM é definida como "uma entidade clínica caracterizada por dor crônica com duração maior que três meses" e que acomete primordialmente mulheres (NUNES et al, 2012. p. 282). As quais, na sua maioria, quando afetadas pela patologia, possuem elevados níveis de estresse comparadas ao grupo sem fibromialgia (não FM). Isso porque, segundo os estudos de Calais, Andrade e Lipp (2003) e Sadir, Bignotto e Lipp (2010), as mulheres estão mais expostas à situação de estresse, tanto por sua condição biológica quanto pelos papéis culturais que a sociedade historicamente lhes impõe.

Logo, buscamos averiguar na literatura como a relação entre a psicopatologia e a FM é entendida, levando em consideração as visões de somatização. Adota-se para as e reflexões sobre a possibilidade de somatização a visão da relação entre mente-corpo e os mecanismos de 
produção de enfermidades, geralmente impulsionados por fenômenos do estresse (MELLOFILHO et al, 2010. p. 29). Isto é, há um deslocamento do sofrimento psíquico para um sintoma físico, no caso da pesquisa em questão, às dores corpóreas e o conjunto de sintomas relacionados a FM. Deslocamento pode ser definido, de acordo com Silva (2010), como um "mecanismo psicológico de defesa onde a pessoa substitui a finalidade inicial de uma pulsão por outra socialmente mais aceita" (p. 5), ou seja, é uma estratégia mental para canalização da dor, de acordo com a vertente psicanalítica.

A depressão "tem como elementos mais salientes o humor triste e o desânimo" (DEL PINO, 2003 apud DALGALARRONDO, 2008. p. 307). Entretanto, Dalgalarrondo (2008. p. 307-308) elucida a noção de que há uma "multiplicidade de sintomas afetivos, instintivos e neurovegetativos, ideativos e cognitivos, relativos à autovaloração, à vontade e à psicomotricidade", ou seja, os transtornos depressivos ultrapassam a noção de uma tristeza forte e persistente, afetando a saúde física e o bem-estar do portador. A persistência da dor física durante a vivência de uma dor psicológica descrita por relatos de caso ${ }^{4}$ fortalece a hipótese e apontamentos de que a FM é um transtorno psicossomático.

A pesquisa e reflexão acerca da FM e da sua correlação com as doenças psicológicas envolvidas no presente artigo é de extrema importância, visto a gravidade das doenças e como elas impactam no status quo vital dos portadores.

A dificuldade na identificação das causas do surgimento da FM e do seu tratamento acaba por marginalizar os portadores a partir do viés de saúde pública, e prejudicar o próprio sistema de saúde, afinal, sem o conhecimento prático acerca da doença e da influência das patologias psicológicas no seu surgimento e tratamento, não há como definir métodos de prevenção e tratamento, evidenciando assim, uma maior quantidade de consultas paliativas e de tempo útil utilizando medicamentos aliviadores que poderiam ser evitados com um tratamento mais direcionado (RAMIRO et al., 2013).

Portanto, visa-se a verificação literária especializada de como andam as pesquisas acerca da FM enquanto consequência das doenças psicológicas aqui investigadas. Logo, enquanto hipótese, pensamos que as psicopatologias, como a ansiedade e depressão, suscitam um processo de somatização da dor psíquica, motivando a sintomatologia da FM. Sendo assim, busca-se verificar se a depressão e a FM são associadas ou apenas coexistem.

Sendo assim, o método escolhido foi a Revisão de Literatura de base integrativa, uma vez que esse método dá margem a um maior cuidado com temas voltados para a área da saúde,

\footnotetext{
${ }^{4}$ NUNES et al. Transtorno depressivo e fibromialgia: associação com estresse de vida precoce. Relato de caso. Revista Dor. São Paulo, v. 13 n. 3 p. 282-286, jul./set., 2012.
} 
pois correlaciona dados teóricos e empíricos.

Enquanto objetivo geral, buscamos verificar se a depressão é uma patologia que suscita o aparecimento dos sintomas da FM e analisar o motivo dessa ocorrência, partindo do pressuposto da somatização dos sofrimentos psíquicos.

Enquanto objetivos específicos, há a necessidade de: investigar a FM enquanto doença psicossomática e a sua correlação com a psique; e, primordialmente, revisitar o olhar teórico descrito até agora sobre a influência das questões psicossomatopatológicas no surgimento da FM.

\section{FUNDAMENTAÇÃO TEÓRICA}

Visando elucidar conceitos essenciais para o desenvolvimento do artigo, como os de estresse, depressão e somatização, o presente artigo se debruça sobre os escritos de Dalgalarrondo (2008) e Mello-Filho \& Burd (2010), pois estes são autores fundamentais para os estudos das psicopatologias, sua sintomatologia e como estas condições afetam o indivíduo.

Geralmente, os dados achados no campo científico são voltados para as outras ciências da saúde, sempre em busca de novas formas de cura ou com vistas a explicar e diagnosticar a FM a partir puramente do viés biológico, o que é complexo, haja visto que os sintomas da FM são "desvinculados de alterações orgânicas passíveis de detecção e invariavelmente relacionadas a alterações no humor, na memória e no sono" (CLAUW, 2014; BELLATO et al., 2012 apud PELLOSI e PERES, 2017).

Em vista disso, a supervalorização das ciências biológicas e exatas em detrimento dos conhecimentos voltados para o entendimento do humano, ou seja, o positivismo científico, infelizmente ainda em voga no meio acadêmico, "tem levado muitos pesquisadores - inclusive no campo da Psicologia - a negligenciarem os aspectos subjetivos da fibromialgia" (PELLOSI e PERES, 2017). Ou seja, há uma necessidade de lançar luz sobre a FM a partir do olhar psicológico alinhado ao olhar biológico, para criar formas eficazes de identificar, diagnosticar e tratar os pacientes acometidos dessa síndrome.

Faz-se necessário ainda compreender as concepções encontradas na literatura sobre a condição do estresse, uma vez que este é frequentemente percebido como provável desencadeador da FM. Entende-se por estresse o conjunto de reações psicofisiológicas e comportamentais complexas, cuja origem está na necessidade de o organismo estabelecer a homeostase interna frente a uma situação ameaçadora (LIPP, 2001).

A desestabilização acontece quando o próprio organismo necessita responder a uma demanda que supere sua capacidade adaptativa. Esse processo, dependendo da quantidade extra 
de demanda, gera necessidade de adaptação do organismo e, como consequência, exerce papel fundamental na patogênese do estresse (LIPP, 2001). Logo, é perceptível então, que na síndrome complexa da FM, o conjunto de sintomas extrapola a capacidade adaptativa do ser (HOMANN et al, 2012).

Na atualidade, a partir de Lipp (2000), entende-se a evolução do estresse como um processo que compreende quatro fases, abordadas no Inventário de Sintomas de Estresse para adulto de Lipp (ISSL), são elas: a fase de alerta, fase de resistência, fase de quase-exaustão e a fase de exaustão. A primeira é entendida como o momento positivo do estresse, ou seja, um estresse mais natural para lidar com as atitudes adversas. A persistência desse estresse pode configurar a fase de resistência, que pode ser entendida como um esforço do organismo para se adaptar, que acaba num cansaço do mesmo. Quando o processo continua, entra-se na terceira fase, que é caracterizada por sintomas clínicos importantes que denotam o cansaço, mas ainda não é um esgotamento completo. Quando os fatores estressores continuam, é caracterizada uma fase de quase-exaustão, na qual se é observado que a reserva de energia do organismo se exaure, afetando o sistema imunológico como um todo (LIPP, 2000).

O estresse é um sistema amplo, não só com fases, mas também com tipos e formas de combate. A fase de exaustão (última fase do estresse) pode ser o estopim para outras como depressão e ansiedade, levando até mesmo o trabalhador ao interrupção laboral.

De acordo com Besset et al (2010) "o momento em que irrompe um mal-estar e a esse mal-estar é atribuído um nome, por exemplo, o nome de uma doença, o corpo desse sujeito fica, para sempre, afetado por um efeito de nomeação, marca do significante sobre sua carne” (p. 1258), ou seja, quando um sujeito é minimizado ao seu quadro fisiológico, em detrimento de sua subjetividade e seu ser psicológico, há uma marcação cujo sujeito nunca se livra completamente.

Os fatores estressores, a longo prazo, podem culminar em uma série de transtornos dentre eles o tratado na presente pesquisa, a depressão, a qual pode apresentar duas formas: os episódios e o transtorno recorrente. Um episódio depressivo pode ser: leve, moderado ou grave com ou sem sintomas psicóticos, a recorrência desses episódios é que caracteriza um transtorno (DATASUS, 2008). Classificado no CID 10 com o código F32 e F33, a depressão e suas formas são descritas enquanto um transtorno bem delimitado de humor, no qual

\footnotetext{
o paciente apresenta um rebaixamento do humor, redução da energia e diminuição da atividade [...] alteração da capacidade de experimentar o prazer, perda de interesse, diminuição da capacidade de concentração, associadas em geral à fadiga importante, mesmo após um esforço mínimo. (DATASUS, 2008).
}

A partir do aporte teórico acerca dos principais temas abordados, foi possível realizar 
uma pesquisa que poderá contribuir ainda que de maneira preliminar ou introdutória aos estudos sobre a temática desenvolvida.

\section{METODOLOGIA}

Enquanto metodologia de pesquisa, utilizou-se a Revisão de Literatura Integrativa, que consiste em um instrumento próprio da Prática Baseada em Evidências, a qual é constituída dos seguintes passos:

a definição do problema clínico, a identificação das informações necessárias, à condução da busca de estudos na literatura e sua avaliação crítica, a identificação da aplicabilidade dos dados oriundos das publicações e a determinação de sua utilização para o paciente (SOUZA et al, 2010. p. 102)

Dentre os modos de Revisão de Literatura disponíveis e amplamente utilizados, como a sistemática, a escolhida foi a Integrativa, pois, ao combinar dados da literatura teórica e empírica, abre-se um leque de propósitos (SOUZA et al, 2010.). Sendo assim, dialoga-se melhor com questões como o cuidado com o humano, ponto fundamental e basilar da psicologia. Logo, buscaremos analisar artigos em português e inglês que estejam na base de dados PePsic (Periódicos Eletrônicos em Psicologia), SciELO (Scientific Electronic Library Online) e no Google Scholar.

Enquanto critério de inclusão, utilizaremos em nosso recorte textos que versem acerca de depressão e FM, num recorte temporal dos últimos 10 anos. Os textos utilizados serão apenas artigos científicos, ou seja, os critérios de exclusão são: quaisquer textos que não sejam artigos científicos; que estejam em outra língua que não o português ou o inglês; textos que tenham como metodologia a revisão de literatura; ou textos que correspondam a todos os critérios, mas que não verse atentamente sobre o subtema de pesquisa do presente artigo.

Durante a pesquisa primeira, foram identificados 4 textos no PePsic, 4 no Scielo e 36 no Google Scholar. Após a triagem e enquadramento dos critérios acima citados, delimitamos 4 artigos que foram analisados na presente pesquisa. Para ilustrar melhor os dados analisados na pesquisa, segue abaixo um quadro com as devidas informações.

Para a realização das tarefas descritas anteriormente, partimos da seguinte pergunta norteadora: qual a relação entre a fibromialgia e a depressão denotada nas pesquisas mais recentes? 


\section{RESULTADOS E DISCUSSÃO}

Quadro 1: quadro descritivo dos artigos analisados.

\begin{tabular}{|c|c|c|c|}
\hline Procedência & Título do artigo & Autores & Periódico (vol, no, pág, ano) \\
\hline PEPSIC & $\begin{array}{l}\text { Neuropsychological assessment of } \\
\text { patients with fibromyalgia. }\end{array}$ & $\begin{array}{l}\text { GOULART, R.; } \\
\text { PESSOA, C. e } \\
\text { LOMBARDI } \\
\text { JUNIOR, I. }\end{array}$ & $\begin{array}{l}\text { Estud. psicol. (Natal) [online]. vol.22, } \\
\text { n.3, p. 264-273, } 2017 .\end{array}$ \\
\hline SCIELO & $\begin{array}{l}\text { Investigação do estresse, ansiedade e } \\
\text { depressão em mulheres com } \\
\text { fibromialgia: um estudo comparativo. }\end{array}$ & $\begin{array}{l}\text { RAMIRO, } \\
\text { Fernanda de } \\
\text { Souza et al. }\end{array}$ & $\begin{array}{l}\text { Rev. Bras. Reumatol. [online]. vol.54, } \\
\text { n.1, p. 27-32, } 2014 .\end{array}$ \\
\hline $\begin{array}{l}\text { Google } \\
\text { Scholar }\end{array}$ & $\begin{array}{l}\text { A prática de caminhada diminui a } \\
\text { depressão em pacientes com síndrome } \\
\text { de fibromialgia. }\end{array}$ & $\begin{array}{l}\text { ANDRADE, } \\
\text { Alexandro et al }\end{array}$ & $\begin{array}{l}\text { ConScientiae Saúde, vol. 15, núm. 2, } \\
\text { 2016, pp. 217-224 }\end{array}$ \\
\hline $\begin{array}{l}\text { Google } \\
\text { Scholar }\end{array}$ & $\begin{array}{l}\text { Avaliação de Flexibilidade, Tender } \\
\text { Points e nível de ansiedade e depressão } \\
\text { em pacientes com síndrome da } \\
\text { fibromialgia. }\end{array}$ & $\begin{array}{l}\text { BARROS, T. R. } \\
\text { M. et al. }\end{array}$ & Colloq Vitae, vol. 7, nº 2, p. 13-19, 2015. \\
\hline
\end{tabular}

Fonte: própria.

Um ponto a ser destacado durante a construção do trabalho foi obtida durante a realização da pesquisa é escassez de artigos voltados ao viés psicológico da Fibromialgia denotando a necessidade de uma investigação mais ampla e profunda sobre o tema ainda tão pouco elucidado pela literatura e que acomete tantas pessoas. A necessidade de estudos mais aprofundados sobre as relações entre depressão e FM se torna ainda mais urgente quando nos deparamos com o significativo aumento de casos, já que no Brasil a quantidade de pessoas com FM chega na faixa de $3 \%$ da população, nos quais $80 \%$ das afetadas são mulheres na faixa etária de 35 à 55 anos (BRASIL, 2017). Dos quatro artigos analisados, 75\% são de áreas do conhecimento como a reumatologia, e apenas um é voltado pra a Psicologia. Quando há pouquíssimos estudos recentes desenvolvidos por profissionais da psicologia a área, o entendimento acerca da patologia, o seu diagnóstico, prognóstico e tratamento torna-se complexo para profissionais e pacientes.

Segundo Ramiro et al. (2013), que realizou uma pesquisa com uma amostragem de 50 mulheres, sendo 25 com FM e 25 com não FM, de idade de 20 a 65 anos, utilizando o Inventário de Depressão de Beck (BDI), um formulário que contém 21 afirmações que se referem a sintomas cognitivos e afetivos, sensações somáticas e desempenho, há um maior índice de depressão em pessoas com Fibromialgia. A pesquisa obteve como resultado uma média de 21,48 pontos para o grupo com FM. Um elevado nível médio comparado ao grupo com não FM, que obteve uma média de 7,36 pontos. Indicando assim, a presença de depressão moderada no grupo com FM, enquanto no não FM indica a ausência de depressão. 
Ainda assim, Barros et al. (2019) a partir de um estudo de caráter qualitativo comparativo dos resultados desses testes antes e após dois meses de intervenção por hidroterapia, exercícios aeróbios e alongamento no tratamento da FM, realizado com oito participantes do sexo feminino, com avaliação do questionário HADS - que possui um total de 14 itens, para a avaliação da depressão (HADS-D), número de tender points e teste terceiro dedo-chão, chega à conclusão de que houve diminuição no nível de depressão de pacientes que possuem FM, quando analisados antes e após a intervenção. Obtendo, então, a confirmação que hidroterapia e exercícios aeróbicos são importantes fatores que aliados aos tratamento psicológico e médico da FM, auxilia na diminuição dos reflexos negativos da FM, como a depressão, evidenciado pelo fato de além dos fatores biológicos, proporcionar a minimização do isolamento dessas pacientes e possíveis chances de estopim para ingresso em transtorno ou episódio depressivo.

Segmento esse ainda abordado por Andrade et al. (2016), que realizou um estudo clínico de delineamento pré e pós-tratamento, sem grupo controle, com 12 mulheres diagnosticadas com FM, com idade entre 18 a 70 anos. O objetivo desse estudo foi de verificar o efeito de sessões de caminhada, com duração de 60 minutos cada, e realização de 2 vezes na semana, com duração de 8 semanas, sobre a depressão em mulheres com fibromialgia. Como resultado verificou-se que o escore médio de depressão, que foi calculado a partir do BDI, diminuiu de 22,75 para 14,33. Evidenciando que existiu uma melhora, tendo em vista que ao início do programa de caminhada 41,6\% dos participantes apresentaram depressão grave e após a intervenção a maioria apresentou depressão mínima. Mas ainda assim, os mesmos autores afirmam que "é necessário definir um protocolo padrão que possa servir de guia na prática de atividades físicas para essa população".

E no estudo elaborado por Goulart et al (2017), foram avaliadas 32 mulheres com diagnóstico de FM, todas as voluntárias da pesquisa passaram por uma bateria de testes neuropsicológicos voltados para: memória, atenção, funções executivas, dor percebida, ansiedade e depressão. O objetivo do artigo era verificar as associações entre a sintomatologia da depressão, ansiedade, percepção de dor e déficits cognitivos em pacientes com FM. A conclusão foi que há uma coexistência da ansiedade e depressão nas pacientes, mas o quadro de ansiedade é mais relevante, ao passo que o nível de dor é mais alto e os prejuízos cognitivos mais evidentes, prejudicando significativamente a memória e atenção. Pacientes fibromiálgicos parecem ser menos eficazes ao desempenharem tarefas relacionadas às funções executivas.

\section{- Condições socioeconômicas e de gênero}

Pudemos constatar que, em todos os textos, o público de participantes era composto por 
mulheres, reforçando o fato de que, como dito anteriormente, a doença atinge majoritariamente a população feminina. A partir dos estudos de Andrade et al (2016), foi possível identificar que a maioria das mulheres do estudo tinham como agravante a condição socioeconômica e o nível de escolaridade mais baixo. Podemos considerar a relevância desses dados para o surgimento da depressão, afinal, a partir do estudo realizado por Santos e Kassouf (2007), constata-se que as condições socioeconômicas podem interferir na probabilidade de desenvolvimento dos sintomas depressivos, mas o efeito destas condições é superior nas mulheres. Além disso, ainda de acordo com Santos e Kassouf (2007), um maior nível educacional pode diminuir as chances do desenvolvimento desta patologia.

Então, se considerarmos a fibromialgia e a depressão enquanto comorbidades, podemos entender que os fatores sociais e econômicos impactam diretamente no surgimento e desenvolvimento das doenças, pois interferem na construção de subjetividade do indivíduo. No entanto, apesar da influência do fator econômico sobre a depressão, apenas o estudo acima citado denotou-a, ainda que de forma sucinta. Já a disparidade entre os gêneros afetados é informada em todos os estudos analisados.

Apenas no artigo desenvolvido por Ramiro et al (2014), há um parágrafo no qual se pondera o porquê de haver mais mulheres acometidas pelo mal da FM, explicitando o fato de que "estudos apontam que as mulheres estão mais expostas a situações de estresse, tanto pela sua condição biológica quanto pelos papéis culturais que a sociedade historicamente lhes impõe" (RAMIRO et al, 2014. p. 28). Dentre os autores estudados, Ramiro et al (2014) foram os únicos autores que se debruçaram em pontuar um possível porque de haver mais casos no público feminino, mesmo que não havendo uma explanação profunda sobre o tema.

Fica explícito a necessidade de pensar não só na FM ou na depressão, mas no recorte social que estas estão inseridas e como uma patologia impacta na outra, logo, fica claro a urgência de um maior quantitativo de pesquisas sobre o tema, principalmente do viés psicológico, considerando o indivíduo enquanto biopsicossocial e espiritual, como preconiza a OMS, visando esclarecer essa associação.

\section{- A visão partilhada de depressão}

Em todos os textos analisados os autores encaram a depressão como um sintoma que surge em decorrência da FM, que dificulta a vida dos pacientes acometidos pela patologia. Em Andrade et al (2016), a visão que se tem de depressão é como uma experiência que dificulta muito e a vida das pessoas fibromiálgicas e sua melhora. Ou seja, para esse autor, não há uma comorbidade, mas uma influência notória.

A mesma visão é sustentada por Barros et al (2015), que nãog explicita no artigo uma 
informação concreta acerca da depressão, apenas sinaliza a importância da análise emocional do paciente, evidenciando que "há prejuízos desde o desempenho profissional até o social, desestabilizando as relações familiares, restringindo o contato social e interferindo nos hábitos e rotinas dos pacientes, enfim, no geral há uma piora da qualidade de vida" (BARROS et al, 2015. p. 15).

Em Goulart, Pessoa e Júnior (2017), a literatura é mais voltada para a neurologia e a neuropsicologia e é evidenciado que "em dois estudos clássicos, há uma mudança no volume cerebral dos pacientes, mas em diferentes regiões" (p. 265). Ou seja, a FM causa danos biológicos ao cérebro, incluindo, ainda de acordo com o mesmo estudo, a diminuição na produção do neurotransmissor dopamina, que é responsável, dentre outras funções, pela sensação de prazer. Logo, é percebido que há uma relação, mesmo que indireta, com o surgimento dos sintomas da depressão.

A partir dos apontamentos anteriores, foi possível compreender que as pesquisas não denotar uma visão da depressão enquanto um transtorno bem definido, como ele é descrito no CID-10. A visão é apenas de uma consequência da FM, em decorrência da dor e das dificuldades enfrentadas pelos indivíduos acometidos. Não houve nenhum artigo que versou acerca do caráter psicopatológico que pode ser adotado enquanto ponto de vista, apenas Ramiro et al (2014) traz a visão do estresse como precursor da piora da patologia analisada.

\section{- A Síndrome da Fibromialgia em uma perspectiva de cura e tratamento.}

Todos os artigos trazem a visão de que a doença não tem uma causa definida, o que é condizente com a premissa trazida pela Sociedade Brasileira de Reumatologia, de que "alguns pacientes com FM desenvolvem a condição após um gatilho, como uma dor localizada maltratada, um trauma físico ou uma doença grave.” (SBR, 2019). Essa falta de informação pode estar associada à falta de pesquisas na área, como já foi indicado posteriormente, e a falta de socialização do conhecimento acadêmico, o que dificulta o diagnóstico da doença e, posteriormente, o seu prognóstico e um plano efetivo de tratamento para o sujeito.

Há uma consonância entre os textos de que "não existem cura ou tratamentos que sejam considerados muito eficazes" (BARROS et al, 2015. p. 14) apenas tratamentos e práticas que possam melhorar a qualidade de vida do paciente, como "o incremento da prática de atividade física (que) pode ser considerado como um tratamento importante em pessoas com síndrome de fibromialgia" (ANDRADE, 2014. p. 218).

Há menção a importância do trabalho da psicologia no quadro de um paciente fibromiálgico em apenas Barros et al (2015), que preconiza sobre a importância da terapia cognitivo-comportamental. Não foi encontrado nenhum trecho dos textos que versasse sobre a 
importância da psicoterapia para o paciente, mesmo havendo sempre associações acerca da depressão nas pacientes. Além disso, há a indicação de uma abordagem específica sem justificativa clara sobre o motivo dela ser importante.

\section{CONSIDERAÇÕES FINAIS}

Portanto, a partir da leitura dos artigos e análise por meio da metodologia supracitada, pudemos compreender a importância de estudos que tenham enquanto temática central a Fibromialgia, principalmente na área da Psicologia. Além disso, o entendimento acerca da relação entre a depressão e a FM merece lugar de destaque, afinal, a grande maioria dos casos relatados disserta acerca da coexistência dessas duas patologias.

Durante a análise, foi possível observar a relação entre o surgimento das doenças e os fatores sociais e econômicos, como gênero e nível de escolaridade, mas não foi identificada nenhuma relação com o local de residência dos participantes, não havendo de forma explícita um lugar onde há mais casos, por exemplo. A não consideração desta dimensão da realidade do público pode dificultar tanto o diagnóstico quanto o prognóstico de pacientes acometidas(os) pela doença.

Desse modo, há um consenso entre os autores acerca da depressão enquanto um sintoma que surge em decorrência da FM, e não como um transtorno bem delimitado na fundamentação teórica, a partir do CID- 10 (DATASUS, 2008) e de Dalgalarrondo (2008). Lançar luz para a depressão dessa forma acaba por negligenciar aspectos subjetivos do paciente, como sua história de vida e sua forma de olhar para sua existência, descartando informações que poderiam ser associadas ao tratamento do indivíduo, espelhando uma maior expectativa de melhora.

Portanto, é visivelmente necessária uma fomentação das discussões sobre o tema, e esse artigo busca ser um pontapé inicial para levar os leitores a reflexão acerca da importância de tratar de forma humana tantos indivíduos que sofrem. Para tal, faz-se necessário o entendimento do tema e a consideração dos fatores intrínsecos de cada ser, que é único e ao mesmo tempo está inserido num contexto social que deve ser validado e reconhecido.

\section{REFERÊNCIAS}

ANDRADE, Alexandro et al. A prática de caminhada diminui a depressão em pacientes com síndrome da fibromialgia. Conscientiae Saúde, Santa Catarina, v. 15, n. 2, p.217-224, maio 2016.

BESSET, V. L. et al. Um nome para a dor: fibromialgia. Revista Mal-Estar e Subjetividade. Fortaleza, v. 10 n. 4 p. 1245-1269, dez., 2010. 
BRASIL. MINISTÉRIO DA SAÚDE. Fibromialgia: os desafios de uma doença invisível. 2017. Elaborada por Ana Cláudia Felizola. Disponível em: <http://www.blog.saude.gov.br/b463z2>. Acesso em: 17 out. 2019.

CALAIS, Sandra Leal; ANDRADE, Lívia Márcia Batista de; LIPP, Marilda Emmanuel Novaes. Diferenças de sexo e escolaridade na manifestação de Stress em adultos jovens. Psicologia: Reflexão e Crítica, [s.1.], v. 16, n. 2, p.257-263, 2003. FapUNIFESP (SciELO). http://dx.doi.org/10.1590/s0102-79722003000200005.

DALGALARRONDO, P. Psicopatologia e semiologia dos transtornos mentais. $2^{\mathrm{a}}$ ed. Porto Alegre: Artmed, 2008.

DATASUS. F30-F39: Transtornos do humor [afetivos]. 2008. Disponível em: <http://www.datasus.gov.br/cid10/V2008/WebHelp/f30_f39.htm>. Acesso em: 18 out. 2019.

GOULART, Rubens; PESSOA, Cinthia; LOMBARDI JÚNIOR, Império. Neuropsychological assessment of patients with fibromyalgia. Estudos de Psicologia, Natal, v. 22, n. 3, p.264-273, jul./set. 2017.

HOMANN, Diogo et al . Percepção de estresse e sintomas depressivos: funcionalidade e impacto na qualidade de vida em mulheres com fibromialgia. Rev. Bras. Reumatol., São Paulo , v. 52, n. 3, p. 324-330, Jun., 2012 . Disponível em: <http://www.scielo.br/scielo .php?script=sci_arttext\&pid=S0482-50042012000300003\&lng=en\&nrm=iso >. acesso em 17 Out. 2019. http://dx.doi.org/10.1590/S0482-50042012000300003.

LIPP, M. E. N. Inventário de Sintomas de Estresse para Adultos. São Paulo: Casa do Psicólogo, 2000.

LIPP, M. E. N. (Org.). Pesquisas sobre stress no Brasil: Saúde, ocupações e grupos de risco. Campinas: Papirus, 2001

MELLO-FILHO, J.; BURD, M. Psicossomática Hoje. $2^{\text {a }}$ ed. São Paulo: Artmed, 2010.

BARROS, T. R. M. et al Avaliação de Flexibilidade, Tender Points e nível de Ansiedade e Depressão em Pacientes com Síndrome da Fibromialgia. Colloquium Vitae. ISSN: 1984-6436, v. 7, n. 2, p. 13-19, 27 abr. 2016.

NUNES, S. O. V. et al. Transtorno depressivo e fibromialgia: associação com estresse de vida precoce. Relato de caso. Revista Dor. São Paulo, v. 13, n. 3, p. 282-286, jul./set., 2012.

PELLOSI, E. F.; PERES, R. S. A fibromialgia sob a ótica psicanalítica: um breve panorama. Polêm!ca, [S.1.], v. 17, n. 1, p. 1-15, abr. 2017. Disponível em: <https://www.epublicacoes.uerj.br/index.php/polemica/article/view/28292/20339>. Acesso em: 17 abr. 2019.

RAMIRO, Fernanda de Souza et al . Investigação do estresse, ansiedade e depressão em mulheres com fibromialgia: um estudo comparativo. Rev. Bras. Reumatol., São Paulo, v. 54, n. 1, p. 27-32, Fev. 2014 . Disponível em: <http://www.scielo.br/scielo.php? script=sci_arttext\&pid=S0482-50042014000100027\&lng=en\&nrm=iso>. Acesso em: 15 Out. 2019. http://dx.doi.org/10.1016/j.rbr.2013.04.006. 
SADIR, Maria Angélica; BIGNOTTO, Márcia Maria; LIPP, Marilda Emmanuel Novaes. Stress e qualidade de vida: influência de algumas variáveis pessoais. Paidéia, Ribeirão Preto, v. 20, n. 45, p.73-81, abr. 2010. FapUNIFESP (SciELO). http://dx.doi.org/10.1590/s0103$863 \times 2010000100010$.

SANTOS, Marcelo Justus dos; KASSOUF, Ana Lúcia. Uma investigação dos determinantes socioeconômicos da depressão mental no Brasil com ênfase nos efeitos da educação. Econ. Apl., Ribeirão Preto, v. 11, n. 1, p.5-26, jan./mar. 2007. Trimestral. Disponível em: <http://www.scielo.br/scielo.php?script=sci_arttext\&pid=S1413-80502007000100001>.

Acesso em: 09 out. 2019.

SILVA, E. B. T. Mecanismos de defesa do Ego. Portal dos Psicólogos. Belo Horizonte, 15 jul. de 2011. Disponível em: <http://www.psicologia.pt/artigos/textos/TL0212.pdf>. Acesso em: 20 set. de 2019.

SOCIEDADE BRASILEIRA DE REUMATOLOGIA. . Fibromialgia. 2019. Disponível em: $<$ https://www.reumatologia.org.br/doencas-reumaticas/fibromialgia-e-doencas-articularesinflamatorias/>. Acesso em: 14 out. 2019.

SOUZA, M. T.; SILVA, M. D.; CARVALHO, R. Revisão integrativa: o que é e como fazer. Einstein, São Paulo, v. 8, n. 1, p. 102-106, mar., 2010. 


\title{
MECANISMOS DE EMPODERAMENTO: O QUE DIZEM OS AGENTES COMUNITÁRIOS DE SAÚDE (ACS) A RESPEITO DA SAÚDE SEXUAL NA ATENÇÃO BÁSICA
}

\author{
MECANISMOS DE EMPODERAMIENTO: LO QUE DICEN LOS AGENTES \\ COMUNITARIOS DE SALUD (ACS) AL RESPECTO DE LA SALUD SEXUAL EN \\ LA ATENCIÓN BÁSICA
}

\section{EMPOWERMENT MECHANISMS: WHAT THE COMMUNITY HEALTH AGENTS (CHA) SAY ABOUT SEXUAL HEALTH IN BASIC CARE}

\author{
Thiago Rubens da Silva ${ }^{1}$; Paulo Marcelo Freitas de Barros ${ }^{2}$
}

DOI: https://doi.org/10.31692/978-65-991061-9-4.14-28

\section{RESUMO}

Um dos maiores desafios dos tempos atuais está sendo o deixar de pensar e agir de forma fragmentada para o pensar e agir de forma sistêmica e interconexa. É comum o hábito de se pensar a sexualidade como sendo apenas o ato sexual, sendo essa, uma redução de algo muito mais amplo. O proposito desta pesquisa foi estudar a opinião dos Agentes Comunitários de Saúde (ACS) em relação ao nível de abrangência dos conceitos sobre saúde, sexualidade e solução de problemas vivenciados por quatro ACS que atuam em territórios assistidos pela Estratégia de Saúde da Família no Município de Olinda. Na análise qualitativa das respostas foram priorizados os seguintes itens: a compreensão de saúde com um direcionamento para os aspectos: físico, mental, espiritual, social e ambiental. Em seguida, a compreensão em relação à saúde sexual e a possibilidade de sua transmissão de saúde em relação aos cinco aspectos supracitados. Após a realização de quatro entrevistas semiestruturadas a análise de conteúdo revelou que o concito de saúde, apresentou características sistêmicas abordando as dimensões física, mental e social, não houve menções em relação aos aspectos espiritual e ambiental. Já no conceito de saúde sexual, houve um predomino de aspectos relacionados às doenças sexualmente transmissíveis, mas, também, ocorreu relatos dos aspecto mental e social. O tema transmissão de saúde sexual chegou a ser referido por dois dos entrevistados. $\mathrm{Na}$ área da sexualidade, os principais problemas referidos foram: iniciação precoce à vida sexual, resistência à prevenção, tabu sobre sexualidade, ausência de sexualidade na terceira idade e o preconceito sexual. Quanto à abrangência das soluções constatou-se que os entrevistados fizeram uma abordagem voltada apenas para os aspectos ligados à gestão e sócio-culturaleducacional. Em relação ao seminário, foram distribuídos um resumo dos resultados e a cartilha. Os participantes referiram não lidaram habitualmente com os conteúdos sobre saúde sistêmica, mas sim com apenas patologias. Além disso, relataram não lidarem com o aspecto espiritual no âmbito da atenção básica. De forma geral, constatou-se a necessidade de se aprofundar os temas supracitados tanto na formação profissional quanto em constantes capacitações da equipe de saúde na UBS.

Palavras-chave: Sexualidade, Saúde Pública, Centro de saúde.

\section{RESUMEN}

Uno de los mayores desafíos en los tiempos actuales es el dejar de pensar y actuar de forma fragmentada para pensar y actuar de forma sistémica e interconectada. Es común el hábito de pensar en la sexualidad como algo referido a apenas el acto sexual, siendo esa una reducción

\footnotetext{
${ }^{1}$ Fonoaudiologia, UNICAP, ichthiago@gmail.com

${ }^{2}$ Fonoaudiologia, UNICAP, paulofreitasb@gmail.com
} 
de algo que es mucho más amplio. El propósito de esta investigación fue estudiar la opinión de los Agentes Comunitarios de Salud (ACS) en relación al nivel de alcance de los conceptos sobre salud, sexualidad y la solución de problemas experimentados por cuatro ACS que trabajan en territorios asistidos por la Estrategia de Salud de la Familia en el Municipio de Olinda. En el análisis cualitativo de las respuestas fueron priorizados los siguientes aspectos: la comprensión de la salud con un direccionamiento para los aspectos: físico, mental, espiritual, social y ambiental. En seguida, la comprensión en relación a la salud sexual y la posibilidad de su transmisión de salud en relación a los cinco aspectos supracitados. Después de la realización de cuatro entrevistas semiestructuradas, el análisis de contenido reveló que el concepto de salud presentó características sistémicas abordando las dimensiones física, mental y social, no hubo menciones en relación a los aspectos espiritual y ambiental. En el concepto de salud sexual, hubo un predominio de aspectos relacionados a las enfermedades de transmisión sexual pero, también ocurrieron relatos de los aspectos mental y social. El tema transmisión de salud sexual llegó a ser mencionado por dos entrevistados. En el área de la sexualidad, los principales problemas mencionados fueron: inicio precoz en la vida sexual, resistencia a la prevención, tabú sobre sexualidad, ausencia de sexualidad en el adulto mayor y el preconcepto sexual. En cuanto al alcance de las soluciones, se constató que los entrevistados realizaron un abordaje enfocado apenas en los aspectos referidos a la gestión y la educación sociocultural. En relación al seminario, fueron distribuídos un resumen de los resultados y un folleto. Los participantes manifestaron que no lidiaron habitualmente con contenidos sobre salud sistémica, pero si apenas con patologías. Además, relataron que no trabajaron con el aspecto espiritual en el ámbito de la atención básica. De forma general, se constató la necesidad de profundizar en los temas supracitados tanto en la formación profesional como en las constantes capacitaciones del equipo de salud en la UBS.

Palabras-claves: Sexualidad, Salud Pública, Centro de Salud.

\section{ABSTRACT}

One of the biggest challenges of the present time is to move from thinking and acting in a fragmented way to thinking and acting in a systemic and interconnected way. It is common to think of sexuality as merely the sexual act, which is a reduction of something much broader. The purpose of this research was to study the opinion of the Community Health Agents (CHA) regarding the level of comprehension of the concepts on health, sexuality and problem solving experienced by four CHAs acting in territories assisted by the Family Health Strategy in the Municipality of Olinda. In the qualitative analysis of the answers, the following items were prioritized: the understanding of health with a direction to the aspects: physical, mental, spiritual, social and environmental. Then, the understanding of sexual health and the possibility of its transmission of health in relation to the five aspects mentioned above. After conducting four semi-structured interviews, the content analysis revealed that the health concern presented systemic characteristics addressing the physical, mental and social dimensions, there were no mentions regarding the spiritual and environmental aspects. In the concept of sexual health, there was a predominance of aspects related to sexually transmitted diseases, but there were also reports of mental and social aspects. The subject of sexual health transmission was mentioned by two of the interviewees. In the area of sexuality, the main problems mentioned were: early initiation into sexual life, resistance to prevention, taboo on sexuality, lack of sexuality in old age and sexual prejudice. Regarding the comprehensiveness of the solutions, it was found that the interviewees took an approach focused only on aspects related to management and socio-cultural-educational. Regarding the seminar, a summary of the results and the booklet were distributed. Participants reported that they did not usually deal with systemic health content, but only with pathologies. In addition, they reported not dealing with the spiritual aspect in primary care. In general, it was noted the need to deepen the 
aforementioned themes both in vocational training and in constant training of the health team at UBS.

Keywords: Sexuality, Public Health, Health Center.

\section{INTRODUÇÃO}

O presente estudo foi desenvolvido no contexto da Atenção Básica-AB enfocando a solução de problemas na área de transmissão de saúde e sexualidade. De acordo com a portaria 2.436 de 21 de setembro de 2017, que regula as normas da Assistência Básica no âmbito do SUS, a AB é o nível de atenção preferencial responsável pela entrada do usuário na Rede de Assistência à Saúde. Mundialmente, esse primeiro nível responsabiliza-se por solucionar aproximadamente $80 \%$ dos problemas.

Nesse contexto, é importante saber a opinião dos Agentes Comunitários de Saúde-ACS e como lidam com essa temática na $\mathrm{AB}$. Diante disso, é importante utilizarmos um conceito de saúde que abranja a complexidade de tais dimensões e inclua o tema, não menos complexo, da sexualidade que, particularmente, precisa ser visto muito além do ponto de vista da saúde como ausência de doenças. E necessário que a sexualidade na saúde seja percebido de um ponto de vista sistêmico envolvendo o corpo, a mente, a espiritualidade, a sociedade e o meio ambiente.

Para Barros (2003) a Soluciologia é a área do conhecimento que tem a solução como objeto de estudo que, numa visão sistêmica em saúde, é bem mais complexa que os problemas por envolver diversas áreas simultaneamente: gestão, finanças, legislações, múltiplas especialidades, diferentes níveis de comunicação, mudanças de comportamento, dentre outras.

O ACS tem um papel importante na $\mathrm{AB}$, segundo a portaria $\mathrm{N}^{\circ} 648$, DE 28 DE MARÇO DE 2006, define suas várias atribuições, que entre elas se destacam: desenvolver ações que busquem a integração entre a equipe de saúde e a população adscrita à UBS, articular a micro área colocando-a em contato permanente com as famílias, desenvolver ações educativas visando à promoção da saúde e a prevenção das doenças de acordo com o planejamento da equipe. O trabalho do ACS é considerado uma extensão dos serviços dentro das comunidades, já que é um membro da comunidade, o que ajuda a criar confiança e vínculo mutuamente estabelecidos entre eles.

Se a AB é considerada a porta de entrada nos Sistema Único de Saúde-SUS, o ACS pode ser considerado a "porta de entrada" do usuário na AB devido ao íntimo convívio desse profissional com os moradores de cada território e com as equipes de saúde. Valendo-se dessa proximidade, esse estudo justifica-se pela necessidade de fortalecimento das relações na $\mathrm{AB}$ a partir da sua missão de promoção de saúde e não apenas da premissa curativa de suas intervenções. 
Além disso, é muito precário o quantitativo de estudos que focalizem a "solução de problemas" na $\mathrm{AB}$ e, em especial, ao lidarem com a temática da transmissão de saúde no âmbito da sexualidade. Responsabilizando-se por ações resolutivas em saúde, a AB é um ambiente favorável à expansão de tais conceitos. Sore a solução de problemas, Barros (2003) refere que, devido à sua complexidade e importância, esse tema precisa existir contextualizado em todos os níveis de educação. A principal contribuição do estudo foi identificar, no cotidiano dos ACS, as principais lacunas a respeito da amplitude do conceito de saúde, resolução de problemas e transmissão de saúde na área da sexualidade. Certamente, ele pode servir de modelo para que seja aperfeiçoado, adaptado e replicado para as necessidades epidemiológicas de outros municípios.

Devido a atual capacitação oferecida aos ACS muito provavelmente, há predomínio do conceito fragmentado de saúde, pouca abrangência na solução de problemas e pouco conhecimento sobre transmissão de saúde na área de sexualidade. Portanto, o objetivo do estudo foi identificar a opinião dos ACS a respeito dos temas em questão além disso, foi realizado um seminário temático na comunidade envolvendo os ACS para que tais conteúdos pudessem ser melhor aprofundados no seu cotidiano.

\section{FUNDAMENTAÇÃO TEÓRICA}

Um dos maiores desafios dos tempos atuais está sendo o deixar de pensar e agir de forma fragmentada para o pensar e agir de forma sistêmica e interconexa. É comum o hábito de se pensar a sexualidade como sendo apenas o ato sexual, sendo essa, uma redução de algo muito mais amplo (PINTO, 2002). De acordo com o Ministério da Saúde (2006), a sexualidade é muito mais do que sexo, é um aspecto central da vida das pessoas e envolve sexo, papéis sexuais, orientação sexual, erotismo, prazer, envolvimento emocional, amor e reprodução.

Epistemologicamente, a compreensão da ciência sobre a realidade que nos cerca, tem sofrido diversas transições. Uma das mais significativas está sendo o mirarmos de uma percepção newtoniana cartesiana fragmentada (linear) em que o mundo é constituído de partes isoladas e independentes, para uma percepção sistêmica (Não linear) em que o mundo é percebido como sendo uma complexa rede interativa de infinitas relações (CAPRA, 2002).

O autor ainda revela, o fato de não percebermos a realidade como algo único e unificado, fragmentando o mundo e ignorando a interligação dinâmica de todas as coisas, constitui-se no erro de percepção responsável por nossos problemas, na ciência, em nossa vida pessoal, em nossa sociedade e no meio ambiente. A partir dessa perspectiva sistêmica, como revisitar nossos conceitos de saúde e sexualidade no contexto da atenção básica? Além do estudo das patologias, 
seria interessante estudarmos a possibilidade de se transmitir saúde? Usualmente, a transmissão de saúde é compreendia apenas com a transmissão de informações para se evitar doenças (CARVALHO,1999).

Além disso faz se necessário utilizarmos um conceito de saúde que abranja a complexidade de tais dimensões e inclua o tema, não menos complexo, da sexualidade que, particularmente, precisa ser visto muito além do ponto de vista da saúde como ausência de doenças, é necessário vermos a sexualidade na saúde do ponto de vista sistêmico que inclua o físico, o psicológico, o espiritual, o social e o ambiental (CAPRA, 2002).

Inevitavelmente, o conceito de saúde e o estabelecimento de práticas dependem do grau de conhecimento disponível na ciência e do grau de conhecimento particular de cada profissional de saúde (FONSECA, 2007).

Concordando com Carvalho (1999) é realmente importante estar bem informado tanto para se ter saúde quanto para resolver os problemas de saúde. Uma vez que o conceito ampliado de saúde e, também, de sexualidade envolvem todos os aspectos de vida do ser humano, a convivência de quem não tem saúde com quem a possui, por ressonância, também é fundamental como forma de aprendizagem. Nos sistemas vivos, segundo Capra (2002) a bioressonância pode ser observada em padrões de comportamento ou na aquisição e uso da linguagem. Silva Santos (2016) também confirma esse padrão de imitação comportamental, por ressonância, em nossos hábitos sociais e de consumo. Portanto, quanto mais sadia uma pessoa ou uma sociedade estiver, mais fácil será a transmissão de saúde.

Para Barros (2003) a soluciologia é a área do conhecimento que tem a solução como objeto de estudo que, numa visão sistêmica em saúde, são bem mais complexas que os problemas por envolverem diversas áreas simultaneamente: gestão, finanças, legislações, múltiplas especialidades, diferentes níveis de comunicação, mudanças de comportamento, dentre outras.

No estudo de uma solução pode-se optar por dois caminhos básicos: 1) verificar a abrangência da solução ou 2) verificar se a solução proposta teria condições de resolver o problema ou não. No presente estudo optou-se pela primeira possibilidade, ou seja, o estudo da abrangência identificando, em quantas e quais áreas as soluções foram relatadas e qual o nível de complexidade desse relacionamento (de superficial até muito complexo) em seis áreas básicas: gestão, jurídico, formação de redes, mudanças de comportamento, mudanças socioculturais- educacionais e aspectos financeiros BARROS (2013).

A problemática sexual, muitas vezes extrapola o aspecto físico da disfunção, originando problemas na vida profissional, nos relacionamentos familiares e sociais, na relação com seu 
parceiro e em sua saúde psíquica (FEIJÓ, 2007).

Durante a confecção do presente estudo, ao realizarmos um levantamento feito nas bases de dados BVS, LILACS e SCIELO, percebeu-se uma escassez de estudos que abordem a sexualidade e a transmissão de saúde numa visão sistêmica. É natural que tenhamos dificuldades em lidarmos com a sexualidade sob a nova concepção de saúde do ponto de vista sistêmico envolvendo os cinco aspectos constituintes do conceito de saúde mencionado anteriormente.

No Brasil, a Estratégia de Saúde da Família (ESF) representa o primeiro nível de atenção que considera os indivíduos, famílias e comunidades como objetos centrais em ações de prevenção, promoção e tratamento (FIALHO, 2016). Para isso, conta com uma equipe multiprofissional responsável pela saúde da população local e uma de suas exigências é a presença de um ACS. Lotado geralmente em Unidades Básicas de Saúde-UBS, este profissional executa atividades domiciliares, tais como visitas e orientações às famílias (COTTA, R. M. M., 2013).

O fato é que, os ACS são profissionais fundamentais para o funcionamento da promoção de saúde e o funcionamento da Atenção Básica. De acordo com a Portaria 2.439 de 21 de setembro de 2017, a Atenção Básica caracteriza-se por um conjunto de ações de saúde, no âmbito individual e coletivo, que abrange a promoção, a proteção da saúde, com o objetivo de desenvolver uma atenção integral que impacte na situação de saúde, autonomia das pessoas, nos determinantes e condicionantes de saúde das coletividades (BRASIL, 2017).

Dessa forma fez se necessário saber como os ACS estão lidando com a transição do conceito de saúde em sua aplicabilidade na área da sexualidade para que, de forma interconexa, possamos ter cada vez mais saúde do ponto de vista sistêmico integrando, apropriadamente, o corpo, a mente, a espiritualidade, a sociedade e o meio ambiente.

\section{METODOLOGIA}

\section{Coleta e Análises dos Dados:}

A presente pesquisa foi uma continuidade do projeto aprovado pelo Comitê de Ética da Unicap-parecer:025/2016 (CAAE: 56350316.7.0000.5206) e realizada entre os meses de agosto de 2018 até junho de 2019 no Programa de Bolsas de Iniciação Científica Universidade Católica de Pernambuco-UNICAP. O estudo estará dividido em duas etapas. Uma voltada à coleta de dados e outra voltada para a realização de um seminário.

Na primeira etapa, em relação à seleção dos Agentes Comunitários de Saúde, tivemos quatro indivíduos. Todos eles integrantes de Unidades Básicas de Saúde do Município de 
Olinda. Naturalmente, foram excluídos os que se recusaram a participar ou que estiveram ausentes no período por motivos alheios à pesquisa.

Após um estudo piloto para aprimoramento do instrumento de coleta, todos os participantes assinaram o TCLE (anexo I), responderam, a uma entrevista composta por quatro perguntas, realizadas pelos pesquisadores e gravadas por meio de um gravador de voz em ambiente reservado (anexo II). A análise de conteúdo das respostas forma orientada por alguns princípios norteadores inspirados no modelo proposto por Laurence Bardin (2011) e por princípios da soluciologia propostos por Barros (2018) (Anexo III). Os dados foram coletados através de entrevista piloto realizada com um profissional de saúde.

A análise de conteúdo das respostas ocorreu a partir do seguinte roteiro: foi realizada uma leitura minuciosa da transcrição, a fim de formular uma ideia geral do que foi abordado. Em seguida, identificadas as unidades significativas de interesse para depois, organizá-las e transforma-las em categorias que correspondam ao agrupamento de unidades de significado, buscando traduzir a essência da fala do entrevistado em relação aos objetivos do estudo. Na análise qualitativa das respostas foram priorizados os seguintes itens: a compreensão de saúde que o entrevistado relatou com um direcionamento para os aspectos: físico, mental, espiritual, social e ambiental. Em seguida, a compreensão do entrevistado em relação à saúde sexual e a possibilidade de sua transmissão em relação aos cinco aspectos supracitados. De forma complementar, foram investigados os principais problemas e as principais soluções, na área da sexualidade, vivenciados no cotidiano da respectiva UBS. Em ambos os casos, a análise se conteúdo teve como foco, apenas o nível de abrangência das respostas e não a viabilidade ou não de seus conteúdos.

Na segunda etapa, foi realizada uma oficina com todos os seguimentos participantes com o intuito de apresentar os resultados do estudo e elaborar, conjuntamente, uma cartilha instrucional sobre o tema saúde sexualmente transmissível dentro do conceito de saúde sistêmica.

\section{RESULTADOS E DISCUSSÃO}

Os resultados serão apresentados de forma textual em relação os quatros Agentes Comunitários de Saúde entrevistadas, sendo ACS1 a primeira, ACS2 a segunda, ACS3 a terceira e ACS4 a quarta. Inicialmente os entrevistados foram questionados no que diz respeito o conceito de saúde do ponto de vista sistêmico. 


\section{Conceito de saúde sistêmico}

Quadro 1: distribuição do espectro de abrangência do conceito geral de saúde.

\begin{tabular}{|c|c|c|c|c|c|}
\hline ACS & Física & Mental & Espiritual & Social & Ambiental \\
\hline 1 & $\mathrm{x}$ & $\mathrm{x}$ & & $\mathrm{x}$ & \\
\hline 2 & $\mathrm{x}$ & & & $\mathrm{x}$ & \\
\hline 3 & $\mathrm{x}$ & $\mathrm{x}$ & & $\mathrm{x}$ & \\
\hline 4 & $\mathrm{x}$ & & & $\mathrm{x}$ & \\
\hline
\end{tabular}

A seguir serão apresentados recortes das opiniões relatas pelos os ACS sobre as suas concepções em saúde englobando ou não os cinco aspectos investigados (físico, mental, espiritual, social e ambiental:

- $\quad$ ACS1 = “É ver o paciente como um todo, não só a causa médica. Porque existe vários problemas vários, familiares como, problema com o filho, das drogas, problema com marido, problema com doença e é preciso ver essa parte também”. Nas respostas da entrevistada observou-se apenas a presença dos aspectos físico, mental e social dento do conceito de saúde referido.

- $\quad \mathbf{A C S 2}=$ "Para ter saúde tem que ter um emprego, ter salário digno... Uma pessoa para ter saúde tem que ter lazer, tem que estar preparado fisicamente e financeiramente. Viver com dignidade. Se você tiver tudo isso irar ter mais saúde". Nas respostas da entrevistada observou-se apenas a presença dos aspectos físico e social dento do conceito de saúde referido.

- $\quad \mathbf{A C S 3}=$ "Uma pessoa saudável que não tenha nenhum problema de doença, tanto como mentalmente, intelectualmente que ela usufrua da sua vida com todo gozo". Nas respostas da entrevistada observou-se apenas a presença dos aspectos físico, mental e social dento do conceito de saúde referido.

- $\quad \mathbf{A C S 4}=$ "A integração do sistema político de saúde, cultural, econômico, porque tudo isso vai ajudar para uma saúde de qualidade". Nas respostas da entrevistada observouse apenas a presença dos aspectos físico e social dento do conceito de saúde referido.

$\mathrm{Na}$ "concepção de saúde" referida pelas entrevistadas em relação aos paradigmas sistêmico ou fragmentado, percebeu-se que os participantes apresentaram uma visão sistema em saúde alinhado com os preceitos da OMS (2006) caracterizarem "saúde" não apenas como a ausência de doença, mas como uma situação de bem-estar físico, mental e social. Entretanto, ao considerarmos os cinco aspectos juntos: físico, mental, espiritual, social e ambiental, 
perceberemos que nenhuma das entrevistadas abordou todos em seus discursos. Apesar da presença da visão sistêmica identificada, ela não totalmente abrangente. Houve predomínio dos aspectos físico e social e omissão dos aspectos espiritual e ambiental.

Nessa perspectiva utilizando o conceito de saúde no ponto de vista sistêmico, em relação ao conceito de saúde sexual os entrevistados foram questionados qual seria a sua opinião sobre o tema.

\section{Saúde sexual}

Quadro 2: distribuição do espectro de abrangência do conceito de saúde sexual.

\begin{tabular}{|c|c|c|c|c|c|}
\hline Sujeitos & Física & Mental & Espiritual & Social & Ambiental \\
\hline 1 & & $\mathrm{x}$ & & & \\
\hline 2 & $\mathrm{x}$ & $\mathrm{x}$ & & $\mathrm{x}$ & \\
\hline 3 & $\mathrm{x}$ & $\mathrm{x}$ & & $\mathrm{x}$ & \\
\hline 4 & $\mathrm{x}$ & $\mathrm{x}$ & & & \\
\hline
\end{tabular}

A seguir serão apresentados recortes das opiniões relatas pelos os ACS sobre o tema abordado acima.

- CSA1 = “É quando você está bem com você mesmo. Porque quando a pessoa não está bem psicologicamente não consegue ter uma relação com o marido”.

- $\quad \mathbf{A C S 2}=$ "Se você tem a base que é ter um emprego, lazer, estar preparado fisicamente e financeiramente. Isso tudo contribui para que você sinta mais prazer sexualmente. Mas se você estiver mal e não tiver nada disso... Só o sexo. Você “esfria' também. E se você não tiver bem fisicamente não vai ter ânimo para a sexualidade vai faltar o prazer e também só a cama não serve meu filho tem que ter os outros prazeres".

- $\quad \mathbf{A C S 3}=$ "Tem tabus né... Porque a gente para ter uma saúde sexual tem que está bem de mente, tem que está bem com todos, tem que está bem com o parceiro. O parceiro satisfazer a gente nos pontos que a gente precisa que.... Hoje tem muito tabu muitas mulheres não conseguem ter orgasmos e... Acho que falta hoje muita parceria, contato”.

- ACS4= “ Saúde sexual... É quando a pessoa é bem resolvida, porque a saúde sexual é bom para o corpo e até para cabeça. É necessário para que se tenha uma saúde de qualidade, ter sexo... Porque faz parte da vida"

Em relação ao tema "saúde sexual", ficou evidente que dentre os quatros participantes, todos relataram uma abordagem focada nas dimensões física, mental e social. Segundo a ACS A1 a sexualidade valoriza a sua relação com ela mesma. Além disso, a saúde sexual seria uma 
interação entre os aspectos físico, social e mental que serão determinantes para uma vida sexual prazerosa visão percebida pela ACS A2. Para ter uma saúde sexual é preciso está com uma mente sadia, está bem com o outro e com o mundo; socialmente existem tabu sobre a temática que por esse fato muitas mulheres não conseguem sentir prazer sexual e ter seus orgasmos, segundo relato da ACS A3. Dessa forma, a sexualidade faz parte da vida e é necessário para que se tenha uma saúde de qualidade, segundo a ACS A4.

Quanto a abrangência do conceito de sexualidade de saúde sexual ficou evidente o predomínio das dimensões física, mental e social com omissão das dimensões espiritual e ambiental. Utilizando o conceito de saúde referido no estudo os participantes foram questionados sobre transmissão de saúde sexual.

\section{Saúde sexualmente transmissível}

Quadro 3: distribuição do espectro de abrangência para a possibilidade de a saúde ser transmissível.

\begin{tabular}{|c|c|c|c|c|c|}
\hline Sujeitos & Física & Mental & Espiritual & Social & Ambiental \\
\hline 1 & $\mathrm{x}$ & $\mathrm{x}$ & & & \\
\hline 2 & $\mathrm{x}$ & & & & \\
\hline 3 & $\mathrm{x}$ & & & & \\
\hline 4 & $\mathrm{x}$ & $\mathrm{x}$ & & & \\
\hline
\end{tabular}

A seguir serão apresentados recortes das opiniões relatas pelos os ACS sobre o tema abordado acima:

- $\quad \mathbf{A C S 1}=$ "Se a pessoa tiver uma determinada doença e passa para a esposa, ela desabafa com uma amiga intima, se essa amiga estiver bem de saúde irar transmitir um conforte para aquela dificuldade que ela estar passando, explicando para ela o que é preciso fazer, isso irar transmitir autoestima para ela".

- $\quad \mathbf{A C S 2}=$ " Se você se previne e tem os seus cuidados com o seu corpo, assim você vai ter saúde e vai oferecer uma vida conjugal ao seu parceiro sadia. Assim você vai oferecer segurança ao seu parceiro"

- $\mathbf{A C S 3}=$ "Se você está todo sadio, você tem uma relação prazerosa, aquilo está transmitindo saúde, porque faz bem para o corpo, faz bem para pele"

- $\mathbf{A C S 4}=$ “ Com prevenção, usando camisinha... E também dialogando com o parceiro, mostrando a necessidade da prevenção e nessa conversa saber o que é bom para ele, como para os dois... Não forçar o parceiro a ter uma relação que não quer. Porque na minha área converso muito sobre isso e geralmente as reclamações é que eles só pensam nele, não querem saber se a parceira está satisfeita, se ela está gostando. 
Em relação à transmissão de 'saúde sexual' ficou evidente dentre os quatros participantes, dois ACS1 E ACS2 privilegiaram uma abordagem focada na dimensão física a partir da prevenção de doenças sexualmente transmissíveis. Entretanto, foi relatada a possibilidade da transmissão de autoestima e segurança, dois aspectos mentais. ACS3 E ACS4 abordaram à transmissão de saúde sexual como, ter uma relação sexual prazerosa, satisfazendo o parceiro sexualmente, o autocuidado, diálogo e respeito.

De forma geral, apesar de relatos pouco abrangentes sobre a possibilidade de se transmitir saúde através da sexualidade, ficou evidente que tal conteúdo foi um tema pouco discutido no âmbito da Atenção Básica que, no Brasil, de acordo com a Portaria 2.436, ela é a porta de entrada do sistema de saúde e, dentre outras, tem a função de promover, prevenir, diagnosticar e tratar os problemas de saúde. A atenção básica é, portanto, um local propício para que seja aprofundado os conhecimentos sobre saúde e não apenas sobre doenças.

\section{Problemas e Soluções}

Primeiramente, serão apresentados os problemas coletados. Depois, as soluções e, ao final, as análises a partir dos referenciais de abrangência adotado pelo autor BARROS (2013).

Vale ressaltar que não foi objetivo do estudo verificar se as soluções teriam condições de resolver o problema ou não. Optou-se por verificar apenas a abrangência das soluções que foram referidas identificando-se em quantas e quais áreas as soluções foram relacionadas aos aspectos: gestão, jurídico, formação de redes, mudanças de comportamento, mudanças socioculturais- educacionais e aspectos financeiros. Em seguida, será apresentada a nota/conceito atribuída a cada solução.

\section{ACS 1}

\section{PROBLEMAS:}

1- Prevenção; 2 - Tabu sobre sexualidade; 3- Falta de informação na primeira relação sexual (Educação sexual); 4 Orientação familiar; 5- Sexualidade na terceira idade.

\section{SOLUÇÕES:}

1-Convencer as pessoas a usar preservativo para prevenir as doenças; 2- Elaboração de palestras sobre a temática; 3- Elaboração de palestras sobre a temática; 4-: os profissionais de saúde orientar aos pais conversarem com os filhos sobre sexualidade. 5- Conscientizar aos idosos que eles podem ter uma vida sexual. 
Quadro 1: distribuição do espectro de abrangência para as soluções (S1).

\begin{tabular}{|c|c|c|c|c|c|c|c|c|c|c|c|}
\hline \multirow{3}{*}{ Sujeito } & \multicolumn{6}{|c|}{ Aspectos } & \multirow{3}{*}{ Nota } & \multicolumn{4}{|c|}{ Conceito } \\
\hline & Gestão & Redes & Sócio/c/e & Mudança/Cpto. & Financeir & Jurid. & & $\mathrm{r}$ & $\mathrm{R}$ & B & $\mathrm{E}$ \\
\hline & & & & & & & & & & & \\
\hline 1 & 2 & 0 & 1 & 0 & 0 & 0 & 3 & $\mathrm{X}$ & & & \\
\hline
\end{tabular}

r-ruim (0 a 3 pontos); R-regular (4 a 11); B-bom (12 a 14); E-excelente (16 a 18)

\section{ACS 2}

\section{PROBLEMAS:}

1- Sexualidade precoce; 2 - Prevenção; 3- Prostituição; 4 Falar sobre sexualidade na terceira idade; 5- Falta de informação.

\section{SOLUÇÕES:}

1- Elaboração de palestras sobre DST; 2- Elaboração de palestras sobre DST; 3- Incentivo educativo ao uso de preservativo; 4-: "se precisar abordar o assunto, mas é normal quando se chega uma certa idade parar a vida sexual'. 5- Um trabalho informativo sobre sexualidade para as pessoas.

Quadro 2: distribuição do espectro de abrangência para as soluções (S2).

\begin{tabular}{|c|c|c|c|c|c|c|c|c|c|c|c|}
\hline \multirow[b]{2}{*}{ Sujeito } & \multicolumn{6}{|c|}{ Aspectos } & \multirow{2}{*}{ Nota } & \multicolumn{4}{|c|}{ Conceito } \\
\hline & Gestão & Redes & Sócio/c/e & Mudança/Cpto. & Financeiro & Jurid & & $\mathrm{r}$ & $\mathrm{R}$ & B & $E$ \\
\hline 2 & 2 & 0 & 1 & 0 & 0 & 0 & 3 & $\mathrm{x}$ & & & \\
\hline
\end{tabular}

r-ruim (0 a 3 pontos); R-regular (4 a 11); B-bom (12 a 14); E-excelente (16 a 18)

\section{ACS 3}

\section{PROBLEMAS:}

1- Tabu em falar sobre sexualidade; 2 - Educação sexual; 3- Prazer sexual na relação; 4 Autoestima feminina é necessário para satisfazer na relação; 5- Preconceito sexual.

\section{SOLUÇÕES:}

1- Orientação, elaboração de palestras sobre sexualidade ; 2- Orientação, elaboração de palestras sobre a temática; 3- Orientação com os parceiros das mulheres e instigar as mulheres a conversar com os seus parceiros.; 4-: Que as mulheres recebam o apoio dos profissionais de saúde e também tenha um apoio psicológico; 5- Orientação, elaboração de palestras sobre a temática.

Quadro 3: distribuição do espectro de abrangência para as soluções (S3).

\begin{tabular}{|c|c|c|c|c|c|c|c|c|c|c|c|}
\hline \multirow[b]{2}{*}{ Sujeito } & \multicolumn{6}{|c|}{ Aspectos } & \multirow{2}{*}{ Nota } & \multicolumn{4}{|c|}{ Conceito } \\
\hline & Gestão & Redes & Sócio/c/e & Mudança/Cpto. & Financeiro & Jurid & & $\mathrm{r}$ & $\mathrm{R}$ & B & $\mathrm{E}$ \\
\hline 3 & 2 & 0 & 1 & 0 & 0 & 0 & 3 & $\mathrm{x}$ & & & \\
\hline
\end{tabular}

r-ruim (0 a 3 pontos); R-regular (4 a 11); B-bom (12 a 14); E-excelente (16 a 18) 


\section{$\operatorname{ACS} 4$}

\section{PROBLEMAS:}

1- Resistencia da prevenção; 2 - Iniciação precoce a vida sexual; 3- Prazer sexual na relação; 4 Tabu sexualidade na terceira idade; 5- Preconceito, mente fechada.

\section{SOLUÇÕES:}

1- Informação, elaboração de uma reciclagem que envolvesse os profissionais e a comunidade;

2- Elaboração de palestras sobre o assunto; 3 Trabalho educativo com elaboração de palestras que chamasse a comunidade, tanto as mulheres como os homens também; 4 Conversar com os idosos, incentivando e orientando que eles podem ter uma vida sexual; 5- Trabalhar o preconceito com informação para essas pessoas.

Quadro 4: distribuição do espectro de abrangência para as soluções (S4).

\begin{tabular}{|c|c|c|c|c|c|c|c|c|c|c|c|}
\hline \multirow{3}{*}{ Sujeito } & \multicolumn{5}{|c|}{ Aspectos } & \multicolumn{3}{|c|}{ Conceito } \\
\cline { 2 - 14 } & Gestão & Redes & Sócio/c/e & Mudança/Cpto. & Financeiro & Jurid & & r & R & B & E \\
\hline 1 & 2 & 0 & 1 & 0 & 0 & 0 & $\mathrm{x}$ & 3 & & & \\
\hline
\end{tabular}

r-ruim (0 a 3 pontos); R-regular (4 a 11); B-bom (12 a 14); E-excelente (16 a 18)

Ao observar todas as respostas pode-se constatar que todos os quatro entrevistados fizeram uma abordagem voltada apenas para os aspectos ligados à gestão e sócio-culturaleducacional, não foram abordados os itens jurídicos, parcerias, mudanças de comportamento e custos e nenhum entrevistado incluiu-se nas soluções. Desse modo o nível de abrangência foi classificado como ruim com três pontos.

\section{Seminário}

Ao final realizou-se um seminário para informar aos participantes da pesquisa os resultados obtidos. No momento da reunião, que constou de seis participantes e quatro pesquisadores, optou-se por uma roda de conversa. Primeiramente, foi distribuído um resumo dos resultados e a cartilha sobre saúde sexualmente transmissível. Durante a reunião os participantes referiram não lidaram habitualmente com os conteúdos sobre saúde, mas sobre patologias. Além disso, relataram não lidaram habitualmente com os conteúdos sobre saúde sistêmica, mas sim, com patologias. Foi necessário ampliar alguns conceitos como: transmissão de saúde, sexualidade e ressonância comportamental. Eles fizeram relatos de diversas experiências vividas na própria UBS. Relataram que a temática do estudo era muito interessante, como também, o fato pensar em saúde sem estar atrelado a doenças demostrarando interesse em buscar esse conhecimento. 


\section{CONSIDERAÇÕES FINAIS}

A partir do objetivo do estudo que foi estudar a opinião dos Agentes Comunitários de Saúde (ACS) a respeito das relações entre sexualidade e transmissão de saúde. Na análise do conteúdo percebeu-se que o conceito de saúde, identificado no discurso dos entrevistados, apresentou características sistêmicas abordando as dimensões física, mental e social, não houveram menções, por nenhum dos entrevistados, em relação aos aspectos espiritual e ambiental. Já no conceito de saúde sexual, houve um predomino de aspectos relacionados às doenças sexualmente transmissíveis, mas, também, ocorreu relatos dos aspecto mental e social. O tema transmissão de saúde sexual chegou a ser referido por dois dos entrevistados. A possibilidade de se transmitir saúde através da sexualidade foi um tema pouco discutido no âmbito da Atenção Básica. Na área da sexualidade, os principais problemas referidos na UBS, foram eles: iniciação precoce a vida sexual, resistência a prevenção, tabu sobre sexualidade, ausência de sexualidade na terceira idade e o preconceito sexual. Quanto à abrangência das soluções constatou-se que os entrevistados fizeram uma abordagem voltada apenas para os aspectos ligados à gestão e sócio-cultural-educacional, foram abordados os itens jurídicos, parcerias, mudanças de comportamento e custos. Desse modo o nível de abrangência foi classificado como ruim com três pontos. De forma geral, constatou-se a necessidade de se aprofundar os temas supracitados tanto na formação profissional quanto em constantes capacitações da equipe de saúde, particularmente, no âmbito da atenção básica que é a porta de entrada do sistema de saúde e, dentre outras, tem a função de promover, prevenir, diagnosticar e tratar os problemas de saúde.

\section{REFERÊNCIAS}

BARDIN, Laurence. Análise de conteúdo. São Paulo: Edições 70, 2011, 229

BARROS, P.M.F. A solução como objeto de estudo: Soluciologia. Olinda: Livro Rápido Elógica, 2013.

BARROS, M.F.B. Soluciologia: coleta de dados. Disponível em: <http://soluciologia.blogspot.com/>. Acesso em junho de 2019.

BRASIL. Ministério da Saúde. Portaria 2.436 de 21 de setembro de 2017. Brasília: Diário Oficial [da] República Federativa do Brasil, 2017.

CAPRA, Fritjof. Conexões ocultas: Ciência para uma vida sustentável. São Paulo. Cultrix, 2002. 296 p. Tradução de: The web of life; a new science understanding of living systems.

CARVALHO Teixeira, J. A. Psicologia da saúde e prevenção do cancro. Desafios para a 
psicologia da saúde. Análise Psicológica, 14 (1), 135-139. 1999.

CORDIOLI, S. Enfoque participativo no trabalho com grupos. In: BROSER, M. Metodologia participativa: uma introdução a 29 instrumentos. Porto Alegre: Tomo Editorial, 2001.

FEIJÓ, M. R. Práticas sistêmicas com casais e famílias com dificuldades afetivo-sexuais. (Orgs.), Sexualidade na família. (pp. 111-124). São Paulo: Expressão e Arte. 2007

FIALHO, Juliana Aparecida. Percepção dos Agentes Comunitários de Saúde sobre seu trabalho na estratégia de saúde da família. Minas Gerais: UF Viçosa, 2016.

FONSECA, Angélica Ferreira (Org.) O território e o processo saúde-doença. Rio de Janeiro: EPSJV/Fiocruz, 2007.

Ministério da Saúde. Direitos sexuais, direitos reprodutivos e métodos anticoncepcionais. Secretaria de Atenção à Saúde, Departamento de Ações Programáticas Estratégicas. Brasília DF. Disponível em: $<$ http://docs.google.com/viewer?a=v\&q=cache:pmEmCS7X8b4J:portal.saude.gov.br/portal/ar quivos/pdf/cartilha_direitos_sexuais_2006.pdf>. Acesso em 30 jan. 2018.

PINTO, E. B. Sexualidade: um bate-papo com o psicólogo. São Paulo: Paulinas, 2002.

RIBEIRO, J. P., \& SANTOS, A. (2005). Estudo exploratório da relação entre função eréctil, disfunção eréctil e qualidade de vida em homens portugueses saudáveis. Análise Psicológica, 3(23), 341-349.

ROLIM, L. B. Saúde em Debate. Rio de Janeiro, v. 37, n. 96, p. 139-147, jan./mar. 2013. 


\title{
MECANISMOS DE EMPODERAMENTO: O QUE DIZEM OS ENFERMEIROS A RESPEITO DA SAÚDE SEXUAL NA ATENÇÃO BÁSICA
}

\author{
MECANISMOS DE EMPODERAMIENTO: LO QUE LAS ENFERMERAS DICEN \\ SOBRE LA SALUD SEXUAL EN LA ATENCIÓN BÁSIC
}

\author{
EMPOWERMENT MECHANISMS: WHAT DO YOU NURSE DICEN ABOUT \\ SEXUAL SALUD IN LA BASIC CARE
}

Alexsandra Aderita da Silva ${ }^{1}$; Paulo Marcelo Freitas de Barros $^{2}$

DOI: https://doi.org/10.31692/978-65-991061-9-4.29-43

\section{RESUMO}

Um dos maiores desafios dos tempos atuais está sendo o deixar de pensar e agir de forma fragmentada para o pensar e agir de forma sistêmica. Para os que atuam na Atenção Básica-AB, lidando com a área da sexualidade, esse desafio apresenta particularidades específicas que merecem estudos aprofundados para a solução de problemas. Portanto, o objetivo do presente estudo foi estudar a opinião dos Enfermeiros que atuam na $\mathrm{AB}$ identificando o nível de abrangência dos seus conceitos sobre saúde, sexualidade e solução de problemas. Certamente, conhecer a opinião de uma equipe de saúde é fundamental para se planejar um aumento coletivo do nível geral de consciência. No presente estudo qualitativo, foram realizadas quatro entrevistas semiestruturadas com Enfermeiros. Em relação ao conceito de saúde houve o predomínio do aspecto físico sobre os demais. Já no conceito de saúde sexual houve uma limitação ao orgânico com total exclusão dos demais aspectos. Ficou omisso o conceito de transmissão de saúde e os principais problemas citados foram: prostituição, doenças sexualmente transmissíveis e banalização do sexo. Quanto às soluções, às áreas de gestão, parcerias, redes e sócio-cultural-educacional, não incluindo os elementos jurídicos, mudanças de comportamento e custos. Nenhum incluiu a si mesmo nas soluções apresentadas e o nível de abrangência obteve a pontuação quatro sendo considerado como regular. No que diz respeito ao seminário, em uma roda de conversa, eles receberam uma síntese escrita dos resultados e uma cartilha. Referiram o fato de não abordar os novos conceitos ampliados de Saúde, mas que a partir do que foi discutido, iriam estar mais atentos em inserir esses novos aspectos para melhoria dos atendimentos nas UBS. Tais achados apontam para a necessidade de acrescentarmos, nos currículos acadêmicos, mais atividades integrativas interprofissionais que proporcionem uma crescente visão interconexa dos fenômenos de saúde e suas soluções.

Palavras-chave: Sexualidade, Saúde Pública, Centro de Saúde.

\section{RESUMEN}

Uno de los mayores desafíos de la actualidad es dejar de pensar y actuar de manera fragmentada para pensar y actuar de manera sistémica. Para quienes laboran en Atención Primaria-AB, ocupándose del área de la sexualidad, este desafío presenta particularidades específicas que merecen profundos para la resolución de problemas. Por lo tanto, el objetivo del presente estudio fue estudiar la opinión de los Enfermeros que trabajan en la $\mathrm{AB}$, identificando el nivel de alcance de sus conceptos sobre salud, sexualidad y solución de problemas. Ciertamente, conocer la opinión de un equipo de salud es fundamental para planificar un aumento colectivo del nivel general de conciencia. En el presente estudio cualitativo, se realizaron cuatro entrevistas semiestructuradas con Enfermeros. En relación al concepto de salud, predominó el

\footnotetext{
${ }^{1}$ Fonoaudiologia, UNICAP, sanndra222@gmail.com

${ }^{2}$ Fonoaudiologia, UNICAP, paulofreitasb@gmail.com
} 
aspecto físico sobre los demás. En lo tocante al concepto de salud sexual hubo una limitación a lo orgánico con total exclusión de los otros aspectos. Se omitió el concepto de transmisión de la salud y los principales problemas citados fueron: prostitución, enfermedades de transmisión sexual y banalización del sexo. En cuanto a las soluciones, las áreas de gestión, asociaciones, redes y socioculturales-educativas, sin incluir los elementos jurídicos, cambios de comportamiento y costos. Ninguno se incluyó asimismo en las soluciones presentadas y el nivel de alcance obtuvo una puntuación de cuatro, siendo considerado como regular. Con respecto al seminario, en un círculo de conversación, recibieron una síntesis escrita de los resultados y una cartilla. Mencionaron el hecho de que no abordaron los nuevos conceptos amplios de Salud, pero que a partir de lo que fue discutido, estarían más atentos a incluir esos nuevos aspectos para la mejoraría de la atención en las UBS. Estos hallazgos apuntan a la necesidad de agregar, en los currículos académicos, más actividades integradoras interprofesionales que brinden una visión creciente e interconectada de los fenómenos de la salud.

Palabras clave: Sexualidad, Salud Pública, Centro de Salud.

\begin{abstract}
One of the biggest challenges of the present time is to move from thinking and acting in a fragmented way to thinking and acting in a systemic way. For those who work in Primary Care$\mathrm{AB}$, dealing with the area of sexuality, this challenge presents specific characteristics that deserve in-depth studies to solve problems. Therefore, the aim of the present study was to study the opinion of nurses working in BA by identifying the level of comprehension of their concepts about health, sexuality and problem solving. Certainly, knowing the opinion of a health team is critical to planning a collective increase in the general level of awareness. In the present qualitative study, four semi-structured interviews with Nurses were conducted. Regarding the concept of health, there was a predominance of the physical aspect over the others. Already in the concept of sexual health there was a limitation to the organic with total exclusion of the other aspects. The concept of health transmission was omitted and the main problems cited were: prostitution, sexually transmitted diseases and trivialization of sex. As for solutions, the areas of management, partnerships, networks and socio-cultural-educational, not including the legal elements, behavioral changes and costs. None included themselves in the solutions presented and the level of coverage scored four was considered as regular. Concerning the seminar, in a conversation circle, they received a written synthesis of the results and a primer. They mentioned the fact that they did not address the new expanded concepts of health, but from what was discussed, they would be more attentive to inserting these new aspects to improve care at the UBS. These findings point to the need to add, in academic curricula, more interprofessional integrative activities that provide a growing interconnected view of health phenomena.
\end{abstract}

Keywords: Sexuality, Public Health, Health Center.

\title{
INTRODUÇÃO
}

O presente estudo foi desenvolvido no contexto da Atenção Básica-AB envolvendo Enfermeiros, com foco na solução de problemas, na área de transmissão de saúde e sexualidade.

Segundo a Portaria 2.436 de 21 de setembro de 2017, que regula as normas da Assistência Básica no âmbito do SUS, a AB é a porta de entrada do sistema de saúde e, dentre outras, tem a função de promover, prevenir, diagnosticar e tratar os problemas de saúde, sendo responsável por solucionar aproximadamente $80 \%$ dos problemas de saúde utilizando ações der prevenção, promoção e intervenção. 
De forma geral, quanto aos problemas, percebe-se que eles são muito mais estudados do que as soluções. Os problemas podem ser estudados de forma fragmentada, mas as soluções não.

Segundo Barros (2013), a Soluciologia é a área do conhecimento que tem a solução como objeto de estudo, numa visão sistêmica em saúde elas são bem mais complexas e exigem uma percepção envolvendo, legislações, custos, mudanças de comportamento, equipes profissionais, participação poupar, mídias, dentre outros, de forma a envolver os três setores da sociedade (Governo, Empresas e Entidades Civis).

O Enfermeiro é o profissional, historicamente marcado pelo compromisso com a saúde pública. Ele está presente na maioria das ações desenvolvidas na atenção básica/saúde da família do sistema único de saúde-SUS ocupando importantes espaços estratégicos para implementação de políticas sociais.

Mediante esse contexto faz-se necessário saber a opinião desses profissionais a respeito do conceito ampliado de saúde envolvendo a solução de problemas associada às relações entre sexualidade e transmissão de saúde.

Devido a atual capacitação oferecida aos Enfermeiros, muito provavelmente, há predomínio do conceito fragmentado de saúde, pouca abrangência nas estratégias de solução de problemas e pouco conhecimento sobre transmissão de saúde na área de sexualidade.

Portanto, o objetivo do presente estudo foi não só identificar a opinião dos Enfermeiros a respeito dos temas em questão, mas, também, realizar um seminário temático na comunidade envolvendo esses profissionais para que tais conteúdos pudessem ser melhor aprofundados em seu cotidiano.

A Atenção Básica-AB caracteriza-se por um conjunto de ações de saúde, no âmbito individual e coletivo, que abrange a promoção e a proteção da saúde, a prevenção de agravos, o diagnóstico, o tratamento, a reabilitação e a manutenção da saúde. É o contato preferencial dos usuários com os sistemas de saúde, sendo o Enfermeiro o profissional que tem esse acesso direto com os usuários proporcionando ações de assistência integral.

Ainda é muito precário o quantitativo de estudos que focalizem a "solução de problemas" ao lidarem com a temática da transmissão de saúde no âmbito da sexualidade. Responsabilizando-se por ações resolutivas em saúde, a $\mathrm{AB}$ é um ambiente plenamente favorável à expansão de tais conceitos. Sore a solução de problemas Barros (2013), refere que, devido à sua complexidade e importância, esse tema precisa existir contextualizado em todos os níveis de educação.

Para a realização do estudo, adotou-se uma abordagem qualitativa com análise de 
conteúdo para a coleta e análise de dados e uma abordagem participativa para a realização de um seminário integrado abordando os temas: visão sistêmica em saúde, solução de problemas e transmissão de saúde na área da sexualidade. Ao final, apresentou-se o protótipo de uma cartilha que foi avaliada pelos participantes para posterior impressão e divulgação.

A principal contribuição do estudo foi identificar, no cotidiano dos Enfermeiros, as principais lacunas a respeito da amplitude do conceito de saúde, resolução de problemas e transmissão de saúde na área da sexualidade. Certamente, ele pode servir de modelo para que seja aperfeiçoado, adaptado e replicado para as necessidades epidemiológicas de outros municípios.

\section{FUNDAMENTAÇÃO TEÓRICA}

Um dos maiores desafios dos tempos atuais está sendo o deixar de pensar e agir de forma fragmentada para o pensar e agir de forma sistêmica. De acordo com Bohm (1998) e Capra (2011), o fato de não percebermos a realidade como algo único e unificado, fragmentando o mundo e ignorando a interligação dinâmica de todas as coisas, constitui-se no erro de percepção responsável por nossos problemas, na ciência, em nossa vida pessoal, em nossa sociedade e no meio ambiente. A partir dessa perspectiva sistêmica, como revisitar nossos conceitos de saúde e sexualidade no contexto da atenção básica? Além do estudo das patologias, seria interessante estudarmos a possibilidade de se transmitir saúde? Usualmente, a transmissão de saúde é compreendia apenas com a transmissão de informações para se evitar doenças (CARVALHO,1999).

A Organização Mundial de Saúde (OMS) define "saúde" não apenas como a ausência de doença, mas como a situação de perfeito bem-estar físico, mental e social. É importante perceber que houve um avanço em se acrescentar à dimensão orgânica, as dimensões mental e social. De acordo com o Ministério da Saúde (2006), a sexualidade é muito mais do que sexo, é um aspecto central da vida das pessoas e envolve: sexo, papéis sexuais, orientação sexual, erotismo, prazer, emoções, amor e reprodução. Mais recentemente, o conceito de saúde tem convivido, também, com as dimensões espiritual e ambiental (KOENIG, 2009; CAPRA, 2012).

Nesse contexto, a possibilidade de se transmitir saúde através da sexualidade é um tema pouco discutido, em especial, no âmbito da Atenção Básica que, no Brasil, de acordo com a Portaria 2.436, ela é a porta de entrada do sistema de saúde e, dentre outras, tem a função de promover, prevenir, diagnosticar e tratar os problemas de saúde.

Quanto aos problemas percebe-se que eles são muito mais estudados do que as soluções. Os problemas podem ser estudados de forma fragmentada, mas as soluções não. Segundo 
Barros (2013), elas são bem mais complexas e exigem uma percepção sistêmica envolvendo, legislações, custos, mudanças de comportamento, equipes profissionais, participação poupar, mídias, dentre outros, de forma a envolver os três setores da sociedade (Governo, Empresas e Entidades Civis).

Concordando com Carvalho (1999) é realmente importante estar bem informado tanto para se ter saúde quanto para resolver os problemas de saúde. Uma vez que o conceito ampliado de saúde e, também, de sexualidade envolvem todos os aspectos de vida do ser humano, a convivência de quem não tem saúde com quem a possui, por ressonância, também é fundamental como forma de aprendizagem. Nos sistemas vivos, segundo Capra (1998) a biorressonância pode ser observada em padrões de comportamento ou na aquisição e uso da linguagem. Silva Santos (2016), também confirma esse padrão de imitação comportamental, por ressonância, em nossos hábitos sociais e de consumo. Portanto, quanto mais sadia uma pessoa ou uma sociedade estiver, mais fácil será a transmissão de saúde.

No estudo de uma solução pode-se optar por dois caminhos básicos: 1) verificar a abrangência da solução ou 2) verificar se a solução proposta teria condições de resolver o problema ou não. No presente estudo optou-se pela primeira possibilidade, ou seja, o estudo da abrangência identificando, em quantas e quais áreas as soluções foram relatadas e qual o nível de complexidade desse relacionamento (de superficial até muito complexo) em seis áreas básicas: gestão, jurídico, formação de redes, mudanças de comportamento, mudanças sócioculturais-educacionais e aspectos financeiros (BARROS, 2013).

A problemática sexual, muitas vezes extrapola o aspecto físico da disfunção, originando problemas na vida profissional, nos relacionamentos familiares e sociais, na relação com seu parceiro e em sua saúde psíquica (FEIJÓ, 2007).

Em níveis de Atenção Primária à Saúde (APS), no Brasil, a Estratégia de Saúde da Família (ESF) representa o primeiro nível de atenção que considera os indivíduos, famílias e comunidades como objetos centrais em ações de prevenção, promoção e tratamento (FIALHO, 2016).

De acordo com a Portaria 2.439 de 21 de setembro de 2017, a Atenção Básica caracteriza-se por um conjunto de ações de saúde, no âmbito individual e coletivo, que abrange a promoção, a proteção da saúde, com o objetivo de desenvolver uma atenção integral que impacte na situação de saúde, autonomia das pessoas, nos determinantes e condicionantes de saúde das coletividades (BRASIL, 2017).

Dessa forma fez se necessário saber como os Enfermeiros estão lidando com a transição do conceito de saúde em sua aplicabilidade na área da sexualidade para que, de forma integrada, 
possamos ter cada vez mais saúde do ponto de vista sistêmico integrando, apropriadamente, o corpo, a mente, a espiritualidade, a sociedade e o meio ambiente. Após conhecidas as concepções sobre saúde, de forma complementar, será importante conhecer, também, os problemas e as soluções relatadas pelos Enfermeiros em relação à temática do estudo.

\section{METODOLOGIA}

Coleta e Análises dos Dados:

A presente pesquisa está sendo uma continuidade do projeto aprovado pelo Comitê de Ética da Unicap-parecer: 025/2016 (CAAE: 56350316.7.0000.5206) e realizada entre os meses de agosto de 2018 até junho de 2019 no Programa de Bolsas de Iniciação Científica Universidade Católica de Pernambuco-UNICAP. O estudo estará dividido em duas etapas. Uma voltada à coleta de dados e outra voltada para a realização de um seminário.

$\mathrm{Na}$ primeira etapa, em relação à seleção dos Enfermeiros, tivemos quatro indivíduos. Todos eles integrantes de Unidades Básicas de Saúde do Município de Olinda. Naturalmente, foram excluídos os que se recusaram a participar ou que estiveram ausentes no período da coleta.

Após um estudo piloto para aprimoramento do instrumento de coleta, todos os participantes assinaram o TCLE (anexo I), responderam, a uma entrevista composta por quatro perguntas, realizada pelos pesquisadores e gravada por meio de um gravador de voz em ambiente reservado (anexo II). A análise de conteúdo das respostas foi orientada por alguns princípios norteadores inspirados no modelo proposto por Laurence Bardin (1977) e por princípios da soluciologia propostos por Barros (2018) (Anexo III).

A análise de conteúdo das respostas ocorreu a partir do seguinte roteiro: foi realizada uma leitura minuciosa da transcrição, a fim de formular uma ideia geral do que foi abordado. Em seguida, identificadas as unidades significativas de interesse para depois, organizá-las e transforma-las em categorias que correspondam ao agrupamento de unidades de significado, buscando traduzir a essência da fala do entrevistado em relação aos objetivos do estudo. $\mathrm{Na}$ análise qualitativa das respostas foram priorizados os seguintes itens: a compreensão de saúde que o entrevistado relatou com um direcionamento para os aspectos: físico, mental, espiritual, social e ambiental. Em seguida, a compreensão do entrevistado em relação à saúde sexual e a possibilidade de sua transmissão em relação aos cinco aspectos supracitados. De forma complementar, foram investigados os principais problemas e as principais soluções, na área da sexualidade, vivenciados no cotidiano da respectiva UBS. Em ambos os casos, a análise se conteúdo teve como foco, apenas o nível de abrangência das respostas e não a viabilidade ou 
não de seus conteúdos.

$\mathrm{Na}$ segunda etapa, foi realizada uma oficina com os seguimentos participantes com o intuito de apresentar os resultados do estudo e elaborar, conjuntamente, uma cartilha instrucional sobre o tema saúde sexualmente transmissível dentro do conceito de saúde sistêmica.

\section{RESULTADOS E DISCUSSÃO}

Ao apresentar o espectro de abrangência das respostas dos entrevistados em relação ao conceito geral de saúde integrando os aspectos físico, mental, espiritual e ambiental, será exposto, inicialmente, um quadro geral comparativo, alguns recortes ilustrativos dos discursos de cada entrevistado seguidos de comentários relacionando os achados mais significativos aos conteúdos referidos pelos teóricos selecionados para a compreensão do estudo.

\section{Conceito geral de saúde}

Quadro 1: distribuição do espectro de abrangência do conceito geral de saúde.

\begin{tabular}{|c|c|c|c|c|c|}
\hline Sujeitos & Física & Mental & Espiritual & Social & Ambiental \\
\hline 1 & $\mathrm{x}$ & $\mathrm{x}$ & & & \\
\hline 2 & $\mathrm{x}$ & $\mathrm{x}$ & & & \\
\hline 3 & $\mathrm{x}$ & $\mathrm{x}$ & & $\mathrm{x}$ & \\
\hline 4 & $\mathrm{x}$ & $\mathrm{x}$ & & & \\
\hline
\end{tabular}

- Sujeito 1: "Saúde é o bem-estar de cada um, não só o bem-estar físico e mental é ausência das doenças".

- Sujeito 2: "Saúde não é apenas o bem-estar físico e ausência de doenças para, sabemos que vai além disso e para ter saúde precisa estar bem emocionalmente também".

- Sujeito 3: "Saúde não é apenas a ausência de doença e bem-estar físico, mas estar bem emocionalmente, viver bem consigo e com a sociedade".

- Sujeito 4: "Saúde é um termo bem amplo, além de estar bem físicamente é preciso está bem em vários outros aspectos como o emocional, para se obter saúde física".

Comentários:

Percebe-se que, todos os entrevistados fizeram referência à dimensão física e mental aproximando-se do preconizado pela Organização Mundial de Saúde - OMS (2006) define "saúde" não apenas como a ausência de doença, mas como a situação de perfeito bemestar físico, mental e social. Entretanto, apenas um participante mencionou o aspecto social. 


\section{Conceito de saúde sexual}

Quadro 2: distribuição do espectro de abrangência do conceito de saúde sexual.

\begin{tabular}{|c|c|c|c|c|l|}
\hline Sujeitos & Física & Mental & Espiritual & Social & Ambiental \\
\hline 1 & $\mathrm{x}$ & & & & \\
\hline 2 & $\mathrm{x}$ & & & & \\
\hline 3 & $\mathrm{x}$ & & & & \\
\hline 4 & $\mathrm{x}$ & & & & \\
\hline
\end{tabular}

- Sujeito 1: "Saúde sexual, atualmente vejo como prevenção de doenças, gravidez precoce e uso de preservativos".

- Sujeito 2: "Saúde sexual é estar saudável sexualmente com os órgãos genitais saudáveis e sem doença".

- Sujeito 3: "Saúde sexual é você estar bem fisicamente e se prevenir para não contrair nenhuma DST - Doença Sexualmente Transmissível”.

- Sujeito 4: "Seria estar bem fisicamente, sem doenças sexualmente transmissíveis".

Comentários:

Ficou evidente o direcionamento apenas para o aspecto físico, abordando a ausência de doenças sexualmente transmissíveis em desacordo com o que afirma o Ministério da Saúde (2006), a sexualidade é muito mais do que sexo, é um aspecto central da vida das pessoas e envolve sexo, papéis sexuais, orientação sexual, erotismo, prazer, envolvimento emocional, amor e reprodução. Mais recentemente, o conceito de saúde tem convivido, também, com as dimensões espiritual e ambiental (KOENIG, 2009; CAPRA, 2012).

\section{Saúde sexualmente transmissível}

Quadro 3: distribuição do espectro de abrangência para a possibilidade de a saúde ser transmissível.

\begin{tabular}{|c|c|l|l|l|l|}
\hline Sujeitos & Física & Mental & Espiritual & Social & Ambiental \\
\hline 1 & $\mathrm{x}$ & & & & \\
\hline 2 & $\mathrm{x}$ & & & & \\
\hline 3 & $\mathrm{x}$ & & & & \\
\hline 4 & $\mathrm{x}$ & & & & \\
\hline
\end{tabular}

- Sujeito 1: "Para se transmitir saúde é necessário que os parceiros conheçam a si próprios, o que está normal e não patológico para não se transmitir doenças".

- Sujeito 2: "Para se transmitir saúde é necessário não se transmitir doenças, usando preservativo para evitar a contaminação de doenças".

- Sujeito 3: "Da mesma forma que transmitimos doença é possível transmitir saúde sim, e saúde sexual pode ser transmitida com a prevenção, se você estar saudável não 
transmitirá doença para o seu parceiro".

- Sujeito 4: “Através de relações sexuais seguras, com uso de preservativos, para que não venham a transmitir e nem adquirir doenças”.

\section{Comentários}

Em relação à transmissão de "saúde sexual" ficou evidente entre os participantes a associação de seus discursos voltados para uma abordagem direcionada apena para o aspecto físico e prevenção das doenças sexualmente transmissíveis. Nesse contexto, a possibilidade de se transmitir saúde através da sexualidade foi um tema não abordado, em especial, no âmbito da Atenção Básica que, no Brasil, de acordo com a Portaria 2.436, ela é a porta de entrada do sistema de saúde e, dentre outras, tem a função de promover, prevenir, diagnosticar e tratar os problemas de saúde. Mediante esta situação, percebe-se ser urgente a necessidade de se estudar também a saúde e sua forma de transmissão, e não apenas a doença.

\section{Problemas e Soluções}

Serão apresentados, hierarquicamente, os principais problemas referidos pelos entrevistados em relação à sexualidade no seu cotidiano na Atenção Básica. E em seguida, serão expostas as soluções apresentadas para cada problema mencionado por eles.

Vale ressaltar que não foi objetivo do estudo verificar se as soluções teriam condições de resolver o problema ou não. Optou-se por verificar apenas a abrangência das soluções que foram referidas identificando-se em quantas e quais áreas as soluções foram relacionadas aos aspectos: gestão, jurídico, formação de redes, mudanças de comportamento, mudanças socioculturais- educacionais e aspectos financeiros. Em seguida, será apresentada a nota/conceito atribuída a cada solução.

\section{PROBLEMAS:}

- Sujeito 1: 1- Falta de libido principalmente nas mulheres; 2 - Baixa estima nas mulheres; 3-preconceito em falar sobre sexo; 4- banalização do sexo, principalmente através de músicas; 5- ausência de sexo na terceira idade.

\section{SOLUÇÕES:}

"1-Oferecer profissionais especialistas no assunto para esclarecer as possíveis causas e realizar o tratamento de forma correta; 2-procurar profissionais que ajudem essas mulheres a se amar em primeiro lugar, se aceitarem como são, porque a partir daí elas poderiam ter saúde física emocional e sexual; 3-tentar mudar essa visão que falar sobre sexo e sexualidade implica em falar sobre algo imoral; 4-formação de um grupo que trabalhe com os adolescentes, público 
mais afetado, as questões sobre a banalização sexual e sua repercussão na sociedade e na vida de cada um deles; 5-identificar como está a vida sexual desse público e daí falar sobre saúde sexual".

Quadro 4: distribuição do espectro de abrangência para as soluções (S1).

\begin{tabular}{|c|c|c|c|c|c|c|c|c|c|c|c|}
\hline \multirow[b]{2}{*}{ Sujeito } & \multicolumn{6}{|c|}{ Aspectos } & \multirow[b]{2}{*}{ Nota } & \multicolumn{4}{|c|}{ Conceito } \\
\hline & $\begin{array}{l}\text { Gestã } \\
\text { o }\end{array}$ & Redes & Sócio/c/e & Mudança/Cpto & Financeiro & Jurid & & $\mathrm{r}$ & $\mathrm{R}$ & B & $\mathrm{E}$ \\
\hline 1 & 2 & 0 & 2 & 0 & 0 & 0 & 4 & & $X$ & & \\
\hline
\end{tabular}

r-ruim (pontos); R-regular (4 a 11); B-bom (12 a 14); E-excelente (16 a 18)

Com relação à abrangência das respostas, pode-se constatar que o entrevistado abordou apenas aspectos ligados à gestão e sócio-cultural-educacional. Não foram abordados os itens jurídicos, parcerias, mudanças de comportamento e custos. Desse modo o nível de abrangência foi classificado como regular com " 4 " pontos.

\section{Sujeito 2:}

\section{PROBLEMAS:}

"1-Prostituição; 2- doenças sexualmente transmissíveis; 3-mulheres que só procuram atendimento quando estão com alguma doença; 4-poucos homens que procuram o atendimento à saúde; 5-preconceito com relação a homossexualidade".

\section{SOLUÇÕES:}

"1-Não é fácil encontrar uma solução para meninas que se prostituem aos nove anos de idade, que cresceu vendo a prostituição e sabem que essa é a única forma de colocar comida dentro de casa; 2-fazer campanhas nas comunidades para conscientizar essas mulheres quanto ao uso de preservativos; 3 - tentar trazer essas mulheres para os postos de saúde e trabalhara questão da prevenção de DST; 4-realizar palestras com profissionais específicos que abordem a saúde sexual do homem ; 5-trabalhar a aceitação por parte desse público, antes de trabalhar a sociedade". 
Quadro 5: distribuição do espectro de abrangência para as soluções (S2).

\begin{tabular}{|c|c|c|c|c|c|c|c|c|c|c|c|}
\hline \multirow[b]{2}{*}{ Sujeito } & \multicolumn{6}{|c|}{ Aspectos } & \multirow{2}{*}{ Nota } & \multicolumn{4}{|c|}{ Conceito } \\
\hline & Gestão & Redes & Sócio/c/e & Mudança/Cpto. & Financeiro & Jurid & & $\mathrm{r}$ & $\mathrm{R}$ & B & $\mathrm{E}$ \\
\hline 2 & 2 & 0 & 2 & 0 & 0 & 0 & 4 & & $\mathrm{X}$ & & \\
\hline
\end{tabular}

r-ruim (0 a 3 pontos); R-regular (4 a 11); B-bom (12 a 14); E-excelente (16 a 18)

No que diz respeito à abrangência das respostas, pode-se constatar que o entrevistado fez uma abordagem voltada apenas para os aspectos ligados à gestão e sócio-culturaleducacional. Não foram abordados os itens jurídicos, parcerias, mudanças de comportamento e custos. Desse modo o nível de abrangência foi classificado como regular com “4” pontos.

\section{Sujeito 3:}

\section{PROBLEMAS:}

"1-Falta de conhecimento sobre sexualidade; 2-banalização do sexo; 3-DST's (doenças sexualmente transmissíveis); 4-prostituição; 5-disfunções sexuais na terceira idade".

\section{SOLUÇÕES:}

"1-Trazer a comunidade para falar sobre sexualidade e seus benefícios e esclarecer dúvidas e tentar quebrar esse tabu; 2-conscientizar a população principalmente os adolescentes que tem a visão que sexo pode ser feito com qualquer pessoa e em qualquer lugar; 3-conscientizar a população, principalmente os adolescentes sobre o uso de preservativos; 4-não é um problema que nós profissionais da saúde podemos resolver, alertar quantos os ricos e dar uma atenção maior, isso podemos fazer mais não é uma solução, acredito que esta possa vir por parte dos governantes; 5-fazer palestras para que a pessoa idosa saiba o que é normal acontecer com a idade, o que doença e disfunção e a partir daí procurar profissionais especialistas, e possam retomar uma vida sexual ativa dentro da sua individualidade".

Quadro 6: distribuição do espectro de abrangência para as soluções (S3).

\begin{tabular}{|c|c|c|c|c|c|c|c|c|c|c|c|}
\hline \multirow[b]{2}{*}{ Sujeito } & \multicolumn{6}{|c|}{ Aspectos } & \multirow[b]{2}{*}{ Nota } & \multicolumn{4}{|c|}{ Conceito } \\
\hline & Gestão & Redes & Sócio/c/e & Mudança/Cpto. & Financeiro & Jurid & & $\mathrm{r}$ & $\mathrm{R}$ & $\mathrm{B}$ & $E$ \\
\hline 3 & 2 & 0 & 2 & 0 & 0 & 0 & 4 & & $\mathrm{X}$ & & \\
\hline
\end{tabular}

r-ruim (0 a 3 pontos); R-regular (4 a 11); B-bom (12 a 14); E-excelente (16 a 18)

Através das representações do entrevistado, sobre à abrangência das respostas, pode-se constatar ele fez uma abordagem voltada apenas para os aspectos ligados a parcerias e sóciocultural-educacional. Não foram abordados os itens jurídicos, mudanças, gestão de 
comportamento e custos. Desse modo o nível de abrangência foi classificado como regular com “4” pontos.

\section{Sujeito 4:}

PROBLEMAS:

“1-Educação sexual; 2-DST's (doenças sexualmente transmissíveis); 3-preconceito ao falar sobre sexo ou sexualidade; 4-prostituição; 5-Pobreza".

\section{SOLUÇÕES:}

"1- abordar o tema sexualidade em todos âmbitos sociais, escolas, igrejas, associação, postos de saúde, dessa forma não haveria tanta falta de informações e teríamos menos doenças; 2 falar sobre assunto, esclarecer dúvidas, e mostrar a forma "correta" ou mais viável de se viver a sexualidade; 3- cada vez mais falar sobre o assunto mostrando para população que sexo, assim como qualquer outro assunto precisa se conversado, discutido, que não é feio, pecado e não é uma coisa ruim; 4-muito difícil encontra uma solução para esse problema, porque ele acontece em virtude de vários outros, teríamos que investigar quais são e tentar resolvê-los para tentar chegar a uma solução para o problema mencionado; 5- a solução precisa vir de autoridades maiores, porque eu, ou nós profissionais de saúde não podemos resolver o desemprego na comunidade ou na sociedade em geral, podemos apenas estar inseridos no conjunto de forma a somar e contribuir".

Quadro 7: distribuição do espectro de abrangência para as soluções (S4).

\begin{tabular}{|l|l|l|l|l|l|l|l|l|l|l|l|}
\hline \multirow{2}{*}{ Sujeito } & \multicolumn{3}{|l|}{ Aspectos } & \multirow{2}{*}{ Nota } & \multicolumn{3}{l|}{ Conceito } \\
\cline { 2 - 11 } & Gestão & Redes & Sócio/c/e & Mudança/Cpto. & Financeiro & Jurid & & r & R & B & E \\
\hline 4 & 0 & 2 & 2 & 0 & 0 & 0 & 4 & & X & \\
\hline
\end{tabular}

r-ruim (0 a 3 pontos); R-regular (4 a 11); B-bom (12 a 14); E-excelente (16 a 18)

Tendo em vista as especificidades relata, no que se refere à abrangência das respostas, pode-se constatar que o entrevistado fez uma abordagem voltada apenas para os aspectos ligados a parcerias e sócio-cultural-educacional. Não foram abordados os itens: jurídico, gestão, mudanças de comportamento e custos. Desse modo o nível de abrangência foi classificado como regular com "4" pontos.

A partir dos discursos apresentados pelos Enfermeiros, constatou-se que todos mencionaram a respeito das soluções aspectos voltados apenas para área de gestão, parcerias e redes e sócio-cultural-educacional, não incluindo os elementos jurídicos, mudanças de comportamento e custos. Alcançando um nível de abrangência regular caracterizado por uma 
pontuação de “4” pontos.

Para que o nível de abrangência geral das respostas dos entrevistados pudesse ter sido considerado excelente (15 a 18 pontos) as soluções precisariam possuir uma visão sistêmica um pouco mais ampliada e aprofundada para ser considerada com o nível máximo de abrangência.

Quanto aos problemas percebe-se que eles são muito mais estudados do que as soluções. Os problemas podem ser estudados de forma fragmentada, mas as soluções não. De acordo com Barros (2013), deve-se dar atenção igual para ambos, mas devido à falta de incentivo, as pessoas não utilizam de suas inteligências para elaborar soluções mais abrangentes.

Diante dos achados a realização do seminário foi de suma importância para orientar os profissionais quanto aos seus conhecimentos em relação aos temas pesquisados.

No momento da reunião fizeram-se presente seis profissionais e quatro pesquisadores, optou-se por uma roda de conversa. Primeiramente, foi distribuída uma síntese escrita dos resultados e a cartilha sobre saúde sexualmente transmissível. Os participantes reconheceram que não lidam com conteúdos relacionados à saúde em nível espiritual e ambiental. Foi necessário ampliar alguns conceitos como: transmissão de saúde, sexualidade e ressonância comportamental. Eles mencionaram diversas experiências vividas na própria UBS. E relataram ser muito interessante pensar em saúde sem estar vinculado a doenças, e que mediante toda contextualização estarão dispostos a abordar esses novos aspectos com a finalidade melhoria na assistência aos serviços prestados nas UBS's.

\section{CONCLUSÕES}

Na concepção sobre o conceito de saúde pode-se perceber que houve um predomínio do aspecto físico sobre os demais aspectos investigados, seguida das concepções: social e mental. As concepções espiritual e ambiental não foram referidas pelos participantes da pesquisa.

Já no conceito de saúde sexual foi realizada uma associação bem evidente, apenas para o aspecto físico, com relevância sobre a necessidade de ausência de doenças sexualmente transmissíveis, não sendo mencionadas as concepções: social, mental, espiritual e ambiental.

Com relação à possibilidade de transmissão de saúde, pode-se constatar que tal conteúdo foi ausente, visto que a maioria dos profissionais entrevistados mencionou nunca ter pensado no assunto e que gostariam de mais informações sobre o tema.

$\mathrm{Na}$ área da sexualidade, os principais problemas referidos foram: prostituição, ausência de sexualidade na terceira idade, doenças sexualmente transmissíveis e banalização do sexo.

Quanto a abrangência das soluções constatou-se que os entrevistados se restringiram às áreas de gestão, parcerias, redes e sócio-cultural-educacional, não incluindo os elementos 
jurídicos, mudanças de comportamento e custos, destacando-se o fato de que nenhum deles incluiu a si mesmo nas soluções apresentadas. Portanto, o nível de abrangência obteve a pontuação " 4 " e, de acordo com os parâmetros utilizados, foi considerado como regular.

No que se refere à realização do seminário, executado com o propósito de devolução dos resultados da pesquisa aos participantes, houve uma participação efetiva dos envolvidos, assim como o reconhecimento quanto à necessidade de um aprofundamento mais abrangente sobre os temas abordados.

De forma geral, constatou-se a necessidade de se aprofundar os temas supracitados tanto na formação profissional quanto em constantes capacitações da equipe de saúde, com participação da comunidade, para que se possa obter um nível geral de "consciência" constantemente ampliado.

\section{REFERÊNCIAS}

BARROS, P.M.F. A solução como objeto de estudo: Soluciologia. Olinda: Livro RápidoElógica, 2013.

BARROS, M.F.B. Soluciologia: coleta de dados. Disponível em:http://soluciologia.blogspot.com/ Acesso em março de 2018.

BOHM, David. A totalidade e a ordem implicada. Tradução por Mauro de Campos Silva. São Paulo: Cultrix, 1998. 292 p. Tradução de: Wholeness and the implicate order.

CAPRA, Fritjof. O tao da Física - Nova Edição: Uma Análise dos Paralelos entre a Física Moderna e Misticismo Oriental São Paulo: Cultrix, 2011. 376 p.

Cultrix, 2012. 432 p.

. O ponto de mutação: A Ciência, A Sociedade e A Cultura Emergente. São Paulo:

CARVALHO Teixeira, J. A. Comunicação e cuidados de saúde. Desafios para a psicologia da saúde. Análise Psicológica, 14 (1), 135-139. 1999.

Ministério da Saúde. Direitos sexuais, direitos reprodutivos e métodos anticoncepcionais. Secretaria de Atenção à Saúde, Departamento de Ações Programáticas Estratégicas. Brasília DF.

Disponível em:http://docs.google.com/viewer?a=v\&q=cache:pmEmCS7X8b4J:portal.saude.gov.br/portal /arquivos/pdf/cartilha_direitos_sexuais_2006.pdf. Acesso em 30 jan. 2018.

Ministério da Saúde. Portaria 2.436 de 21 de setembro de 2017. Aprova a Política Nacional de Atenção Básica, estabelecendo a revisão de diretrizes para a organização da Atenção Básica, no âmbito do Sistema Único de Saúde (SUS). Brasilia-DF. Disponível em: http://www.in.gov.br/materia/-/asset_publisher/Kujrw0TZC2Mb/content/id/19308123/do12017-09-22-portaria-n-2-436-de-21-de-setembro-de-2017-19308031. Acesso em 30 Mar. 2019. 
SILVA, A. A.; BARROS, P. M. F.

KOENIG HG. Research on religion, spirituality, and mental health: a review. Canadian Journal of Psychiatry, 54, 283-291. 2009. 


\title{
PROPRIEDADES MEDICINAIS DE PLANTAS DO MANGUE DO ESTADO DE PERNAMBUCO
}

\section{MEDICINAL PROPERTIES OF MANGROVE PLANTS OF THE STATE OF PERNAMBUCO}

\author{
Ricardo Sérgio da Silva ${ }^{1}$; Zion Nascimento de Souza ${ }^{2}$; Rayza Helen Graciano dos Santos ${ }^{3}$; Elielma Josefa de \\ Moura $^{4}$; Isabelly Fernanda Santos Barbosa ${ }^{5}$
}

DOI: $\underline{\text { https://doi.org/10.31692/978-65-991061-9-4.44-55 }}$

\section{RESUMO}

O Estado de Pernambuco se situa na região Nordeste do Brasil e tem aproximadamente 98.311 $\mathrm{km}^{2}$ de extensão. Além disso, sua vasta biodiversidade é uma das suas principais características, e, dentre seus ecossistemas destaca-se o manguezal, que é um ecossistema costeiro de transição entre os biomas terrestre e marinho. Baseado nisso, o presente estudo tem como objetivo a observação e discussão a respeito das propriedades medicinais de plantas do mangue Pernambucano. Para isso, foi realizado um levantamento qualitativo a respeito das características e propriedades das plantas do manguezal. Tal levantamento foi realizado por meio da análise de 25 artigos das plataformas Scielo e Google Acadêmico, datados entre 2008 e 2019. Por meio destes, foi possível constatar a importância e utilidade das plantas provenientes do mangue do Estado de Pernambuco para a comunidade e para fins farmacêuticos. Como resultados, foram identificadas 4 espécies de plantas pertencentes a 3 famílias e seu caráter medicinal no uso pela população e indústria.

Palavras-chave: Mangue; Pernambuco; Plantas Medicinais; Uso Medicinal.

\section{ABSTRACT}

The state of Pernambuco is located in the northeast region of Brazil and is approximately 98,311 $\mathrm{km}^{2}$ in length. In addition, its vast biodiversity is one of its main characteristics, and among its ecosystems stands out the mangrove, which is a coastal ecosystem of transition between the terrestrial and marine bioms. Based on this, the present study aims to observe and discuss the medicinal properties of mangrove plants in Pernambuco. For this, a qualitative survey was carried out regarding the characteristics and properties of the mangrove plants. This research was carried out through the analysis of 25 articles from Scielo and Google scholar platforms, dated between 2008 and 2019. Through these, it was possible to verify the importance and usefulness of the plants from the mangrove of the state of Pernambuco to the community and for pharmaceutical purposes. As results, 4 species of plants belonging to 3 families and their medicinal nature in the use by the population and industry were identified.

Keywords: Mangrove; Medicinal plants; Medicinal use; Pernambuco.

\section{INTRODUÇÃO}

O manguezal é um ecossistema costeiro, característico de regiões tropicais e subtropicais, situado na interface entre os ambientes terrestres e marinhos. Sujeito ao regime

\footnotetext{
${ }^{1}$ Mestre em Morfotecnologia, UFPE, profricardosergio.bio@gmail.com

${ }^{2}$ Bacharelado em Biomedicina, UFPE, zionnascimento@ hotmail.com

${ }^{3}$ Mestra em Morfotecnologia, UFPE, isabelly_barbosa@ hotmail.com

${ }^{4}$ Bacharelado em Agronomia, IFPE, elielmamoura@outlook.com

${ }^{5}$ Graduada em Ciências Biológicas, UFPE, rayzahelen@ hotmail.com
} 
das marés apresenta sedimentos predominantemente lodosos, com baixos teores de oxigênio dissolvido. A vegetação é uma floresta inundada constituída por espécies lenhosas típicas (Schaeffer-Novelli, 1995).

Os manguezais do Brasil, apresentam uma vasta extensão em toda a região litorânea, disponibilizando uma enorme riqueza de recursos naturais, que são explorados e utilizados por comunidades em geral desde tempos remotos (MATTOS et al., 2012). Esse ecossistema ocupa uma parcela bastante significativa do litoral brasileiro, que se estende desde o extremo norte do Amapá, até o estado de Santa Catarina, apresentando um desenvolvimento mais pleno em regiões mais próximas à linha do Equador (MATTOS et al, 2012).

No litoral brasileiro, os manguezais são caracterizados por diversas formas, extensões e características ambientais. O ambiente de mangue pode ser encontrado desde o litoral de Laguna, no Estado de Santa Catarina (região sul do país), ao Cabo Orange - no Estado do Amapá (região norte brasileira) - ocupando uma área de aproximadamente 14 mil km², o que configura o Brasil como o segundo maior detentor de áreas de manguezais no mundo (LACERDA, 2002).

Dentro da variabilidade de solos dos manguezais existem algumas características que são inerentes, como o alto teor de sais provenientes da água do mar, o hidromorfismo, o fato de que geralmente não há diferenciação de horizontes, além de uma elevada presença de matéria orgânica e cor acinzentada, proveniente do processo de gleização (MARQUES, 2010). Com o intuito de diferenciar e agrupar essas classes de solos utilizando o Sistema Brasileiro de Classificação de Solos (EMBRAPA, 2013), pode-se enquadrar os solos desses ambientes conforme seus atributos morfológicos, químicos e físicos, dentro de uma seção de controle do perfil pedológico, como: Gleissolos Tiomórficos (MARQUES, 2010) ou Organossolos Tiomórficos (FERREIRA, 2002), que apresentam pH menor que 3,5 após oxidado, tendo como produto o ácido sulfúrico, altamente tóxico para as plantas e animais. Outro aspecto importante na formação dos manguezais é a variação do nível médio do mar. Por ser um processo gradual e lento, durante essa variação ocorre uma reorganização constante no espaço desses ambientes. Sendo assim, o desenvolvimento de espaços novos pela fixação das espécies dos mangues é mais acelerado do que o processo de formação de solos. Deste modo, a cada redução ou elevação do nível médio do mar há uma adaptação dos manguezais evitando, portanto, a extinção do ecossistema (ALVES, 2001).

Sua estrutura possibilita a manutenção de diversos habitats propícios à proteção contra predadores, reprodução, desova e crescimento de diversas espécies marinhas ou de água doce. Permite também o abrigo de numerosas espécies terrestres na vegetação (Delabie et al., 2006). 
Em contrapartida, manguezais são favoráveis à instalação de portos e à fundação e expansão de cidades, sofrendo, como consequência, desmatamento, aterramento, eutrofização, entrada de elementos estranhos no sistema (poluição química e orgânica, invasão por espécies exóticas) e impactos de outras naturezas (Macintosh \& Ashton, 2005). Os impactos antrópicos podem causar alterações nas propriedades físicas, químicas e biológicas do ecossistema, refletindo-se diretamente nas relações socioeconômicas da população dependente desse meio.

As atividades tais como o desmatamento em larga escala, poluição por metais pesados provenientes de indústrias, petróleo e seus derivados, pesticidas e herbicidas, que vêm sendo desenvolvidas de forma constante e desenfreada no entorno de manguezais, atualmente e durante um longo período de tempo passado, trazem grandes impactos para o ecossistema por interferirem de forma direta ou indireta no desenvolvimento e regeneração das espécies do mangue (TEIXEIRA, 2008).

O desmatamento em áreas de manguezais é uma das alterações ambientais mais antigas no Brasil, praticado desde o século XVI. Naquela época, o corte de árvores era provocado para obtenção de tinta (tanino) utilizada para tingir tecidos e em curtumes (VANNUCCI, 2002).

O corte da vegetação de mangue além de destruir a flora, expõe o solo ao sol, provocando a evaporação mais rápida da água e, consequentemente, a salinização do substrato, resultando na morte do próprio mangue restante bem como de caranguejos e mariscos, o que afeta a produtividade e a pesca de caranguejos, camarões e peixes (ALVES, 2001).

O interesse por estudos em áreas de mangue vem sendo bastante difundido na comunidade acadêmica em decorrência de fatores como mudanças ambientais que afetam as propriedades físicas, químicas e biológicas do meio ambiente, com isso, é de grande importância a manutenção do equilíbrio ecológico no ecossistema do manguezal, bem como, a preservação da sua vasta biodiversidade (TEIXEIRA, 2008).

De acordo com estudos de Oliveira (2005) e Soares (2017), os estuários são ambientes de transição entre o continente e o oceano, onde há o encontro do rio com o mar. As espécies presentes no mangue, são plantas caracterizadas como halófitas, próprias de ambientes salinos. Esse tipo de ecossistema se destaca como sendo bastante importante para um ambiente equilibrado, pois funcionam como exportadores de matéria orgânica para os estuários, área de abrigo e reprodução para diversas espécies, além da diversidade da flora presente no local (BARBOSA, 2010).

Os manguezais têm sua importância relacionada às suas funções fundamentais, como a manutenção da qualidade da água, fixação do sedimento, fornecimento de produção primária para o entorno e manutenção da biodiversidade (KRUG et al., 2007). 


\section{FUNDAMENTAÇÃO TEÓRICA}

As plantas de mangue possuem um grande potencial para uso na descoberta de compostos bioativos, devido a seus fatores abióticos e condições ambientais severas nas quais essas plantas sobrevivem. (RODRIGUES et al., 2015). Além das marés, a quantidade de água doce que o manguezal recebe também é fundamental para o desenvolvimento e manutenção deste ambiente. Nessa ambiência há uma diluição da salinidade que determina a instalação e sobrevivência das espécies vegetais do manguezal, a distribuição dos organismos aquáticos e fatores ambientais como, por exemplo, temperatura, oxigênio dissolvido, pH, nutrientes e metais (ALVES, 2001).

A temperatura do ar e da água também é fundamental para o desenvolvimento dos manguezais, que preferem os ambientes mais quentes da região tropical com temperaturas médias anuais acima dos $20^{\circ} \mathrm{C}$ (MAJOR, 2002).

Essas espécies conseguem produzir carboidratos, polifenóis e outros compostos químicos que atuam na defesa dessas plantas e promovem seu desenvolvimento efetivo em ambientes agressivos (RODRIGUES et al., 2015).

As espécies de mangue são plantas halófitas ou pelo menos tolerantes à salinidade (VANNUCCI, 1999). A maioria das espécies também cresce em água doce, mas o crescimento é estimulado por condições salinas (BALL, 1988), apresentando crescimento máximo em baixas concentrações de sal (BALL, 1998). Além disso, nessas condições elas dominam por exclusão competitiva de outras espécies que não toleram tais condições (VANNUCCI, 2001). Para viver em ambientes salinos ou fisiologicamente secos, os mangues possuem adaptações xerófitas, incluindo a presença de tecidos de armazenamento de água, estômatos em depressão e aerênquima (THONLINSON, 1986). Algumas espécies possuem glândulas secretoras de sal, que conferem uma maior tolerância e flexibilidade em lidar com as flutuações no fluxo de sal para a parte aérea (YE et al., 2005). Estas espécies apresentam características fisiológicas e adaptações especiais ao local que se encontram, permitindo dessa forma, longos períodos de exposição em água, regime diário das marés, alta salinidade, baixo teor de oxigênio e substratos inconsolidados (REVATHI et al., 2013; ARAÚJO, 2015).

Segundo a Organização Mundial da Saúde (OMS), planta medicinal é considerada todo e qualquer vegetal que possui, em um ou mais órgãos, substâncias que podem ser utilizadas para fins terapêuticos ou que sejam precursores de fármacos semissintéticos. As plantas medicinais estão distribuídas de forma universal em diversos lugares, inclusive no manguezal.

No litoral brasileiro, os gêneros mais abundantes são Avicennia (Avicenniaceae), Laguncularia (Combretaceae) e Rhizophora (Rhizophoraceae), e representantes do gênero 
Conocarpus (Combretaceae) (SILVA, 2004).

Algumas espécies pertencentes ao mangue, como o mangue branco (Laguncularia racemosa) e o mangue vermelho (Rhizophora mangle) apresentam propriedades capazes de sintetizar substâncias (sais, ácidos orgânicos, carboidratos, alcaloides, flavonoides e taninos) utilizados na área médica, agronômica e cosmética (SEBASTIANES, 2010).

Plantas que possuem substâncias com propriedades medicinais de alto interesse farmacológico, demonstram ser uma excelente fonte para produção de medicamentos e seus derivados (SILVA, 2004).

Levando em consideração a grande biodiversidade do manguezal, a importância do seu estudo e a necessidade da busca sobre suas propriedades fitoquímicas para a reafirmação do uso pelas comunidades, o objetivo do presente estudo foi identificar as propriedades medicinais oriundas do mangue do Estado de Pernambuco e conhecer as características e aspectos que fazem com que estabeleçam a cura e o tratamento de diversas doenças.

\section{METODOLOGIA}

A pesquisa é de natureza qualitativa, constituída por pesquisas em artigos científicos, teses e dissertações nos bancos de dados Google Acadêmico e Scielo, entre os anos 2008 a 2019, com o objetivo de reunir dados sobre as propriedades medicinais de plantas do mangue do Estado de Pernambuco. Como critérios de inclusão foram admitidos artigos que apresentaram os usos populares da Avicennia (Avicenniaceae), Laguncularia (Combretaceae), Rhizophora (Rhizophoraceae), e Conocarpus (Combretaceae), bem como os artigos que apresentaram investigações fitoquímicas e propriedades biológicas das referidas plantas. Como critérios de exclusão, não foram adotados para a pesquisa, artigos publicados em datas fora da margem dos anos escolhidos para estudo.

Foram selecionados 25 artigos com base nos critérios de inclusão adotados e os resultados foram agrupados segundo a atividade biológica relatada para cada espécie e a sua respectiva referência bibliográfica.

\section{RESULTADOS E DISCUSSÃO}

De acordo com a pesquisa realizada entre os anos de 2008 a 2019, dos 25 artigos selecionados, foi possível confirmar a publicação de relatos sobre o uso medicinal da Avicennia (Avicenniaceae), Laguncularia (Combretaceae), Rhizophora (Rhizophoraceae) e Conocarpus (Combretaceae) para as para os mais diversos fins medicinais, citados a seguir na tabela 1. 
Tabela 1: Plantas medicinais do mangue pernambucano e suas características.

\begin{tabular}{|c|c|c|c|c|}
\hline $\begin{array}{l}\text { NOME } \\
\text { POPULAR }\end{array}$ & $\begin{array}{l}\text { NOME } \\
\text { CIENTÍFICO }\end{array}$ & FAMÍLIA & $\begin{array}{l}\text { UTILIZAÇÃO } \\
\text { POPULAR }\end{array}$ & AUTOR \\
\hline $\begin{array}{l}\text { Mangue- } \\
\text { Preto }\end{array}$ & Avicennia sp & Avicenniaceae & $\begin{array}{l}\text { Úlceras pépticas, } \\
\text { diarreia } \\
\text { hemorroidas, dor } \\
\text { reumática. }\end{array}$ & $\begin{array}{l}\text { SUMITHRA et al. (2011); } \\
\text { THIRUNAVUKKARASU et al. } \\
\text { (2011). }\end{array}$ \\
\hline $\begin{array}{l}\text { Mangue- } \\
\text { Branco }\end{array}$ & $\begin{array}{l}\text { Laguncularia } \\
\text { racemosa L. }\end{array}$ & Combretaceae & Antimicrobiana. & SILVA et. al., (2011) \\
\hline $\begin{array}{l}\text { Mangue- } \\
\text { Vermelho }\end{array}$ & $\begin{array}{l}\text { Rhizophora } \\
\text { mangle }\end{array}$ & Rhizophoraceae & $\begin{array}{l}\text { Anti-inflamatória } \\
\text { antioxidante, } \\
\text { cicatrizante, contra } \\
\text { úlcera } \\
\text { hipoglicemia. }\end{array}$ & $\begin{array}{l}\text { MARRERO et al., (2006); } \\
\text { BERENGUER et al., (2006), } \\
\text { FERNANDEZ et al., (2002); } \\
\text { PERERA etal.,(2001) ; } \\
\text { ALARCON-AGUILARA et al., } \\
\text { 1998). }\end{array}$ \\
\hline $\begin{array}{l}\text { Mangue-de- } \\
\text { Botão }\end{array}$ & $\begin{array}{l}\text { Conocarpus } \\
\text { erectus } L .\end{array}$ & Combretaceae & $\begin{array}{l}\text { Anemia, febre, } \\
\text { diabetes, diarreia, } \\
\text { hemorragia, } \\
\text { conjuntivite, dor de } \\
\text { cabeça. }\end{array}$ & $\begin{array}{l}\text { ABDEL-HAMEED et al., } \\
(2013) \text {. }\end{array}$ \\
\hline
\end{tabular}

Fonte: Própria (2019)

Mangue-Preto (Avicennia schaueriana)

O mangue-preto apresenta estruturas de respiração chamadas de pneumatóforos, que são raízes que crescem num sistema radicular e que depois sobem, ficando acima do solo, auxiliando assim a respiração da árvore (OLIVEIRA, 2005).

O gênero Avicennia é o único que ocorre em todo o mundo. Junto com Rizophora, eles formam uma dominância em relação as comunidades de florestas de mangue (THATOI et al., 2016).

Há relatos sobre a importância de diversas partes de espécies com uso etnomedicinal, onde o chá preparado a partir da casca é utilizado para tratar uma variedade de distúrbios digestivos como úlceras pépticas, diarreia incluindo hemorróidas, 
dor reumática e assim por diante. (SUMITHRA et al. 2011; THIRUNAVUKKARASU et al. 2011).

As espécies de Avicennia se distribuem por todo o Brasil e se distinguem pelo desenvolvimento pronunciado de raízes salientes, as quais são denominadas de pneumatóforos, pode alcançar alturas de $20 \mathrm{~cm}$ ou mais (RODRÍGUEZ-ZÚÑIGA et al., 2015).

\section{Mangue Branco (Laguncularia racemosa L.)}

Laguncularia racemosa L. Gaertn. f. (Combretaceae) é uma espécie arbórea halófita, que se desenvolve sob influência da inundação pelas marés, nos solos instáveis, salinos e anóxicos característicos do ecossistema manguezal (OLIVEIRA, 2005).

De acordo com Silva et al., (2011), fungos endofíticos isolados das folhas de $L$. racemosa produzem metabólitos secundários com atividade antimicrobiana. $\mathrm{O}$ isolamento e caracterização dessas substâncias podem levar à descoberta de novos compostos de interesse farmacêutico, especialmente no tratamento de infecções causadas por bactérias. Além disso, essas plantas apresentam uma série de defesas contra a herbivoria, destacando-se a síntese de metabólitos secundários. Dentre esses, temos os polifenóis, constituídos principalmente por taninos condensados e outros fenóis com atividade adstringente (KANDIL et al., 2004).

\section{Mangue Vermelho (Rhizophora mangle)}

As espécies vegetais do gênero Rhizophora são conhecidas pelas várias propriedades medicinais que possuem. R. mangle é conhecida popularmente como "Mangue-Vermelho", "Mangue Garobeira", "Mangue de Espeto", "Mangue de Pendão", "Mangue Sapateiro", e "Mangue Verdadeiro", principalmente na região nordeste do Brasil (CARDOSO; SALARO; VILEGAS, 2015).

Rhizophora mangle L., é uma espécie endêmica da vegetação de manguezal, que faz parte da família Rhizophoraceae. Essa vegetação possui caráter arbóreo com folhas simples e adaptações fisiológicas notáveis frente aos substratos anaeróbicos típicos do manguezal, os rizóforos (FERREIRA, et al., 2011).

O mangue-vermelho é rico em substâncias fenólicas, como taninos, que são largamente utilizadas na produção de corantes. Algumas propriedades farmacológicas de Rhizophora mangle L. têm sido determinadas, como as atividades anti-inflamatória (MARRERO et al., 2006), antioxidante (BERENGUER et al., 2006), cicatrizante (FERNANDEZ et al., 2002); contra úlcera (PERERA et al., 2001; BERENGUER et al., 2006) e hipoglicêmica (ALARCONAGUILARA et al., 1998). 
Mangue-de-botão (Conocarpus erectus L.)

A espécie Conocarpus erectus L. é popularmente conhecida por nome popular de "mangue botão" que pertence à família Combretaceae, podendo ser encontrada nos manguezais em regiões tropicais e subtropicais em todo o mundo (VIEIRA, 2017).

As folhas, caules, frutos e flores possuem em sua composição propriedades antioxidantes, anticancerígenos e antimicrobianos. Na medicina popular é utilizada na prevenção de anemia, diabetes, conjuntivite, dor de cabeça, diarreia, febre e, hemorragia (ABDEL-HAMEED et al., 2013).

De acordo com trabalho de Shohayeb et al. (2013), C. erectus é usado como um remédio para vários doenças como anemia, catarro, orquite, úlceras na pele e sífilis. Em análise de extratos de $C$. erectus foram detectadas capacidades antioxidantes e anticancerígenas (NAHLA, 2010). A crescente incidência de resistência de agentes patogênicos e bactérias a antibióticos enfatiza a necessidade de plantas para sua potencial atividade antimicrobiana (SHOHAYEB et al., 2013).

\section{CONCLUSÃO}

Por meio do presente estudo, foi possível constatar a importância e versatilidade quanto ao uso das plantas medicinais oriundas do mangue Pernambucano. Observou-se que as espécies estudadas têm grande potencial de uso, já que são fontes de moléculas bioativas de grande interesse e relevância para uso farmacológico, tais como sais, ácidos orgânicos, carboidratos, alcaloides, flavonoides, taninos, dentre outras, que podem ser extraídas e utilizadas na área médica, cosmética e agronômica.

Além disso, pode-se destacar o variado e recorrente emprego dessas plantas na medicina popular, o que ressalta a necessidade da ocorrência de mais estudos na referida área, visando tanto a ampliação do conhecimento a respeito de suas características e potencialidades quanto a segurança e eficácia de uso por parte da população.

\section{REFERÊNCIAS}

AlbuQUerQue, A.; FREITAS, E.; MOURA-FÉ, M.M.; BARbOSA, W. A PROTEÇÃo DOS ECOSSISTEMAS DE MANGUEZAL PELA LEGISLAÇÃO AMBIENTAL BRASILEIRA. GEOgraphia - Ano. 17 - N³3 - 2015.

ALMEIDA, Z.S; FÔNSECA, V.G. 1999. Análise quali-quantitativa da meiofauna na região de Itapissuma - PE. Pesq. Foco. São Luiz, 7 (9): 115-137. 
ANUNCIADA, CRISTIANE; GOMES, ANDRÉ; SANTOS, PAULO JORGE PARREIRA; ALVES, TATIANA NUNES CAVALCANTI; FILHO, JOSÉ SOUTO ROSA; SANTOS, LÍLIA PEREIRA SOUZA. VARIAÇÃO TEMPORAL DA MEIOFAUNA EM ÁREA DE MANGUEZAL EM ITAMARACÁ - PERNAMBUCO. Atlântica, Rio Grande, 24(2): 8996, 2002.

ARAÚJO, J. G. Desenvolvimento de creme de Rhizophora mangle L.: Avaliação do potencial cicatrizante em feridas cutâneas. Universidade Federal de Pernambuco. Dissertação de Mestrado. Programa de Pós-Graduação em Ciências da Saúde, Recife, 2015.

BANDEIRA, A. R. G. Estudo fitoquímico e atividade biológica de Conocarpus erectus L. (Mangue botão). Universidade Federal de Pernambuco. Dissertação de Mestrado. Centro de Ciências Biológicas, Departamento de antibióticos, Pós-Graduação em biotecnologia de produtos bioativos. Recife, 2003.

BARBOSA, F. G. Estrutura e análise espaço temporal da vegetação do manguezal do Pina, Recife - PE: subsídios para manejo, monitoramento e conservação. Universidade Federal de Pernambuco - CFCH. Dissertação de Mestrado. Programa de Pós-Graduação em Geografia. Recife, 2010.

BERENGUER, B.; SÁNCHEZ, L. M.; QUÍLEZ, A.; LÓPEZ-BARREIRO, M.; HARO, BRANCO, L.H.Z.; MOURA, A.N.; SILVA, A.C.; OLIVEIRA, M.C.B. BIODIVERSIDADE E CONSIDERAÇÕES BIOGEOGRÁFICAS DAS CYANOBACTERIA DE UMA ÁREA DE MANGUEZAL DO ESTADO DE PERNAMBUCO, BRASIL. Acta bot. bras. 17(4): 585-596. 2003.

CARDOSO, C. R. P.; SALARO, M. C. F.; VILEGAS, W. Controle de qualidade preliminar de Rhizophora mangle, planta do litoral brasileiro. III Simpósio de Tecnologia Sucroenergética e de Biocombustíveis. Ciência \& Tecnologia: Fatec-JB, Jaboticabal, v. 7, 2015. Suplemento.

CARNEIRO, M.A.B; FARRAPEIRA, C.M.R; SILVA, K.M.E. O manguezal na visão etnoecológica dos pescadores artesanais do Canal de Santa Cruz, Itapissuma, Pernambuco, Brasil.

EL-SAYED S. ABDEL-HAMEED, SALIH A. BAZAID and ABDEL NASSER A. SABRA.2013. Protective Effect of Conocarpus erectus .Extracts on CC 14-Induced Chronic Liver Injury in Mice. ISSN 1992-0075. DOI: 10.5829/idosi.gjp.2013.7.1.7188. Global Journal of Pharmacology 7 (1): 52-60, 2013.

FERREIRA, F.S.; SANTOS, S.C.; BARROS, T.F.; ROSSI-ALVA, J.C.; FERNANDEZ, L.G. Atividade antibacteriana in vitro de extratos de Rhizophora mangle L. Rev. Bras. Pl. Med., Botucatu, v.13, n.3, p.305-310, 2011.

GOMES, C.A.A.P.; SANTOS, J.P.; ALVES,T.N.C.; FILHO, J.S.R.; SANTOS. L. P.S. VARIAÇÃO TEMPORAL DA MEIOFAUNA EM ÁREA DE MANGUEZAL EM ITAMARACÁ - PERNAMBUCO. Atlântica, Rio Grande, 24(2): 89-96, 2002.

Lima, D.A. ESTUdOS FITOGEOGRÁFICOS DE PERNAMBUCO. Anais da Academia Pernambucana de Ciência Agronômica. 
LIMA, D.ANDRADE. ESTUDOS FITOGEOGRÁFICOS DE PERNAMBUCO. Anais da Academia Pernambucana de Ciência Agronômica, Recife, vol. 4, p.243-274, 2007.

MACEDO \& T LIMA (eds). Gerenciamento participativo de estuários e manguezais. Recife, Cap. 3: 89-102.

MARRERO, E.; SÁNCHEZ, J.; ARMAS, E.; ESCOBAR, A.; MELCHOR, G.; ABAD, M. J.; BERMEJO, P.; VILLAR, A. M.; ALCARAZ, M. J. COX-2 and sPLA2 inhibitory activity of aqueous extract and polyphenols of Rhizophora mangle (red mangrove). Fitoterapia, v.77, n. 4, p.313-5, 2006.

MARTINS, P.T.A; COUTO, E.C. G; DELABIE, J.H.C. Fitossociologia e estrutura vegetal do Manguezal do rio Cururupe (Ilhéus, Bahia, Brasil). Revista da Gestão Costeira Integrada 11(2):163-169 (2011).

MARTINS, Patrick Thomaz de Aquino. Análise das intervenções antrópicas no manguezal do rio Cachoeira, Ilhéus, Bahia. 2008. 85 f. Dissertação (Mestrado em Geografia) Universidade Federal de Sergipe, São Cristóvão, 2008.

MATTOS, P. P.; KONIG, A.; FREIRE, F. A. M.; ALOUFA, M. A. I. Etnoconhecimento e percepção dos povos pesqueiros da Reserva Ponta do Tubarão acerca do ecossistema manguezal. Revista Brasileira de Biociências. ISSN 1980-4849 (on-line) / 1679-2343 (print). Porto Alegre, v. 10, n. 4, p. 481-489, out./dez. 2012.

NAHLA, A. A. A trime thoxyellagic acid glucuronide from Conocarpus erectus leaves: Isolation, characterization and assay of antioxidant capacity. Pharm Biol, 48: 328- 332, 2010.

O.; GÁLVEZ, J.; MARTÍN, M. J. Protective and antioxidant effects of Rhizophora mangle L. against NSAID-induced gastric ulcers. Journal of Ethnopharmacology, v.103, n.2, p.194200, 2006.

OLIVEIRA, V. F. Influência do estresse hídrico e salino na germinação de propágulos de Avicennia schaueriana Stapf e Leechman ex Moldenke e Laguncularia racemosa (L.) Gaertn. f. Rio de Janeiro. Dissertação (mestrado) - Instituto de Pesquisas Jardim Botânico do Rio de Janeiro/Escola Nacional de Botânica Tropical, 2005.

PORTUGAL, Ana Margarida Marques; SCHAEFFER-NOVELLI, Yara. Manguezais de Guaratiba frente à perspectiva de elevação do nível médio relativo do mar, Baía de Sepetiba, Estado do Rio de Janeiro - Brasil. 2002.Universidade de São Paulo, São Paulo, BSP, 2002.

REVATHI, P., SENTHINATH, T. J., THIRUMALAIKOLUNDUSUBRAMANIAN, P.; PRABHU, N. Medicinal Properties of Mangrove Plants - an overview. International Journal of Bioassays, v. 2, n.12, p. 1596-1600, 2013.

RODRIGUES, C. F. B.; GAETA, H. H.; BELCHOR, M. N.; FERREIRA, M. J. P.; PINHO, M. V. T.; TOYAMA, D. O.; TOYAMA, M. H. Evaluation of Potential Thrombin Inhibitors from the White Mangrove (Laguncularia racemosa (L.) C.F. Gaertn.) Mar. 
Drugs 2015, 13, 4505-4519; doi:10.3390/md13074505. Marine drugs ISSN 1660-3397 www.mdpi.com/journal/marinedrugs

RODRÍGUEZ-ZÚNIGA, M. T.; Troche-Souza, C., Vázquez-Lule, A. D., Márquez-Mendoza, J. D., Vázquez-Balderas, B., Valderrama-Landeros, L., Cerdeira-Estrada, S. Comisión Nacional para el Conocimiento y Uso de la Biodiversidad. México DF, 2015 http://www.biodiversidad.gob.mx/ecosistemas/manglares2013/pdf/folleto_manglares_web.pd f> acessado em 10 set. 2016.

SANTOS, P.J.P, GOMES, C.A.A; ALMEIDA, Z.S.; FÔNSECA; V.G \& SANTOS, LPS. 2000. Diversidade de Copepoda Harpacticoida em área de manguezal do Canal de Santa de Cruz, PE, Brasil. Publ. Acad. Sci. São Paulo, 109 (2): 319-326.

SCHAEFFER-NOVELLI, Y.; CINTRÓN, G. M. 1986. Guia para estudo de áreas de manguezal: estrutura, função e flora. [S.1.]: Caribbean Ecological Research. 186 p.

SEBASTIANES, F. L. S. Diversidade genética e potencial biotecnológico de fungos endofíticos de manguezais do estado de São Paulo. 2010. 150f. Tese de doutorado. Universidade de São Paulo, Escola Superior de Agricultura Luiz de Queiroz, Piracicaba, 2010.

Seixas, J..A.S.; Fernandes, M.E.B.; Silva, E.S. Análise estrutural da vegetação arbórea dos mangues no Furo Grande, Bragança, Pará. Bol. Mus. Para. Emilio Goeldi Cienc. Nat. v.1 n.3 Belém dez. 2006.

Sérgio, C; Leite, E.; Pitteri, H.; Martuscelli, J.; Machado, P. CARACTERIZAÇÃO MORFOFISIOLÓGICA DO MANGUEZAL DE CANANÉIA - SP.Environmental and Health World Congress.July 16 - 19, 2006, Santos, BRAZIL.

SHOHAYEB, M.; ABDEL-HAMEED E.; BAZAID, S. ANTIMICROBIAL ACTIVITY OF TANNINS AND EXTRACTS OF DIFFERENT PARTS OF CONOCARPUS ERECTUS L. Available Online through www.ijpbs.com (or) www.ijpbsonline.com. International Journal of Pharmacy and Biological Sciences (e-ISSN: 2230-7605). IJPBS, Volume 3. Issue 2 |APRJUN |2013|544-553.

SILVA, E.V; SOUZA, M.M.A. Principais formas de uso e ocupação dos manguezais do Estado do Ceará. Universidade Federal do Ceará, Fortaleza, CE, Brasil.

SILVA, J. M.; MARTINS, M.B.G.; CAVALHEIRO, A.J. Caracterização anatômica e perfil químico da lâmina foliar de Laguncularia racemosa (L.) Gaertn, de manguezais impactados e não impactados do litoral de São Paulo. Fundação zoobotânica-RS v. 65, n. 2 (2010).

Silva, J.M.; Martins, M.B.G.; Cavalheiro, A.J. Caracterização anatômica e perfis químicos de folhas de Avicennia schaueriana Stapf. \& Leech. ex Moldenke e Rhizophora mangle L. de manguezais impactados e não impactados do litoral paulista.doi: 10.5007/21784574.2010v39p14.

SILVA, M. R. O. Detecção da atividade antifúngica de extratos de plantas do manguezal de Vila Velha, Itamaracá - PE. Universidade Federal de Pernambuco. Dissertação de Mestrado. Pós-Graduação em Biologia de Fungos. Recife, 2004.

SILVA, M. R. O.; ALMEIDA, A. C.; ARRUDA, F. V. F.; GUSMÃO, N. Endophytic fungi 
from brazilian mangrove plant Laguncularia racemosa (L.) Gaertn. (Combretaceae): their antimicrobial potential. Science against microbial pathogens: communicating current research and technological advances A. Méndez-Vilas (Ed.). 2011.

SOARES, S. R. F. Cultivo de mudas de Laguncularia racemosa (L.) C. F. Gaertn com uso de águas hipersalinas e diferentes substratos. Tese de Doutorado. Universidade Federal Rural do Semi-Árido. Programa de pós-graduação em Manejo de Solo e água. Mossoró-RN, 2017.

SUMITHRA M, ANBU J, NITHYA S, RAVICHANDIRAN V. 2011. Anticancer activity of methanolic leaves extract of Avicennia officinalis on ehrlich ascitis carcinoma cell lines in rodents. International Journal of PharmTech Research CODEN (USA): IJPRIF ISSN: 09744304 Vol.3, No.3,pp 1290-1292, July-Sept 2011.

TEIXEIRA, K. C. S. Propagação de plantas de mangue visando a recuperação de áreas degradadas. Universidade Federal de Sergipe. Dissertação de Merstrado. Núcleo de PósGraduação em Desenvolvimento e Meio Ambiente, Pró-Reitoria de Pós-Graduação e Pesquisa. Sergipe, 2008.

THATOI, H.; SAMANTARAYB, D.; DAS. S. K. The genus Avicennia, a pioneer group of dominant mangrove plant species with potential medicinal values: a review. FRONTIERS IN LIFE SCIENCE, $2016 \quad$ VOL. $\quad 9, \quad$ NO. $\quad 4, \quad 267-291$ http://dx.doi.org/10.1080/21553769.2016.1235619.

THIRUNAYUKKARASU P, RAMANATHAN T, RAMKUMAR L, SHANMUGAPRIYA R, RENUGADEVI G. 2011. The antioxidant and free radical scavenging effect of Avicennia officinalis. Journal of Medicinal Plants Research Vol. 5(19), pp. 4754-4758, 23 September, 2011 Available online at http://www.academicjournals.org/JMPR ISSN 1996-0875 (C2011 Academic Journals

VIEIRA, V. R. ATIVIDADE CITOPROTETORA E CICATRIZANTE DA ESPÉCIE Conocarpus erectus L EM LESÕES GÁSTRICAS INDUZIDAS EM RATOS WISTAR ADULTOS. UNIVERSIDADE FEDERAL DO PARÁ INSTITUTO DE CIÊNCIAS DA SAÚDE PROGRAMA DE PÓS-GRADUAÇÃO EM QUIMICA MEDICINAL E MODELAGEM MOLECULAR. Dissertação de Mestrado, Belém-PA, 2017. 


\title{
UM OLHAR SOB A PERSPECTIVA DA OFICINA "EU RECONHEÇO SINAIS DE ALERTA NO PRÉ-NATAL E PUERPÉRIO" - DISTRITO SANITÁRIO VII - RECIFE - PE
}

\author{
UNA MIRADA BAJO LA PERSPECTIVA DEL TALLER "YO RECONOZCO \\ SEÑALES DE ADVERTENCIA EN EL PRENATAL Y POSPARTO” - DISTRITO DE \\ SALUD VII - RECIFE - PE
}

\section{A LOOK FROM THE PERSPECTIVE OF THE WORKSHOP "I RECOGNIZE WARNING SIGNS IN PRENATAL AND POSTPARTUM" - SANITARY DISTRICT VII - RECIFE - PE}
Ariosto Afonso de Morais ${ }^{1}$; Thâmara Onofre de Melo $^{2}$; Fernanda Evelyn Silva ${ }^{3}$; Eliane Barbosa da Silva ${ }^{4}$; Christiane Walburga Ferreira de Azevedo ${ }^{5}$

DOI: https://doi.org/10.31692/978-65-991061-9-4.56-61

\section{INTRODUÇÃO}

De acordo com o Ministério da Saúde (BRASIL, 2019) a gravidez é um fenômeno fisiológico, de grandes transformações para a mulher, para seu (sua) parceiro (a) e para toda a família. Este período inicia-se com a fecundação, se estende por um período de cerca de 40 semanas e encerra com o parto (COUTINHO et al, 2014). A partir do nascimento e seguindo até a recuperação anatômica e fisiológica completa, está o período denominado puerpério, onde o organismo retorna às condições pré-gestacionais (SÁEZ et al., 2018); didaticamente, pode ser dividido em três fases, sendo imediato, tardio e remoto (ANDRADE et al., 2015).

A Atenção Básica é porta de entrada dos serviços de pré-natal e acompanhamento puerperal e conta com profissionais médicos e enfermeiros, que devem tratar o ciclo gravídicopuerperal de forma integrada (ANDRADE et al., 2015). Toda mulher tem direito garantido a atendimento seguro, humanizado e qualificado na gravidez, parto e após o nascimento do bebê (BRASIL, 2018).

A assistência pré-natal pode auxiliar positivamente o diagnóstico e tratamento adequado das afecções, além de fiscalizar fatores de risco que gerem complicações na saúde da mãe e do bebê, tendo também como finalidade prevenir complicações durante a gravidez e no parto; proporcionar agradável saúde materna e bom desenvolvimento fetal; e diminuir os índices de morbimortalidade fetal e materna (MARTINS et al, 2015).

\footnotetext{
${ }^{1}$ Medicina, Universidade Católica de Pernambuco, ariostodireito@yahoo.com.br

${ }^{2}$ Odontologia, Universidade Tiradentes de Pernambuco, thamaraonoffre@ hotmail.com

${ }^{3}$ Fisioterapia, Universidade Federal de Pernambuco, ferevelyn7@ gmail.com

${ }^{4}$ Enfermagem, Universidade Estadual de Pernambuco, elibarbosa2009@gmail.com

${ }^{5}$ Especialista em Saúde Pública, FIOCRUZ, christiane.walburga@ hotmail.com
} 
No puerpério a mulher apresenta inúmeras modificações internas e externas, o que configura um período repleto de mudanças psíquicas e físicas, onde ela continua necessitando de proteção e cuidado. Dessa forma, há a necessidade da usuária continuar sendo atendida em sua totalidade, por meio de um olhar integral que leve em consideração o contexto sociocultural e familiar (ANDRADE et al., 2015).

Considerada um importante indicador da realidade social de um país, a mortalidade materna é indicativo de precárias condições socioeconômicas e representa um grande problema de saúde pública por se tratar de uma morte evitável em praticamente 100\% dos casos (CARVALHO et al, 2015).

Visando a formação de profissionais cada vez mais capacitados faz-se necessário a preparação e constante atualização destes profissionais. Nesse contexto, as metodologias ativas de aprendizagem ganham espaço; uma vez que se baseiam em formas novas de desenvolver o processo de aprendizagem, estimulando processos de reflexão, mediado por facilitadores que permitam que os participantes assumam posturas ativas em relação ao seu processo de aprendizagem, a fim de solucionar situações problemas (GARCIA; OLIVEIRA; PLANTIER, 2019).

A implementação dessas metodologias favorece a motivação de cada um quando inclui o fortalecimento da percepção de ser fator modificador de seu próprio conhecimento, deste modo, as metodologias ativas têm o potencial de despertar a curiosidade, à medida que os integrantes se inserem na teorização e buscam trazer novos elementos, ainda não considerados nas aulas ou na perspectiva dos demais.

Considerando o exposto e entendendo a importância do pré-natal e acompanhamento puerperal na redução da mortalidade materna, o objetivo do presente trabalho foi descrever a aplicação da oficina "Eu reconheço sinais de alerta no pré-natal e puerpério" no Distrito Sanitário VII- Recife-PE utilizando metodologia ativa de transferência de conhecimento.

\section{FUNDAMENTAÇÃO TEÓRICA}

O Ministério da Saúde, utilizando o Programa de Humanização do Pré-natal e Nascimento (PHPN), trouxe à pauta o acesso e a qualidade do cuidado no ciclo gravídicopuerperal (CORREA et al, 2017) que respalda a busca para uma assistência mais qualificada à gestantes. Uma experiência positiva no pré-natal contribui para o alcance da qualidade, uma vez que dispõe de profissionais capacitados para identificar precocemente os fatores de risco para a mulher e controlá-los oportunamente. Dessa forma, entende-se que a qualidade da 
assistência pré-natal impacta diretamente nos indicadores de saúde (LIVRAMENTO et al, 2019).

O puerpério também é um período que requer atenção por ocorrer mudanças anatômicas, fisiológicas e transformações profundas (GOMES; SANTOS, 2017). No planejamento das ações da equipe de Atenção Básica, deve ser garantido o acompanhamento integral da mulher e da criança que devem ser assistidos por profissionais atentos e preparados para prestar assistência a mulher e sua família, para reconhecer condições de risco e vulnerabilidade física, psíquica e social, e para utilizar os recursos das redes de saúde e intersetorial para lidar com os problemas que possam surgir nessa fase (BRASIL, 2016).

Pensando na necessidade de ofertar um atendimento qualificado, foi proposta a oficina objetivando capacitar os profissionais e aguçar o pensamento crítico; desta forma foi elegida a metodologia ativa que coloca o profissional no centro do ensino-aprendizagem, como participante ativo desse processo. Essa metodologia proporciona o aprendizado baseado em experiências e uma de suas vantagens é promover a interelação entre a teoria e a prática, que motiva a participação (VARGAS; GONZALEZ; NAVARRETE, 2018).

\section{METODOLOGIA}

Trata-se de um estudo descritivo abrangendo a Oficina: "Eu reconheço sinais de alerta no pré-natal e puerpério" do Projeto de Redução da Mortalidade Materna, que foi ministrada primeiramente pelo Hospital Albert Einstein (SP) em parceria com o Hospital Agamenon Magalhães (PE), buscando capacitar lideranças assistenciais e profissionais da APS; e formar facilitadores que reproduzam a capacitação no município do Recife.

Esses profissionais habilitados facilitadores repassaram os conteúdos da Oficina de prénatal, através de uma metodologia ativa para os profissionais da APS do Distrito Sanitário VII, em de três (03) encontros.

O processo do facilitador na replicação da oficina: - Eu reconheço sinais de alerta no pré-natal, foi:

- Na abertura foi contextualizado o projeto e os desafios para a redução da mortalidade materna.

- Os participantes foram divididos em 6 grupos. Cada grupo com seu facilitador.

- A metodologia ativa "Problem Based Learning" (PBL - Aprendizagem baseada em problemas), foi aplicada nos pequenos grupos, envolvendo os participantes na leitura das referências disponibilizadas- guias, protocolos ou artigos- e questionamentos sobre a aplicação das informações aos problemas do dia a dia. 
- Após a discussão dos temas nos pequenos grupos, os conhecimentos são compartilhados por todos envolvidos, em um grande grupo.

Os materiais utilizados na dinâmica foram cartolina, projetor para apresentação em powerpoint, canetas coloridas, etiquetas auto adesivas para identificação, pastas com material do curso, cópia das referências bibliográficas para trabalho nos pequenos grupos.

\section{RESULTADOS E DISCUSSÕES}

No que se refere ao acompanhamento pré-natal foi evidenciada a necessidade de ser iniciado o mais precocemente possível, de forma integral, e que sejam realizados os exames recomendados, detectadas e tratadas precocemente as alterações, evitando qualquer risco ao binômio mãe-bebê. Tratando-se do período puerperal evidenciou-se que é essencial a continuação do acompanhamento à essa paciente e a nova vida gerada, para prevenção de afecções e redução também dos índices de mortalidade materna.

Chhabra et al. notaram que a metodologia ativa tem demonstrado ser uma técnica efetiva para o desenvolvimento profissional e do pensamento crítico. Uma das principais vantagens do uso da metodologia seria garantir a cada participante a oportunidade de desenvolver habilidades com raciocínio clínico.

O papel do facilitador na metodologia da oficina consistiu em desenvolver problemas relevantes que estimulassem a interpretação de dados científicos e clínicos com a finalidade de aperfeiçoar o tratamento e acompanhamento de condições frequentes no pré-natal e puerpério.

A oficina por sua vez não objetivou apenas disseminar a informação, mas também mostrar aos profissionais como usá-la frente a novas situações e problemas a serem solucionados. Estudos realizados comparando as metodologias tradicionais passivas e a aprendizagem baseada em equipes mostram que a metodologia ativa resulta em desempenhos melhores e maior satisfação dos profissionais, bem como em maior engajamento e participação (NASCIMENTO et al, 2019). Sendo assim, a metodologia ativa usada na oficina foi uma ferramenta de extrema importância por priorizar o trabalho em equipe na resolução dos casos.

\section{CONCLUSÕES}

A mortalidade materna é um grave problema de saúde pública no Brasil e apresenta um grande desafio para os profissionais em geral. Levando em consideração esse problema, o projeto Redução de Mortalidade Materna buscou sensibilizar os profissionais médicos e enfermeiros a conduzir de forma correta o pré-natal e a identificar fatores de risco, como: 
diabetes gestacional, sífilis, infecção do trato urinário, infecção puerperal e síndromes hemorrágicas.

A partir da oficina ofertada pela Secretária Municipal de Saúde de Pernambuco evidenciou a necessidade de ampliar o entendimento clínico para identificação precoce de sinais de alerta às condições ameaçadoras à vida materna e ações de auxilio imediato a serem iniciados pela atenção básica de saúde, sendo assim, busca-se diminuir a incidência de morbimortalidade materna no nosso território.

Desse modo, através de uma metodologia ativa permitiu à construção coletiva da qualificação e aplicabilidade na prática assistencial dos profissionais médicos e enfermeiros do Distrito Sanitário VII a assistência ao pré-natal e puerpério.

\section{REFERÊNCIAS}

ANDRADE, R. D. et al. Fatores relacionados à saúde da mulher no puerpério e repercussões na saúde da criança. Esc. Anna Nery. Rio de Janeiro, v. 19, n. 1, p. 181-186, 2015.

BRASIL. Ministério da Saúde. Caderneta da Gestante. Brasília: Ministério da Saúde, 2018. Disponível em: <http://portalarquivos2.saude.gov.br/images/pdf/2018/agosto/31/Cadernetada-Gestante-2018.pdf.> Acesso em: 03 de julho de 2019.

BRASIL. Ministério da Saúde. Saúde de A a Z. Brasília: Ministério da Saúde, 2019. Disponível em: <http://www.saude.gov.br/saude-de-a-z/gravidez.>. Acesso em: 15 de julho de 2019.

BRASIL. Ministério da Saúde. Protocolo da Atenção Básica: Saúde das Mulheres. Instituto Sírio-Libanês de Ensino e Pesquisa - Brasília: Ministério da Saúde, 2016. Disponível em:< http://bvsms.saude.gov.br/bvs/publicacoes/protocolos_atencao_basica_saude_mulheres.pdf.>. Acesso em: 21 de julho de 2019.

CARVALHO, M.L. et al. Prevenção da mortalidade materna no pré-natal: uma revisão integrativa. R. Interdisciplinar. 8(2):178-184, 2015.

CHHABRA, N. et al. Team-based learning strategy in biochemistry: Perceptions and attitudes of faculty and 1st-Year medical students. Int J App Basic Med Res. 7:S72-7, 2017.

CORREA, M. S. M. et al. Acolhimento no cuidado à saúde da mulher no puerpério. Cad. Saúde Pública. Rio de Janeiro, v. 33, n. 3, 2017.

COUTINHO, E.C. et al. Gravidez e parto: O que muda no estilo de vida das mulheres que se tornam mães?. Rev. esc. enferm-USP. São Paulo, v.48, n.spe2, p.17-24, 2014.

GARCIA, M.B.O.; OLIVEIRA, M.M.; PLANTIER, A. P. Interatividade e Mediação na Prática de Metodologia Ativa: o Uso da Instrução por Colegas e da Tecnologia na Educação Médica. Rev. bras. educ. med. Brasília, v. 43, n. 1, p. 87-96, 2019. 
GOMES, G. F,; SANTOS, A.P.V. Assistência de enfermagem no puerpério. Revista Enfermagem Contemporânea. Bahia, 6 (2):211-220, 2017.

LIVRAMENTO, D.V.P. et al. Percepções de gestantes acerca do cuidado pré-natal na atenção primária à saúde. Rev. Gaúcha Enferm. Porto Alegre, v. 40, e 20180211, 2019.

MARTINS, Q.P.M. et al. Conhecimentos de gestantes no pré-natal: evidencias para o cuidado de enfermagem. S A N A R E, Sobral, V.14, n.02, p.65-71, 2015.

NASCIMENTO, E.N. et al. Aprendizagem Baseada em Equipes na Fonoaudiologia: experiência na formação em Saúde Coletiva. Rev. CEFAC. São Paulo, v. 21, n. 2, e 15918, 2019.

SÁEZ, Z.A. et al. Estudio comparativo de la recuperación postparto en base a los Patrones de Marjory Gordon. Enfermería Global, v. 18, n. 1, p. 183-214, 2018.

VARGAS, I.; GONZALEZ, X.; NAVARRETE, T. Metodología activa en el Estudio de Caso para desarrollo del pensamiento crítico y sentido ético. Enferm. Univ. México, v. 15, n. 3, p. 244-254, 2018. 


\title{
AÇÃO COMPORTAMENTAL RELACIONADA À ANSIEDADE E ASPECTOS ELETROFISIOLÓGICOS CEREBRAIS DA CAFEÍNA: ANÁLISE EM RATOS ALBINOS EM DESENVOLVIMENTO
}

\section{ACCIÓN DE COMPORTAMIENTO RELACIONADA CON LA ANSIEDAD Y LOS ASPECTOS ELECTROFISIOLÓGICOS CEREBRALES DE LA CAFEÍNA: ANÁLISIS EN EL DESARROLLO DE LAS RATAS ALBINAS}

\section{BEHAVIORAL ACTION RELATED TO ANXIETY AND BRAIN ELECTROPHYSIOLOGICAL ASPECTS OF CAFFEINE: ANALYSIS IN DEVELOPING ALBINE RATS}

\begin{abstract}
Maria Luísa Figueira de Oliveira ${ }^{1}$; Camila Lima Chagas ${ }^{2}$; Regina de Deus Lira Benevides ${ }^{3}$; Fernanda das Chagas Angelo Mendes Tenório ${ }^{4}$
\end{abstract}

DOI: https://doi.org/10.31692/978-65-991061-9-4.62-67

\section{INTRODUÇÃO}

A cafeína é uma das substâncias mais consumidas no mundo e está relacionada a várias funções fisiológicas, como, resistência física, alteração de humor e sono, atuando como um potente estimulador do Sistema Nervoso Central (SNC) (FREDHOLM et al., 1999). Em relação à sua ação sobre o SNC, a substância parece passar livremente do sangue para o cérebro, exercendo um efeito protetor dose-dependente, principalmente em doenças como Parkinson (CHEN, 2010). Com isso, prejuízos causados por essa substância durante o período de desenvolvimento podem acarretar déficits em longo prazo na função cerebral.

A cafeína é um psicoestimulante que parece agir através dos receptores da adenosina dos tipos A1 e A2 e dos receptores de dopamina do tipo D2. Seu consumo tem sido associado à melhora da cognição e desempenho de atletas, além do aumento do gasto energético e diminuição da ingestão energética. No entanto, quando consumida em doses altas (acima de $40 \mathrm{mg} / \mathrm{Kg}$ ) pode provocar insônia, irritabilidade e até mesmo ansiedade (FREDHOLM et al., 1999). Em ratos, observa-se que certas alterações comportamentais causadas pelo consumo de cafeína dependem da quantidade consumida (CHEN, 2010).

As propriedades da cafeína ocorrem devido à sua capacidade de interagir com neurotransmissores em diferentes regiões do encéfalo podendo, dessa forma, influenciar propriedades eletrofisiológicas no cérebro (POLESZAK et al., 2015). Evidencias apontam que a exposição à cafeína durante o desenvolvimento cerebral leva a um comprometimento da memória seletiva, que parece ser maior em ratas do que em ratos (CARROLL et al., 2004).

\footnotetext{
${ }^{1}$ Biomedicina, Universidade Federal de Pernambuco, malufigueira_2@outlook.com

${ }^{2}$ Curso, Instituição E-mail

${ }^{3}$ Curso, Instituição, E-mail

4 Titulação, Instituição, e-mail
} 
Dessa forma, objetiva-se investigar, em ratos albinos, a ação de diferentes doses de cafeína, aplicadas durante o desenvolvimento do sistema nervoso, no que se refere aos seus efeitos sobre o comportamento de ansiedade e peso corporal.

\section{FUNDAMENTAÇÃO TEÓRICA}

Estudos clínicos têm apontado para uma maior susceptibilidade de mulheres aos efeitos de outros psicoestimulantes (TEMPLE e ZIEGLER, 2011; ARDAIS et al., 2016). Além disso, alguns estudos demonstraram que o consumo agudo e crônico da cafeína em ratos adultos leva a alterações comportamentais sugestivas de ansiogênese.

$\mathrm{Na}$ literatura, foi analisado o efeito da administração da cafeína aguda no eixo hipotálamo-pituitária-adrenal (HPA). Embora não se tenha comprovação de um papel causal do HPA na ansiedade (ARMARIO et al, 2012), admite-se que ele pode contribuir de forma importante para a patogênese da depressão e ansiedade. (JEZOVA e HLAVACOVA, 2008;). Tanto em seres humanos, quanto em ratos, a cafeína aumenta expressivamente o hormônio adrenocorticotrófico (ACTH) (PATZ et al., 2006; O’NEILL, 2016).

Os efeitos da cafeína são comumente investigados em diversos sistemas fisiológicos, porém, no cérebro ainda não estão claramente definidos. (BLAHA et al., 2007). Diante disto, no presente estudo, ratos machos da linhagem Wistar foram submetidos, durante o período de desenvolvimento, a diferentes doses de cafeína através de gavagem e os efeitos desse tratamento sobre funções neurais foram então observados através de testes comportamentais e da Depressão Alastrante Cortical (DAC), uma resposta propagável, de despolarização celular com redução (depressão) da atividade elétrica do tecido cerebral cortical. (LEÃO, 1944). Essa resposta é consequência da estimulação de um ponto do tecido, sendo totalmente reversível. A estimulação, por sua vez, pode ser mecânica, química ou elétrica (LEÃO, 1944; GUEDES, 2005).

\section{METODOLOGIA}

O estudo foi realizado com ratos albinos Wistar machos. A cafeína foi administrada por gavagem, do $7^{\circ}$ ao $27^{\circ}$ dia de vida pós-natal, ( $n=15$ por grupo). Os grupos receberam solução contendo respectivamente 15, 30 ou $45 \mathrm{mg}$ de cafeína/Kg de peso corporal/dia (grupos Caf15, Caf30 e Caf45, respectivamente). Além desses, um grupo recebeu água destilada, isto é, o veículo usado para diluir a cafeína (grupo-V) e outro grupo não recebeu qualquer gavagem (grupo ingênuo-I). Os pesos corporais foram aferidos aos 7, 14, 21, 28 dias de vida. O teste de avaliação comportamental no labirinto em cruz elevado foi realizado aos 28 dias de vida e o 
teste do campo aberto aos 30 dias de vida. O trabalho foi aprovado pela Comissão de Ética (protocolo $\mathrm{n}^{\circ}$ 23076.034601/2015-22). Para as análises estatísticas utilizou-se a ANOVA, seguida, quando necessário, pelo teste de Holm-Sidak. Foram consideradas significativas as diferenças em que $\mathrm{p}<0,05$.

\section{RESULTADOS E DISCUSSÕES}

Aos 28 dias de vida os grupos Caf30 e Caf45 apresentaram pesos corporais menores (respectivamente $64,6 \pm 4,0 \mathrm{~g}$ e $58,9 \pm 3,8 \mathrm{~g}$ ) em comparação aos grupos ingênuo $(73,6 \pm 5,5 \mathrm{~g}$ ), veículo $(72 \pm 3,7 \mathrm{~g})$ e Caf15 $(70,5 \pm 4,5 \mathrm{~g})(\mathrm{p}<0,05)$ (Figura 1). Na análise do tempo por cada entrada, houve um aumento de forma dose-dependente nos animais tratados com cafeína no labirinto em cruz elevado e campo aberto, com valores significativamente maiores no grupo Caf45 em comparação ao grupo ingênuo. No teste do labirinto em cruz elevado o número do comportamento de levantar-se foi significativamente menor no grupo Caf45 em relação aos grupos controles, o número desse comportamento nos grupos ingênuo, veículo, CAF15, CAF30 e CAF45 foram respectivamente, $10,6 \pm 1,4,10,8 \pm 1,2,9,5 \pm 1,3,8,8 \pm 0,9,6,9 \pm 1,4$ ( $\mathrm{p}<0,05)$. No campo aberto o número de comportamento de levantar-se foi significativamente menor no grupo Caf45 em relação aos grupos controles e Caf15 (Figura 2). O número do comportamento de levantar-se dos grupos ingênuo, veículo, Caf15, Caf30 e Caf45 foram respectivamente, $9,5 \pm 1,4,9,8 \pm 1,4,7,5 \pm 1,2,6,6 \pm 1,4,4,8 \pm 0,9(\mathrm{p}<0,05)($ Gráfico 2).

Figura 1: Peso Corporal

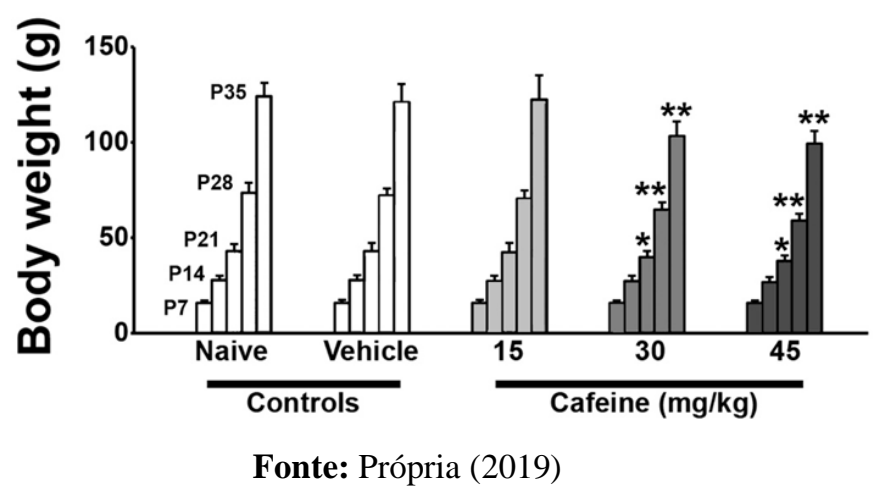

Figura 2: Labirinto em cruz elevada e campo aberto

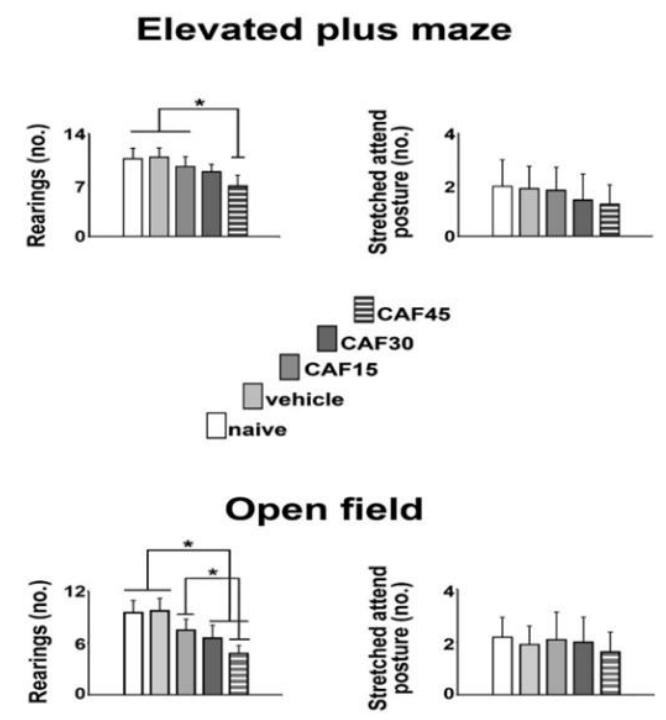

Fonte: Própria (2019) 
O tratamento sistêmico com cafeína reduziu o ganho de peso corporal dos animais, de forma proporcional às doses empregadas e aumentou a velocidade de propagação da DAC, enquanto que o tratamento tópico com cafeína, também alterou os parâmetros da DAC (aumentou velocidade de propagação e amplitude, e reduziu sua duração), refletindo um resultado novo para a ação eletrofisiológica da cafeína (Figuras 3 e 4).

Figura 3: Registro da DAC

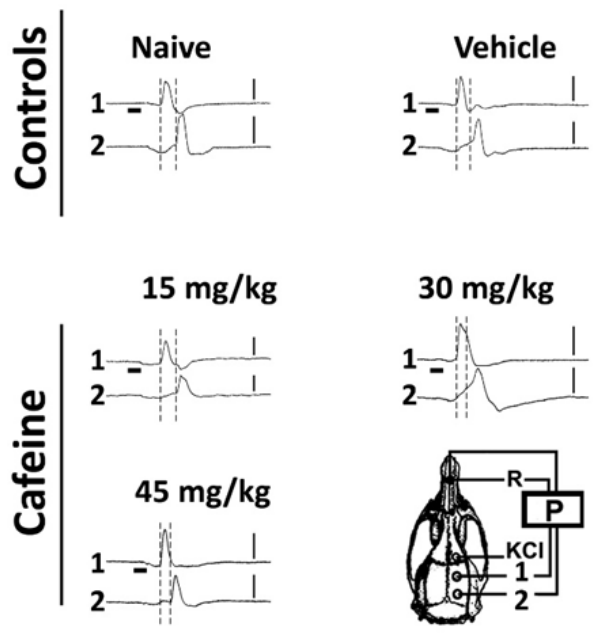

Fonte: Própria(2019)
Figura 4: Velocidade da DAC
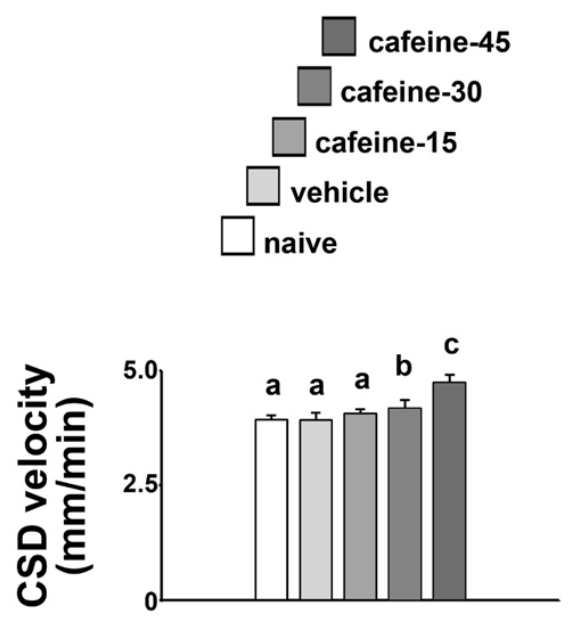

Fonte: Própria (2019)

Este estudo representa um achado pioneiro no que diz respeito à ação eletrofisiológica da cafeína, porém mais estudos são necessários para entender melhor a relação entre cafeína e excitabilidade cerebral. Nossos dados permitem que sugiramos cautela no consumo prolongado de cafeína por parte de gestantes, lactantes e crianças nos primeiros anos de vida, pois tal consumo pode levar a efeitos não desejáveis.

\section{CONCLUSÕES}

Esse estudo sugere que o tratamento com cafeína, em sua maior dose, durante o período de desenvolvimento cerebral causa redução do ganho do peso corporal e reduz o efeito de ansiedade. No entanto, extrapolar para seres humanos os dados encontrados nesse estudo é algo que requer cuidado, assim como a dose de cafeína consumida, visto que, em excesso, essa substância pode ter efeitos não desejáveis. As complexas interações entre cafeína, peso corporal e ansiedade necessitam de mais investigações.

Visando dar continuidade nesse trabalho, sugere-se como perspectivas:

- Investigar os efeitos do tratamento crônico com cafeína durante o período crítico de 
desenvolvimento sobre a memória (por meio de testes comportamentais específicos, como o labirinto aquático de Morris);

- Comparar os efeitos do tratamento com cafeína em diferentes períodos de desenvolvimento e gêneros;

- Analisar parâmetros bioquímicos dos animais tratados com cafeína em longo prazo;

- Comparar a ação do tratamento agudo e crônico da cafeína sobre efeitos eletrofisiológicos;

- Em modelos animais de consumo crônico de cafeína, estudar o impacto da sua abstinência sobre a depressão alastrante cortical;

- Investigar os efeitos da cafeína em condições muito favoráveis, ou desfavoráveis de lactação, representadas respectivamente pelo aleitamento em ninhadas com número reduzido, ou excessivo de filhotes.

\section{REFERÊNCIAS}

ARDAIS, A.P. et al. Caffeine triggers behavioral and neurochemical alterations in adolescent rats. Neuroscience, v. 270, p. 27-39, 2014.

ARMARIO, A. et al. What can we know from pituitary-adrenal hormones about the nature and consequences of exposure to emotional stressors?. Cellular Molecular Neurobiology, v. 32, p. 749-758, 2012.

BLAHA, M. et al. The effect of caffeine on dilated cerebral circulation and on diagnostic $\mathrm{CO} 2$ reactivity testing. Journal of Clinical Neuroscience, v. 14, p. 464-467, 2007.

CARROLL, M.E. et al. Sex and estrogen influence drug abuse. Trends Pharmacological Science, v. 25, p. 273-279, 2004.

CHEN, J. F. et al. What knock-out animals tell us about the effects of caffeine. Journal of Alzheimer's Dis-eases, v. 20, p. S17-S24, 2010.

FREDHOLM, B.B. et al. Actions of Caffeine in the Brain with Special Reference to Factors that Contribute to Its Widespread Use. Pharmacological Reviews, v. 51, p. 83-133, 1999.

GUEDES, R.C.A Electrophysiological Methods: Aplication in Nutritional neuroscience. In: Liebermann, H.; Kanarek, R.; Prasad, C. (eds), Nutritional Neurosciences: Overview of emerging field, p. 39-54, 2005.

JEZOVA, D.; HLAVACOVA, N. Endocrine factors in stress and psychiatric disorders: focus on anxiety and salivary steroids. Academic Science, v. 1148, p. 495-503, 2008.

LEÃO, A.A.P. Spreading depression of activity in the cerebral cortex. Journal of Neurophysiology, v. 7, p.359-390, 1944a. 
PATZ, M.D. et al. Modulation of the hypothalamo-pituitary-adrenocortical axis by caffeine. Psychoneuroendocrinology, v. 31, p. 493-500, 2006.

POLESZAK et al., 2015. The influence of caffeine on the activity of moclobemide, venlafaxine, bupropion and milnacipran in the forced swim test in mice. Life Science, v. 136, p. 13-18, 2015.

TEMPLE, J.L.; ZIEGLER, A.M. Gender differences in subjective and physiological responses to caffeine and the role of steroid hormones, Journal Caffeine Research, v. 1, p. 41-48, 2011. 


\title{
POTENCIAL ANTIMICROBIANO DE ÓLEOS ESSENCIAIS ENCAPSULADOS EM LIPOSSOMAS
}

\section{POTENCIAL ANTIMICROBIANO DE ACEITES ESENCIALES ENCAPSULADOS EN LIPOSOMAS}

\section{ANTIMICROBIAL POTENTIAL OF ESSENTIAL OILS ENCAPSULATED INTO LIPOSOMES}

\begin{abstract}
Jaqueline Barbosa de Souza'; Maria Anndressa Alves Agreles²; Davi de Lacerda Coriolano ${ }^{3}$; Sandrelli Meridiana de Fátima Ramos do Santos Medeiros ${ }^{4}$; Isabella Macário Ferro Cavalcanti ${ }^{5}$
\end{abstract}

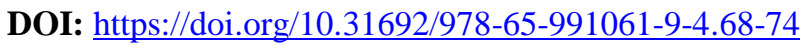

\section{INTRODUÇÃO}

Com o fenômeno da resistência bacteriana associada à pouca descoberta e desenvolvimento de fármacos com atividade antibacteriana frente a cepas resistentes devido a uso excessivo ou insuficiente de antibióticos, a busca por novos tratamentos com maior índice terapêutico têm encontrado espaço nos estudos relacionados a utilização de óleos essenciais como possíveis moléculas bioativas com potencial terapêutica (Miranda et al., 2016). Algumas plantas têm a capacidade de inibir crescimento microbiano mediante a produção de compostos oleosos. Essa capacidade relaciona-se com a composição química dessas substâncias oleosas, que são constituídas principalmente de terpenóides, aldeídos, álcoois, ésteres, fenóis, éteres, cetonas e derivados do oxigênio (Ibrahim et al., 2017).

Óleos essenciais (OE) são produtos odoríferos e constituem-se como elementos voláteis, oriundos do metabolismo secundário das plantas. Têm sido amplamente utilizados na medicina popular para fins antimicrobianos, onde esta capacidade é atribuída, principalmente, aos terpenos e seus derivados (carvacrol, timol, eugenol, terpineno, linalol e carvona). Essas moléculas são capazes de atuarem na funcionalidade da célula bacteriana, principalmente na inibição da síntese de ácidos nucléicos e no metabolismo energético, podendo ser bactericidas ou bacteriostáticos e possuindo espectro de ação tanto frente a bactérias gram positivas, quanto gram negativas (Coimbra et al., 2011; Haiying et al., 2016).

Reações oxidativas, frequentemente presentes em OE, podem formar compostos alergenos e ocasionar redução da atividade biológica. Além disso, os OE podem apresentar baixa solubilidade em meio aquoso, limitando ainda mais suas aplicações farmacêuticas.

\footnotetext{
${ }^{1}$ Bacharelado em Farmácia, Centro Universitário UniSãoMiguel, jaquelinebarbosadesouza@ outlook.com

${ }^{2}$ Bacharelado em Biomedicina, Universidade Federal de Pernambuco, anndressa.agreles@ufpe.br

${ }^{3}$ Bacharelado em Biomedicina, Universidade Federal de Pernambuco, davilacerdas2@ hotmail.com

${ }^{4}$ Doutoranda em Biologia aplicada à saúde, Universidade Federal de Pernambuco, sandrellimeridiana@gmail.com

${ }^{5}$ Professora, Doutora, Universidade Federal de Pernambuco, bel_macario@yahoo.com.br
} 
Visando ultrapassar as limitações de biodisponibilidade, volatilidade e instabilidade química dos $\mathrm{OE}$, foram desenvolvidas estratégias de encapsulação em sistemas de liberação controlada (SLCs). Existem diversos tipos de SLCs, dentre eles, lipossomas, nanopartículas, micelas e micropartículas. Os lipossomas são vesículas esféricas, capazes de encapsular substâncias hidrofílicas e hidrofóbicas, e dessa forma também podem veicular ativos oriundos de fontes naturais, alterando, assim, as propriedades físico-químicas destes, possibilitando um aumento da atividade biológica (Risaliti et al., 2019). Assim, este estudo teve como objetivo realizar uma revisão da literatura sobre como a utilização de OEs encapsulados em lipossomas pode otimizar a atividade antimicrobiana destes compostos.

\section{FUNDAMENTAÇÃO TEÓRICA}

\section{Óleos essenciais (OEs)}

OEs são compostos naturais, voláteis e complexos, produzidos como metabólitos secundários a fim de proteger as plantas de ataques de predadores, parasitas e estresses ambientais (Rai et al., 2017). Sua síntese pode ocorrer em estruturas como botões, flores, folhas, caules, frutas, raízes, e são armazenados, principalmente em células secretoras, células epidérmicas ou tricomas glandulares. Os Oes podem ser constituídos, basicamente, por terpenos, incluindo os mono-, sesqui- e diterpenos (Sherry et al., 2013).

Por possuírem amplo espectro de ações, são relatadas na literatura atividades antifúngica, antioxidante, antiparasitária, e bactericida, que justificam sua aplicação na indústria farmacêutica (Esmaeili et al., 2012; Cui et al., 2015). Entretanto, os OEs apresentam instabilidade nos grupos funcionais, onde o oxigênio age como agente oxidante de álcoois e aldeídos, a luz altera os hidrocarbonetos não saturados e a água causa hidrólise do grupamento éster, levando à perda de sua propriedade terapêutica. Além disso, os OEs apresentam pouca solubilidade em componentes aquosos, portanto, encapsular esses ativos é uma das estratégias necessárias para aumentar a solubilidade, biodisponibilidade, assim como para a proteção e promoção da sua liberação controlada, melhorando, portanto, sua eficácia (Coimbra et al., 2011).

\section{Nanotecnologia e Lipossomas}

A nanotecnologia pode ser definida como o desenvolvimento e caracterização de dispositivos, materiais e sistemas que podem ser manipulados na escala nanométrica. Dentro da nanotecnologia uma área que se destaca é o desenvolvimento de sistemas de liberação controlada de fármacos (SLCs). Os SLCs são nanocarreadores que podem encapsular moléculas 
que apresentam elevada toxicidade e baixa biodisponibilidade e estabilidade físico-química. Dentre os SLC mais utilizados estão os lipossomas.Os lipossomas são nanocarreadores que apresentam uma ou mais bicamadas compostas de fosfolipídios e colesterol em volta de um núcleo aquoso. Essas vesículas podem carrear biomoléculas hidrofílicas e hidrofóbicas, como DNA, RNA, proteínas, vitaminas, fármacos, entre outros, assim proporcionando o aumento do tempo de meia vida e tempo de circulação sistêmica que, por sua vez, possibilita uma redução do número de doses administradas e maior adesão a terapia (Cavalcanti et al., 2015; Bizerra, Silva, 2016).

Ademais, os lipossomas apresentam maior capacidade em otimizar a atividade dos antimicrobianos frente a bactérias resistentes. Eles apresentam uma natureza protetora, pois o fármaco e moléculas encapsuladas ficam protegidas do meio biológico e da ação de moléculas do sistema imunológico do hospedeiro, como interleucinas e proteases do sistema de complemento. Além de melhorar potencialmente a farmacocinética e a farmacodinâmica dos fármacos encapsulados, devido a sua biocompatibilidade e alta biodegradabilidade. Logo, os lipossomas se apresentam como uma alternativa eficaz para encapsulação de fármacos que apresentam baixa biodisponibilidade por liberar o fármaco lentamente e continuamente e/ou certo grau de toxicidade, como é o caso de algumas moléculas de origem vegetal (Liu et al., 2015; Chen et al., 2016).

\section{METODOLOGIA}

Este estudo trata-se de uma revisão integrativa da literatura realizada através de buscas por publicações científicas indexadas nas seguintes bases de dados: PubMed (Publisher Medline), Lilacs (Literatura Latino-Americana e do Caribe em Ciências da Saúde) e SciELO (Scientific Eletronic Library Online). A coleta de dados incluiu artigos publicados entre os anos de 2010 a 2019. Os descritores utilizados foram lipossomas (liposomes), óleos essenciais (essential oils), atividade antimicrobiana (antimicrobial activity) e sistemas de liberação controlada de fármacos (drug delivery systems). Seguindo os critérios de inclusão e exclusão sendo estes, estudos experimentais, disponíveis na íntegra, publicados independente do idioma, nos periódicos indexados foram selecionados 10 artigos. Os artigos selecionados foram lidos, catalogados e analisados dentro da temática sugerida.

\section{RESULTADOS E DISCUSSÕES}

\section{Cravo-da-índia (Syzygium aromaticum)}

O cravo-da-índia, Syzygium aromaticum (SA), pertence à família das Myrtaceae, é 
composto principalmente, por fenilpropanóide, eugenol, $\beta$-cariofileno e o acetato de eugenilo. Essas moléculas são conhecidas por suas aplicações na indústria farmacêutica, pois apresentam, dentre outras atividades, potencial antibacteriano. Entretanto, apresenta limitações consideráveis no que se refere às suas propriedades físico-químicas, pois são quimicamente instáveis na presença de ar, luz, umidade e altas temperaturas (Cui et al., 2015). Dessa forma, muitas estratégias foram utilizadas a fim de melhorar à estabilidade e biodisponibilidade desse OE, entre os quais o uso de SLCs como os lipossomas, é considerado o mais relevante por auxiliar no tratamento de infecções bacterianas. Cui e colaboradores (2015) desenvolveram um estudo para avaliar a atividade antibacteriana do SA encapsulado em lipossomas (SALips), pelo método de contagem de colônias, frente a cepas de Staphylococcus aureus. Nesse estudo, foi demonstrado uma redução de colônias de aproximadamente 99,87\% após 24 horas de tratamento com os SALips.

\section{Alho (Allium sativum L.)}

O alho, Allium sativum L., membro da família Alliaceae, é originalmente da Ásia e amplamente conhecido na culinária de diversos países. Sua atividade antimicrobiana tem sido relatada em vários estudos e, partindo desse conhecimento, Zahibi e colaboradores (2016) propuseram-se a avaliar as características físicoquímicas de $\mathrm{OE}$ de alho encapsulado em lipossomas frente a E. coli O157:H7. A concentração inibitória mínima (CIM) e concentração bactericida mínima (CBM) foram de 0,02\% e 0,03\% para OEs encapsulados em lipossomas, e de $0,03 \%$ e $0,04 \%$ para OE livres. Assim, OE de A. sativum encapsulado em lipossomas demonstrou maior atividade antimicrobiana comparado a sua forma livre.

\section{Árvore do chá (Melaleuca alternifolia)}

Popularmente conhecida como árvore do chá, Melaleuca alternifolia, da família Myrtaceae, produz um óleo com poderosas atividades antibacterianas, antifúngicas, antivirais e antiprotozoárias (Yan e Mingqiao et al., 2016). Para analisar sua atividade antimicrobiana, Yane Mingqiao (2016) encapsularam o óleo da M. alternifolia em lipossomas e avaliaram sua atividade frente a Escherichia coli, Staphylococcus aureus e Candida albicans. Nesse estudo, as CIM do OE foram $0,15 \%-0,3 \%, 0,15 \%-0,3 \%$ e $0,02 \%-0,04 \%$, respectivamente. Os resultados das CBM também foram determinados obtendo valores de 0,15\%-0,3\%, 0,075\%$0,15 \%$ e $0,005 \%-0,01 \%$, respectivamente. Os resultados demonstraram que lipossomas contendo OE obtiveram uma melhora nos aspectos físico-químicos como a solubilidade e permeabilidade, além de que mesmo em baixas concentração de óleo de M. alternifolia 
conseguiu obter uma inibição completa do crescimento microbiano.

\section{Zataria (Zataria multiflora Boiss)}

Zataria, Zataria multiflora Boiss (ZM), é uma erva medicinal aromática distribuída geograficamente nas regiões da Ásia, incluindo Irã, Paquistão e Afeganistão. Representa uma das ervas da família das Lamiaceae com propriedades farmacológicas (Saei-Dehkordi et al., 2010). Levando em consideração as atividades descritas Saei-Dehkordi e Khosravi-Darani (2017) em seus estudos avaliaram a atividade antibacteriana da ZM encapsulada em lipossomas frente a Escherichia coli O157:H7. A enterohemorrágica E. coli sorotipo O157:H7 é o único tipo de E. coli produtora da toxina Shiga, sendo a principal responsável por diarreias. Dessa forma, foram testados e comparados os resultados da ZM livre (ZML) e encapsulada em lipossomas (ZMLips). Em ambos os casos, ZML e ZMLips, a concentração utilizada de ZM foi de $0,04 \%$. A CIM e a CBM para a ZML foi de $0,04 \%$ de $0,08 \%$, respectivamente. Em contrapartida, para a ZMLips, os resultados foram de $0,02 \%$ e $0,04 \%$ respectivamente, demonstrando ser duas vezes menor que a ZML. Dessa forma, o aumento da atividade antimicrobiana após a utilização de ZM encapsulado em lipossomas demonstra que os lipossomas podem ser uma alternativa farmacológica para o tratamento desse sorotipo de $E$. coli.

\section{Sálvia (Salvia triloba)}

Sálvia, Salvia triloba (ST), também é pertencente à família das Lamiaceae e é classificada como Substâncias Geralmente Reconhecidas como Seguras (SGRS) pela Food and Drug Administration (FDA, 2013). Estudos comprovam que seus OEs apresentam propriedades expressivas como antimicrobianos (Risaliti et al., 2019). A fim de explorar a eficácia dos OEs encapsulados em lipossomas frente a Klebsiella pneumoniae, Risaliti e colaboradores (2019) avaliaram em seu estudo a atividade antimicrobiana da ST. Nesse estudo foi percebido que quando submetido apenas a ST livre a inibição da bactéria correspondeu a 12,7 $\pm 0,6 \mathrm{~mm}$, por sua vez, a ST encapsulada em lipossomas apresentou aumento na inibição correspondente a 22,6 \pm 0,6 mm, Assim, a encapsulação de ST em lipossomas pode representar um vetor inovador e completamente biodegradável para a liberação prolongada do OE, preservando ou mesmo e melhorando as propriedades funcionais e biológicas de S. triloba.

\section{Alecrim (Rosmarinus officinalis L.)}

O Alecrim, Rosmarinus officinalis L. (RO), membro da família Lamiaceae, oriundo 
originalmente da região do mediterrâneo ocidental, é bastante utilizado na medicina e na culinária. O seu óleo é composto principalmente de eucaliptol e cânfora e apresenta várias propriedades, dentre elas, a atividade antimicrobiana (Risaliti et al., 2019). Risaliti e colaboradores (2019) encapsularam OE de alecrim em lipossomas e provaram que essa encapsulação apresenta melhor atividade antimicrobiana frente a cepas de Klebsiella pneumoniae, pois nesse estudo, RO livre apresentou halo de inibição de 12,7 \pm 0,6 mm e o RO encapsulado em lipossomas (ROLips) exibiu halo de inibição de 18,5 \pm 0,6 mm.

\section{CONCLUSÕES}

Evidenciou-se que houve um aumento na eficácia dos OEs após sua encapsulação em sistemas de liberação controlada, assim tendo seu potencial antimicrobiano ampliado. Desta forma, o desenvolvimento de pesquisas sobre a avaliação da atividade antibacteriana de OEs encapsulados em lipossomas representa uma grande importância, visto que esses sistemas podem contribuir, no futuro, para a possível diminuição dos casos de infecções.

\section{REFERÊNCIAS}

BIZERRA, A.; SILVA, V. Sistemas de Liberação Controlada: Mecanismos e aplicações. Revista Saúde e Meio Ambiente, v. 3, n. 2, p. 1-12, 2016.

CAVALCANTI, I. M. F. et al. Antimicrobial activity of $\beta$-lapachone encapsulated into liposomes against meticillin-resistant Staphylococcus aureus and Cryptococcus neoformans clinical strains. Journal of Global Antimicrobial Resistance, v. 3, n. 2, p. 103-108, 2015.

COIMBRA, M. et al. Improving solubility and chemical stability of natural compounds for medicinal use by incorporation into liposomes. International journal of pharmaceutics, v. 416, n. 2, p. 433-442, 2011.

CHEN, H. et al. The potential use of novel chitosan-coated deformable liposomes in an ocular drug delivery system. Colloids and surfaces B: biointerfaces, v. 143, p. 455-462, 2016.

CUI, H.; ZHAO, C.; LIN, L. The specific antibacterial activity of liposome-encapsulated Clove oil and its application in tofu. Food Control, vol. 56, p. 128-134, 2015.

ESMAEILI, A. Biological activities of Eremostachys laevigata Bunge. grown in Iran. Pak J Pharm Sci, vol. 25, p. 803-808, 2012.

IBRAHIM, T. A. et al. Chemical composition and antimicrobial activities of essential oils of some coniferous plants cultivated in Egypt. Iranian journal of pharmaceutical research: IJPR, v. 16, n. 1, p. 328, 2017.

KATHIBI, Seyed Amin et al. Encapsulation of Zataria multiflora Bioss. essential oil into nanoliposomes and in vitro antibacterial activity against Escherichia coli O157: H7. Journal 
of Food Processing and Preservation, v. 41, n. 3, p. e12955, 2017.

LIU, J. et al. Liposomes for systematic delivery of vancomycin hydrochloride to decrease nephrotoxicity: Characterization and evaluation. Asian journal of pharmaceutical sciences, v. 10, n. 3, p. 212-222, 2015.

MIRANDA, C. A. S. F et al. Óleos essenciais de folhas de diversas espécies: propriedades antioxidantes e antibacterianas no crescimento espécies patogênicas. Revista Ciência Agronômica, v. 47, n. 1, p. 213-220, 2016.

RAI, M. et al. Synergistic antimicrobial potential of essential oils in combination with nanoparticles: emerging trends and future perspectives. International Journal of Pharmaceutics, v. 519, n. 1-2, p. 67-78, 2017.

RISALITI, L.; et al. Hadjipavlou-Litina, D.; Bilia, A. R. Liposomes loaded with Salvia triloba and Rosmarinus officinalis essential oils: In vitro assessment of antioxidant, antiinflammatory and antibacterial activities. Journal of Drug Delivery Science and Technology, v. 51, p. 493 498, 2019.

SAEI-DEHKORDI, S. S. et al. Chemical composition of essential oils in Zataria multiflora Boiss. from different parts of Iran and their radical scavenging and antimicrobial activity. Food and Chemical Toxicology, v. 48, n. 6, p. 1562-1567, 2010.

SHERRY, M. et al. Essential oils encapsulated in liposomes: a review. Journal of liposome research, v. 23, n. 4, p. 268-275, 2013.

YAN, G.; MINGQIAO, G. Distribution of Melaleuca alternifolia essential oil in liposomes with Tween 80 addition and enhancement of in vitro antimicrobial effect, Journal of Experimental Nanoscience, 11:5, 6345-358, 201 


\title{
RELAÇÃO DA QUALIDADE DO SONO E DESEMPENHO ACADÊMICO DE JOVENS UNIVERSITÁRIOS
}

\section{RELACIÓN DE CALIDAD DEL SUEÑO Y DESEMPEÑO ACADÉMICO DE LOS JÓVENES UNIVERSITARIOS}

\section{RELATIONSHIP BETWEN SLEEP QUALITY AND ACADEMIC PERFORMANCE OF COLLEGE STUDENTS}

\begin{abstract}
Jamilly Henrique Costa da Silva ${ }^{1}$; Jadna Emille da Silva Arruda²; Natália de Castro e Silva Martins ${ }^{3}$; Luciana Moraes Studart Pereira ${ }^{4}$
\end{abstract}

DOI: $\underline{\text { https://doi.org/10.31692/978-65-991061-9-4.75-80 }}$

\section{INTRODUÇÃO}

O estado fisiológico denominado sono é responsável pela restauração do organismo humano necessária à sobrevivência. Alterações no seu padrão podem acarretar sequelas na habilidade de adaptação, humor, comportamento, função psicológica e desempenho das atividades diurnas (SANTOS, 2013). Dentre outros acontecimentos fisiológicos, durante o período do sono, o organismo produz proteínas para fortalecer e aumentar redes neuronais ativas necessárias à consolidação da memória e aprendizado, favorecendo a liberação de hormônios que promovem bem-estar (VALLE et al., 2009).

A privação do sono pode acarretar consequências importantes para a saúde e estabelece relação com o aumento de fadiga, sonolência diurna, alteração do humor, memória e atenção (ABS, 2018). Noites de sono não recuperadas apresentam associação também com lentificação no raciocínio matemático, diminuição da concentração e pensamento, comprometimento e transtornos cognitivos, dificuldades nos relacionamentos familiares, restrição da participação em atividades sociais e sinais de irritabilidade, ou até mesmo euforia à estímulos considerados neutros (VALLE, 2011).

Diante disso, o interesse em relação ao padrão de sono de estudantes universitários tem aumentado, pois a privação do sono e os distúrbios do sono são queixas comuns neste período (BARDINI, 2017). Por isso, se faz cada vez mais necessária a análise da qualidade de sono dessa faixa etária, uma vez que acadêmicos estão sujeitos à alterações do seu padrão de sono, em razão das exigências sociais da idade, hábitos noturnos e a necessidade de manter a vigília

\footnotetext{
${ }^{1}$ Graduanda em Fonoaudiologia pela Universidade de Pernambuco, jamillycostafono@ hotmail.com

${ }^{2}$ Graduanda em Fonoaudilogia pela Universidade de Pernambuco, jadnaemylle@ hotmail.com

${ }^{3}$ Fonoaudióloga Graduanda pela Universidade Federal de Pernambuco, natcsmartins@ hotmail.com

${ }_{4}$ Docente do Curso de Fonoaudiologia da Universidade Federal de Pernambuco, luciana.studart@uol.com.br
} 
durante o dia, e, no caso dos universitários, das modificações que o ingresso no curso de graduação confere ao seu estilo de vida (ALMEIDA, 2011). Adolescentes e universitários que não possuem boa qualidade de sono estão propensos a desencadearem déficits na aprendizagem, comprometimento na capacidade de resolução de problemas, distúrbios de saúde física e mental, alterações nos desempenhos das funções cognitivas e psicossociais (VASCONCELOS et al, 2013).

Ante o exposto, o objetivo desta investigação é relacionar a qualidade do sono de jovens universitários aos seus respectivos desempenhos acadêmicos. Acredita-se que conhecer o panorama da qualidade do sono de adolescentes e jovens universitários, e a relação com o desempenho escolar poderá contribuir de maneira contundente para os estudos da saúde do sono, bem como para o direcionamento de medidas preventivas aos distúrbios do sono em adolescentes e universitários.

\section{FUNDAMENTAÇÃO TEÓRICA}

O sono é definido como um processo neuroquímico que envolve centros cerebrais específicos para promover o adormecer e o acordar. É uma função biológica de extrema importância para o funcionamento normal do sistema nervoso (MAGALHÃES et al., 2007).

Os seres humanos são orientados por ciclos diários com distinção entre o dia e a noite e apresentam preferências, geneticamente determinadas, no que diz respeito aos horários de dormir e acordar. Pessoas consideradas matutinas preferem dormir cedo e acordam cedo, já as vespertinas têm preferência por dormir mais tarde e de despertar mais tarde e as intermediárias ocupam uma posição mediana. Assim como a preferência individual de horários para acordar e adormecer, existem variações particulares com relação à facilidade de execução das funções cognitivas, que também variam com o cronotipo de cada indivíduo.

Essas preferências podem estar associadas ao funcionamento individual do organismo ou a questões relacionadas à rotina e comportamento de cada indivíduo. (FINIMUNDI, 2012). Por exemplo, o período da juventude é marcado por um distúrbio fisiológico denominado atraso de fase, que caracteriza-se, além da necessidade de maior número de horas, pela preferência em ir dormir mais tarde e acordar também mais tarde. Jovens apresentam maior propensão em manter hábitos inadequados, com rotinas noturnas, sedentarismo, uso excessivo de dispositivos eletrônicos, estimulantes de vigília, entre outros fatores, que podem colaborar para que eles deitem mais tarde e durmam menos e fiquem mais sonolentos durante o dia (BARDINI, 2017). Diante de tais preferências, pode acontecer a privação do sono que acarreta consequências importantes para a saúde e estabelece relação com fadiga, sonolência diurna, alteração do 
humor, memória e atenção (ABS, 2018).

Dessa forma, a qualidade do sono pode ser prejudicada de forma transitória ou crônica. Em casos em que a irregularidade do sono se torne duradoura, investigações de distúrbios do sono, como por exemplo, a insônia e apneia do sono, fazem-se necessárias (VALLE, 2009). Além disso, a irregularidade no padrão de sono de adolescentes e universitários pode repercutir negativamente na saúde desses jovens e trazer transtornos para o desempenho acadêmico (SCHNEIDER et al, 2010).

Sabe-se que a juventude é um período de desenvolvimento muito importante para a determinação da carreira acadêmica e profissional dos indivíduos, além da expectativa existente de garantir uma boa qualidade de vida no futuro (STEA, 2014). Para que problemas relacionados à saúde e desempenho acadêmico de jovens universitários sejam minimizados, é de extrema importância que as funções executivas estejam funcionando corretamente. Diante disso, se faz alarmante a necessidade de fatores que contribuam para que esses resultados almejados como a boa qualidade de sono (OWENS, 2014).

\section{METODOLOGIA}

\section{Tipo de estudo}

Tratou-se de um estudo analítico, observacional e de corte transversal.

\section{População do Estudo}

A amostra foi composta por conveniência. Participaram do estudo 150 indivíduos jovens, de ambos os sexos, de cursos da área da saúde de uma universidade pública, com idade média de 22,83, desvio padrão de 3,77 anos e mediana igual a 22,00 anos.

\section{Coleta dos dados}

Os indivíduos foram convidados a participar da pesquisa, e, em seguida, houve a explicação sobre o conteúdo e os objetivos do trabalho e proposta a assinatura do Termo de Consentimento Livre e Esclarecido. Primeiramente, os participantes responderam ao instrumento de coleta contendo informações sobre dados pessoais, informações acadêmicas, hábitos de vida e saúde. Na sequência, preencheram questionário de Pittsburgh, que avalia a qualidade do sono em boa, ruim ou com presença de distúrbio do sono (BUYSSE, et.al, 1989).

\section{RESULTADOS E DISCUSSÕES}

Dos resultados relativos à relação entre a qualidade do sono e o desempenho acadêmico 
da população estudada, pode-se verificar na Tabela 1 que a qualidade do sono mostrou associação significativa com as variáveis "cansaço durante as aulas" e "cochilos durante as aulas" e para as referidas variáveis se destacam as maiores diferenças percentuais. $\mathrm{Na}$ primeira variável citada o maior percentual dos que responderam "às vezes" foi mais elevado entre os que tinham boa qualidade do sono e menos elevado entre os que tinham distúrbio do sono $(60,0 \%$ x 21,9\%), enquanto que o percentual na categoria "muitas vezes / sempre" foi mais elevado nos que tinham o citado distúrbio $(78,1 \%$ x 58,3\%); na variável cochilos durante as aulas o percentual dos que responderam "nunca / raramente", foi mais elevado entre os que tinham qualidade de sono boa quando comparados aos com distúrbio do sono (73,3\% x 25,0\%). Já o percentual que responderam "muitas vezes / sempre" foi mais elevado entre os que tinham distúrbio $(37,5 \%)$ e foi nulo entre os que tinham boa qualidade do sono.

Tabela 1 - Avaliação da qualidade do sono, segundo o resultado do desempenho acadêmico

\begin{tabular}{|c|c|c|c|c|c|c|c|}
\hline \multirow{3}{*}{ Variável } & \multicolumn{6}{|c|}{ Qualidade do sono } & \multirow{3}{*}{ Valor $\mathbf{p}$} \\
\hline & \multicolumn{2}{|c|}{ Boa } & \multicolumn{2}{|c|}{ Ruim } & \multicolumn{2}{|c|}{ Distúrbio } & \\
\hline & n & $\%$ & $\mathbf{n}$ & $\%$ & $\mathbf{n}$ & $\%$ & \\
\hline Desempenho acadêmico & & & & & & & $\mathrm{p}^{(1)}=0,926$ \\
\hline Péssimo / Ruim & - & - & 2 & 1,9 & - & - & \\
\hline Razoável & 4 & 26,7 & 26 & 25,2 & 10 & 31,3 & \\
\hline Bom / Ótimo & 11 & 73,3 & 75 & 72,8 & 22 & 68,8 & \\
\hline Tem reprovação & & & & & & & $\mathrm{p}^{(2)}=0,474$ \\
\hline Sim & 5 & 33,3 & 33 & 32,0 & 14 & 43,8 & \\
\hline Não & 10 & 66,7 & 70 & 68,0 & 18 & 56,2 & \\
\hline Realização de avaliação final & & & & & & & $\mathrm{p}^{(2)}=0,104$ \\
\hline $\operatorname{Sim}$ & 13 & 86,7 & 80 & 77,7 & 30 & 93,7 & \\
\hline Não & 2 & 13,3 & 23 & 22,3 & 2 & 6,3 & \\
\hline Faltas frequentes & & & & & & & $\mathrm{p}^{(2)}=0,423$ \\
\hline $\operatorname{Sim}$ & 1 & 6,7 & 19 & 18,4 & 4 & 12,5 & \\
\hline Não & 14 & 93,3 & 84 & 81,6 & 28 & 87,5 & \\
\hline Cansaço durante as aulas & & & & & & & $\mathrm{p}^{(1)}=0,008^{*}$ \\
\hline Nunca / Raramente & 2 & 13,3 & 4 & 3,9 & - & - & \\
\hline Às vezes & 9 & 60,0 & 39 & 37,9 & 7 & 21,9 & \\
\hline Muitas vezes/ Sempre & 4 & 26,7 & 60 & 58,3 & 25 & 78,1 & \\
\hline Cochilos durante as aulas & & & & & & & $\mathrm{p}^{(1)}=0,002^{*}$ \\
\hline Nunca / Raramente & 11 & 73,3 & 59 & 57,3 & 8 & 25,0 & \\
\hline Às vezes & 4 & 26,7 & 28 & 27,2 & 12 & 37,5 & \\
\hline Muitas vezes/ Sempre & - & - & 16 & 15,5 & 12 & 37,5 & \\
\hline
\end{tabular}

(*) Associação significativa a 5\%

(1) Através do teste Exato de Fisher

(2) Através do teste Qui-quadrado de Pearson.

Trata-se de uma realidade preocupante, visto que a privação do sono que se inicia na juventude tende a se estender à vida do sujeito pelas grandes demandas acadêmicas e 
profissionais. Graduandos estão muitas vezes submetidos a um forte estresse, múltiplas atividades extracurriculares, pressão pela exigência de bom desempenho acadêmico e cumprimento da alta carga horária dos cursos. Tais fatores propiciam distúrbios do sono como a insônia crônica, que, por sua vez, impacta no desempenho das atividades acadêmicas e saúde dessa população, aumentando o índice de má qualidade de sono (SILVA et al., 2016).

\section{CONCLUSÕES}

Conclui-se que em relação ao desempenho acadêmico, evidencia-se a associação significativa da realização de provas finais, cansaço e cochilos nas aulas com a má qualidade do sono e presença de distúrbio do sono. Corroborando com a literatura no que diz respeito ao estilo de vida de universitários que favorecem o desenvolvimento de alterações relacionadas ao sono que por sua vez, impactam negativamente no desempenho acadêmico.

\section{REFERÊNCIAS}

ALMEIDA, J.O.S., et al. Day time sleepiness and sleep quality in physical therapy students. Conscientia e saúde 10(4) 20109. 2011.

Associação Brasileira Do Sono (ABS). Semana do sono 2018 - Respeite seu sono e siga seu ritmo. Cartilha do Sono. Brazil. 2018.

BARDINI, R., et al. Prevalência de sonolência excessiva diurna e fatores associados em adolescentes universitários do sul catarinense. Arq. Catarin Med 46 (1): 107-124. Santa Catarina. 2017.

FINIMUNDI, M., et al. Validação da escala de ritmo circadiano - ciclo vigília/sono para adolescentes. Rev. paul. Pediatr 30(3): 409-414. São Paulo. 2012.

MAGALHÃES, F. et al., orgs. Medicina da noite: da cronobiologia à prática clínica. Editora FIOCRUZ. Rio de Janeiro. ISBN 978-85-7541-336-4. 2007.

OWENS, J. Insufficient sleep in adolescents and young adults: an update on causes and consequences. Pediatrics. n.32, v.134,p. 921, 2014.

SANTOS, A. A., et al. Sono, fragilidade e cognição: estudo multicêntrico com idosos brasileiros. Rev. bras. Enferm. 66(3): 351-357. Brasília. 2013.

SCHNEIDER, M. L. M., et al. Morningness-eveningness, use of stimulants, and minor psychiatric disorders among undergraduate students. Int J Psych ol 46(1): 18-23. 2010.

Silva, G. M., et al. Qualidade do sono em estudantes do regime regular e internato médico. Revista Médica da UFPR 3(1): 19-24. 2016. 
STEA, T. H.; TORSTVEIT, M. K. Association of lifestyle habits and academic achievement in Norwegian adolescents: a cross-sectional study. BMC Public Health. n.14 , 829, 2014.

Valle, L. E. L. R., Valle, E. L. \& Reimao, R. Sono e aprendizagem. Rev. psicopedag. 26(80): 286-290. São Paulo. 2009.

Valle, L. E. L. R. Estresse e distúrbios do sono no desempenho de professores: saúde mental no trabalho. Biblioteca Dante Moreira Leite. São Paulo. 2011.

VASCONCELOS, H. C. A., et al. Correlação entre indicadores antropométricos e a qualidade do sono de universitários brasileiros. Rev. esc. enferm. 47(4): 852-859. USP, São Paulo. 2013. 


\title{
ASSOCIAÇÃO ENTRE RESISTÊNCIA À INSULINA E SÍNDROME METABÓLICA X EM INDIVÍDUOS DO MUNICÍPIO DE CARUARU-PE
}

\author{
ASSLCIACIÓN ENTRE RESISTENCIA A LA INSULINA Y SÍNDROME \\ METABÓLICO X EM INDIVIDUOS DE LA CIUDAD DE CARUARU-PE
}

\section{ASSOCIATION BETWEEN INSULIN RESISTANCE AND METABOLIC SYNDROME X IN INDIVIDUALS FROM CARUARU-PE CITY}

\begin{abstract}
Jeaninne Alexandra de Azevedo Silva ${ }^{1}$; Layse Ciane Silveira Cirino de Britto Galvão²; Antônio Lopes Ferreira Neto $^{3}$; Iasmine Andreza Basilio dos Santos Alves ${ }^{4}$; Bianka Santana dos Santos ${ }^{5}$
\end{abstract}

DOI: https://doi.org/10.31692/978-65-991061-9-4.81-86

\section{INTRODUÇÃO}

Define-se resistência à insulina como a redução das ações biológicas da insulina. Esta condição anormal ocorre em razão da ação ineficaz da insulina nos tecidos periféricos, muscular, adiposo e hepático. Como mecanismo compensatório, há o aumento da secreção e síntese de insulina pelas células $\beta$-pancreáticas e consequente hiperinsulinemia, enquanto a tolerância à glicose permanece de acordo com os valores de referência. Esta se encontra associada a alterações metabólicas, excesso de tecido adiposo, dislipidemias e aumento da pressão arterial que, juntos, constituem a síndrome metabólica, a qual é definida como um transtorno representado por um conjunto de fatores de risco cardiovasculares (DE OLIVEIRA, 2017).

O sistema nervoso autônomo (simpático) pode ser estimulado pela elevação da quantidade de insulina intravascular e desencadear respostas para o aumento da pressão arterial, tais como: aumento da concentração plasmática da norepinefrina, aumento da reabsorção de sódio e água nos túbulos renais distais, vasoconstrição e aumento do volume sanguíneo e débito cardíaco (GONZÁLEZ, 2018). Outra consequência da resistência à insulina é o aumento da quebra por hidrólise dos triglicerídeos de reserva, que leva à elevação de ácidos graxos no sangue. Esses ácidos graxos chegam ao tecido hepático e são reaproveitados para a síntese de lipoproteínas de muito baixa densidade (VLDL), que são ricas em triglicerídeos. Com isso, a VLDL é modificada na quantidade e qualidade, induzindo a modificação das lipoproteínas de

\footnotetext{
${ }^{1}$ Curso de Medicina, Núcleo de Ciências da Vida - Campus Agreste - Universidade Federal de Pernambuco, jeaninne.alexandra@gmail.com

${ }^{2}$ Curso de Medicina, Núcleo de Ciências da Vida - Campus Agreste - Universidade Federal de Pernambuco layse.ciane@hotmail.com

${ }^{3}$ Curso de Medicina, Núcleo de Ciências da Vida - Campus Agreste - Universidade Federal de Pernambuco

${ }^{4}$ Curso de Medicina, Núcleo de Ciências da Vida - Campus Agreste - Universidade Federal de Pernambuco iasmine.bsa@gmail.com

${ }^{5}$ Doutora em Ciências Biológicas e Pós-Doutora em Bioquímica e Fisiologia, Docente do Curso de Medicina, Núcleo de Ciências da Vida - Campus Agreste - Universidade Federal de Pernambuco, biankasantana@gmail.com
} 
baixa densidade (LDL) e reduzindo a quantidade da lipoproteína de alta densidade (HDL) (SANTANA, et al., 2017).

Todas essas alterações acarretam nos sinais e sintomas que caracterizam a Síndrome Metabólica X (SMX). No entanto, a associação deste distúrbio com a resistência à insulina não é investigada como um distúrbio característico para o diagnóstico da SMX. Ademais, esta síndrome está diretamente relacionada à deposição de gordura (aterosclerose) e a uma elevada morbimortalidade por problemas cardiovasculares (SABOYA, 2016). Com exceção das complicações provenientes da gestação, parto e puerpério em Caruaru, as doenças cardiovasculares (DCV) ficaram em primeiro lugar dentre as causas de internações ocorridas nos últimos anos, e a incidência das doenças do aparelho cardiovascular são as principais causas de mortalidade, sendo a segunda causa de óbito, com prevalência em torno de $27 \%$ a $50 \%$. Esta região também apresenta alta mortalidade por diabetes mellitus tipo 2, intimamente associada com resistência à insulina; e também é sabido que estudos sobre resistência à insulina e a identificação de sua prevalência neste município ainda possui caráter de ineditismo (DE ALBUQUERQUE NETO, 2019). Nesse contexto, o presente estudo objetivou analisar a associação entre resistência à insulina e SMX em indivíduos do município de Caruaru-PE, através de um estudo transversal observacional analítico.

\section{FUNDAMENTAÇÃO TEÓRICA}

A síndrome metabólica X (SMX) é caracterizada pelo conjunto de fatores de risco para as doenças do sistema cardiovascular, dentre eles: hiperglicemia, hipertensão arterial sistêmica, hipertrigliceridemia, baixo HDL-colesterol e obesidade abdominal (SANTANA, 2017). Em 1998, a Organização Mundial da Saúde (OMS) incluiu a resistência à insulina como o principal fator de risco para o desenvolvimento da SMX, bem como Reaven, que foi quem definiu a SMX, pela primeira vez, já desde 1988, definiu a SMX como tendo dois dos distúrbios citados anteriormente, além de resistência à insulina como pré-requisito. Ou seja, se houvessem achados que evidenciassem marcadores de resistência à insulina e estes fossem associados a dois ou mais fatores de risco, tais como microalbuminúria, HDL baixo, obesidade abdominal e hipertensão arterial, já seria definido o diagnóstico da síndrome metabólica (VIEIRA, 2014).

Em meados dos anos 2000, o European Group for Study of Insulin Resistance propôs a modificação da definição da SMX. O grupo desejava substituir o termo por "síndrome de resistência insulínica”, baseando-se no marcador de resistência à insulina, expresso pela elevação da insulinemia. Todavia, todos os conceitos que vieram posteriormente, para a definição da SM, retiraram a resistência à insulina como critério diagnóstico, valorizando-se 
mais o aumento da circunferência abdominal (ALBERTI et al., 2009).

Porém, isto dificulta o estudo da identificação do risco de se ter SMX, pois a resistência à insulina pode ser o cerne do desenvolvimento desta síndrome e não apenas a obesidade abdominal, desde que tanto uma como a outra induzem a liberação de citocinas de fase aguda e o aumento de ácidos graxos no sangue, o que desencadeia a dislipidemia característica da SMX, que é hipertrigliceridemia e/ou HDL-colesterol diminuído, os quais levam à maior resistência à insulina, em um mecanismo de retroalimentação positiva, ocasionando hiperglicemia, a qual em associação com a hiperinsulinemia, que ocorre no estado de resistência à insulina, causam aumento da atividade simpática e consequente hipertensão arterial sistêmica (GARCIA LIRA NETO et al., 2018). Nessa perspectiva, o conjunto de fatores de risco para o desenvolvimento de agravos como diabetes e DCV pode acarretar no desenvolvimento da SMX. Ademais, no Brasil, estudos sobre a prevalência de SMX indicam taxas que variam de 30,9 a 53,4\% da população (VIEIRA et al., 2016; GARCIA LIRA NETO, 2018 ).

\section{METODOLOGIA}

Desenho do Estudo e Considerações Éticas. Foi feita uma análise transversal observacional analítica em 1500 indivíduos com idade $\geq 18$ anos, todos provenientes de Caruaru-Agreste-PE, após aprovação no Comitê de Ética em Pesquisa do Centro de Ciências da Saúde/UFPE (nº CAAE 35165214.6.0000.5208). Coleta, Determinações Bioquímicas e Resistência à Insulina. As amostras sanguíneas foram coletadas por punção venosa, após $12 \mathrm{~h}$ em jejum, e processadas para as determinações de Glicose, Colesterol Total, Triglicerídios e HDL-c, por métodos enzimáticos, e de Insulina, por Imunoensaio Enzimático com Micropartículas. Resistência à insulina foi identificada segundo Matthews (1985). Aferição da Circunferência Abdominal, da Pressão Arterial e Identificação dos Distúrbios Metabólicos da SMX. Foram avaliados conforme Alberti et al. (2009). Índices de Risco Cardiovascular Aterosclerótico (RCVA). Índices de Castelli I e II foram calculados, de acordo com Castelli; Abbott; McNaamara (1983). Análise Estatística. Testes de regressão logística, correlação e $t$ desemparelhado $(p<0,05)$ foram realizados.

\section{RESULTADOS E DISCUSSÕES}

Da amostra total de 1500 voluntários do município de Caruaru (PE), 450 voluntários (30\%) foram do sexo masculino e 1050 (70\%), do sexo feminino. Nos indivíduos que foram diagnosticados como resistentes à insulina, após ajustes para idade, parâmetros antropométricos e níveis pressóricos, a fim de não entrarem como variáveis de confusão, foram encontrados 
significativamente maiores concentrações de colesterol total, LDL-colesterol, VLDL-colesterol e de triglicerídios, quando comparados com indivíduos com sensibilidade normal à insulina. A prevalência de resistência à insulina, em ambos os sexos, foi de 31,5\%. Indivíduos com resistência a esse hormônio também mostraram menores níveis de HDL-colesterol, conforme demonstrado na Tabela 1.

Tabela 1. Índices de Castelli I e II e Níveis Séricos de Indivíduos com Resistência à Insulina em Comparação com Indivíduos com Sensibilidade Normal.

\begin{tabular}{cccc}
\hline $\begin{array}{c}\text { Lipídios } \\
(\mathbf{m m o l} / \mathbf{L})\end{array}$ & $\begin{array}{c}\text { Resistentes à Insulina } \\
(\mathbf{m e ́ d i a} \pm \text { erro da média) }\end{array}$ & $\begin{array}{c}\text { Sensíveis à Insulina } \\
(\text { média } \pm \text { erro da média) }\end{array}$ & $\boldsymbol{p}$ \\
\hline Colesterol Total & $5,03 \pm 0,03$ & $4,99 \pm 0,03$ & 0,0001 \\
HDL-colesterol & $1,02 \pm 0,01$ & $1,15 \pm 0,01$ & 0,0001 \\
LDL-colesterol & $3,47 \pm 0,02$ & $3,29 \pm 0,03$ & 0,001 \\
VLDL-colesterol & $0,75 \pm 0,02$ & $0,56 \pm 0,02$ & 0,0001 \\
Triglicerídios & $1,76 \pm 0,02$ & $1,25 \pm 0,03$ & 0,0001 \\
Castelli I & $5,35 \pm 0,04$ & $4,23 \pm 0,03$ & 0,0001 \\
Castelli II & $3,44 \pm 0,03$ & $3,08 \pm 0,02$ & 0,0001 \\
\hline
\end{tabular}

Fonte: Própria (2019)

Na Tabela 1 é possível também observar que os índices de RCVA, Castelli I e II, em indivíduos com resistência à insulina foram maiores em comparação com os insulino-sensíveis. A correlação encontrada entre os índices de Castelli foram significativas e positivas em indivíduos com resistência à insulin,a assim como os valores de todos os lipídios, com exceção dos níveis de HDL-colesterol, com os quais a correlação encontrada foi negativa, como mostrado na Tabela 2.

Tabela 2. Correlação entre níveis séricos de lipídios e índices de RCVA com Resistência à Insulina.

\begin{tabular}{lcc}
\hline Lipídios & $\mathbf{R}$ & $\mathbf{P}$ \\
\hline Colesterol Total & 0,110 & $<0,0001$ \\
HDL-colesterol & $-0,152$ & $<0,0001$ \\
LDL-colesterol & 0,084 & $<0,0001$ \\
VLDL-colesterol & 0,281 & $<0,0001$ \\
Triglicerídios & 0,257 & $<0,0001$ \\
Castelli I & 0,195 & $<0,0001$ \\
Castelli II & 0,141 & $<0,0001$ \\
\hline
\end{tabular}

Fonte: Própria (2019)

A resistência à insulina mostrou uma razão de chance igual a $5(\mathrm{p}<0,0001)$ para a presença de SMX. O estudo mostrou uma associação entre resistência à insulina e alterações lipídicas nos indivíduos de Caruaru, o que destacou um risco elevado para o desenvolvimento de DCV nesta população. A prevalência de resistência a este hormônio foi superior à reportada em estudos anteriores, como o de Garcia Lira Neto (2018). A resistência à insulina também 
esteve firmemente associada à hipertrigliceridemia, corroborando com Chapman e Spósito (2008) e Santana (2017), ligando-se de forma vigorosa com os valores de VLDL-colesterol.

Um maior risco cardiovascular foi encontrado nos indivíduos resistentes à insulina, obtido através das razões lipídicas, corroborando com Hedblad e colaboradores (2002) e González (2018). Este achado mostra que, mesmo em uma cidade situada no Nordeste do Brasil, há um alto risco para o desenvolvimento de DCV, de maneira similar ao encontrado em regiões com hábitos alimentares mais industrializados e desenvolvidos. Os valores de razão de chance encontrados para SMX em indivíduos com resistência à insulina evidenciam o quanto este distúrbio metabólico está envolvido com a fisiopatogenia de tal síndrome na população de Caruaru, corroborando com Reaven (2005), quando diagnosticou a SMX colocando a resistência à insulina em seu foco.

\section{CONCLUSÕES}

Este estudo sugere que a prevalência de resistência à insulina em Caruaru, cidade do Agreste pernambucano, é de fato elevada, pois cerca de um terço dos indivíduos do estudo mostraram-se resistentes a tal hormônio. Esta pode vir a se tornar uma população mais propensa a DCV, devido a alterações no perfil dos lipídios, condizentes com maiores índices de RCVA, sendo exposta a um risco até 5 vezes maior para desenvolver SMX.

\section{REFERÊNCIAS}

ALBERTI, et al. Harmonizing the Metabolic Syndrome A Joint Interim Statement of the International Diabetes Federation Task Force on Epidemiology and Prevention; National Heart, Lung, and Blood Institute; American Heart Association; World Heart Federation; International Atherosclerosis Society; and International Association for the Study of Obesity. Circulation, 120 (16): 1640-1645, 2009.

HEDBLAD, P. et al. Insulin resistance in non-diabetic subjects is associated with increased incidence of myocardial infarction and death. Diabetic Medicine, 19, 470-475, 2002.

CASTELLI W.P et al. Summary estimates of cholesterol used to predict coronary heart disease. Circulation. 1983; $67: 730-734$.

CHAPMAN, M. J. et al. Hypertension and dyslipidaemia in obesity and insulin resistance: Pathophysiology, impact on atherosclerotic disease and pharmacotherapy. Pharmacology \& Therapeutics, 117:354-373, 2008.

DE ALBUQUERQUE NETO, A. T. G. et al. Promoção da saúde através da conscientização da comunidade do bairro Maria Auxiliadora, Caruaru-PE: relato de experiência/Promotion of health through the awareness of the community of the district Maria Helper, Caruaru-PE: experience report. Brazilian Journal of Health Review, v. 2, n. 4, p. 2513-2524, 2019. 
DE OLIVEIRA, C. C. et al. Preditores de Síndrome Metabólica em Idosos: Uma Revisão. International Journal of Cardiovascular Sciences, v. 30, n. 4, p. 343-353, 2017.

GARCIA LIRA NETO, J. C. et al. Prevalência Da Síndrome Metabólica E De Seus Componentes Em Pessoas Com Diabetes Mellitus Tipo 2. Texto \& Contexto Enfermagem, v. 27, n. 3, 2018.

GONZÁLEZ, M. I. M.. Resistencia insulínica y obesidad. ARS MEDICA Revista de Ciencias Médicas, v. 26, n. 1, 2018.

MATTHEWS, D. R. et al. Homeostasis model assessment: insulin resistance and $\beta$-cell function from fasting plasma glucose and insulin concentrations in man. Diabetologia, v. 28, n. 7, p. 412-419, 1985.

REAVEN, G. M. Why Syndrome X? Historical Perspective From Harold Himsworth to the Insulin Resistance Syndrome. Cell Metabolism, 1:9-14, 2005.

SABOYA, P. P. et al. Síndrome metabólica e qualidade de vida: uma revisão sistemática. Revista Latino-Americana de Enfermagem, v. 24, p. 2848, 2016.

SANTANA, L. F. et al. Óleo de Cártamo (Carthamus tinctorius) Aumenta os Níveis de Colesterol Total e LDL-Colesterol em Modelo Experimental de Síndrome Metabólica. International Journal of Cardiovascular Sciences, v. 30, n. 6, p. 476-483, 2017.

VIEIRA, B. A. et al. Timing and type of alcohol consumption and the metabolic syndrome ELSA-Brasil. Plos One, v. 11, n. 9, p. 1-17, 2016. 


\title{
TOXICOLOGICAL EFFECTS OF THALLIUM IN THE EXPERIMENTAL MODEL CAERNOHABDITIS ELEGANS
}

\section{EFEITOS TOXICOLÓGICOS DO TÁLIO NO MODELO EXPERIMENTAL CAERNOHABDITIS ELEGANS}

\section{EFECTOS TOXICOLÓGICOS DEL TALIO EN EL MODELO EXPERIMENTAL ELEGANOS DE CAERNOHABDITIS}

\begin{abstract}
Amanda Onduras de Andrade ${ }^{1}$; Larissa Pereira Dantas ${ }^{2}$; Leandro de Oliveira Amaral $^{3}$; Alexandre Varão de Moura $^{4}$; Priscila Gulbert ${ }^{5}$
\end{abstract}

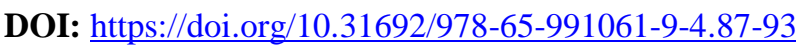

\section{INTRODUCTION}

Thallium is a trace metal widely distributed throughout the Earth, both in the continental and oceanic crust (MARTIN et al., 2018) and that for many years was misused in the composition of depilatory creams and magnetic resonance imaging contrast. Today it is applied optical lenses and semiconductor production, X-ray and ultra-red detectors, and in electronic manufacture, due to its ease of conducting current with low energy dispersion through heat. Recently, a thallium reserve was found in the city of Barreiras, in the western region of Bahia, which raised several questions regarding environmental and toxicological impacts. Due to the similarity to potassium ions, thallium can be captured in cells through potassium pump (TATSI et al., 2015; PRYTULAK et al., 2017; MARTIN et al., 2018).

The exposure, both through inhalation and ingestion, leads to mitochondrial changes and damage to the nervous system resulting in several symptoms, such as gastroenteritis, polyneuropathy, and alopecia (LIU et al., 2019). However, toxic mechanisms are not yet completely elucidated. In this perspective, the experimental model Caenorhabditis elegans $(C$. elegans) has been very useful in neurotoxicological analyses, since it has a fast life cycle (about three days), low maintenance cost, easy manipulation, and large offspring (300 eggs per adult). In addition, its transparency enables the visualization of cholinergic, gabaergic, dopaminergic, and serotonergic neurons by fluorescent labels. The neurotransmitters are related to movement,

\footnotetext{
1 Keizo Asami Immunopathology Laboratory, LIKA. Department of Biochemistry. Federal University of Pernambuco, UFPE. E-mail: amandaonduras@gmail.com

2 Keizo Asami Immunopathology Laboratory, LIKA. Department of Biochemistry. Federal University of Pernambuco, UFPE.

${ }^{3}$ Postgraduate Program in Pure and Applied Chemistry. POSQUIPA. Federal University of Western of Bahia, UFOB.

${ }^{4}$ Postgraduate Program in Pure and Applied Chemistry. POSQUIPA. Federal University of Western of Bahia, UFOB.

5 Keizo Asami Immunopathology Laboratory, LIKA. Department of Biochemistry. Federal University of Pernambuco, UFPE. Postgraduate Program in Pure and Applied Chemistry. POSQUIPA. Federal University of Western of Bahia, UFOB.
} 
egg-laying, and pharyngeal pumping behaviors. Besides, the worm genome has about $60-80 \%$ of similarities to the mammals, preserving similar signaling pathways and metabolism. Thus, to highlight the mechanisms on neuronal effects and resulting behaviors, we analyzed the metal thallium in various concentrations in the experimental model Caernohabditis elegans.

\section{METHODOLOGY}

\section{Maintenance}

Wild-type worms (N2) were acquired at the Caenorhabditis Genetics Center (CGC University of Minnesota) and kept under standard culture conditions in plates containing nematode growth medium (NGM), nutritionally supplied with Escherichia coli (E. coli) strain OP50 (BRENNER, 1974). Adult worms were used to obtain eggs, which lead to a synchronized population of L1 (first larval phase) for the experiments.

\section{Thallium acetate exposure and survival $\left(\mathrm{Cl}_{50}\right)$}

The L1 larval stage worms were exposed to different concentrations of thallium acetate $(50-1000 \mu \mathrm{M})$ for $1 \mathrm{~h}$. After exposure, the worms were washed and centrifuged three times to discontinue treatment. Subsequently, they were transferred to NGM plates inoculated with E. coli/OP50 for further assays. To determine survival, worms were exposed as described above and live nematodes were counted 24 after acute exposure. The lethality was assessed by normalizing the data against the control. Four experiments were performed to determine the lethal concentration.

\section{Larval development}

The worms were monitored from the L1 larval stage to adulthood to assess larval development after thallium acetate exposure. During the observations, the worms were kept at $20^{\circ} \mathrm{C} \pm 2$. The larvae were classified as L1, L2, L3, L4, and gravid adults according to the size, vulva development, and presence of eggs.

\section{Behavioral activity}

The worms in the larval stage of L4 were observed regarding their feeding behavior. The pharyngeal pumping was evaluated by monitoring worms on food. The contractions of the posterior pharyngeal bulb individually counted for 10 seconds, in triplicate, and the mean normalized to one minute (WANG; ROURKE; RUVKUN, 2009). The defecation of each worm was obtained by counting the intervals between the defecation cycles. For each worm, three defecation intervals were measured, and the mean of these intervals was used for further 
comparisons between the groups (WANG; ROURKE; RUVKUN, 2009).

Reproductive profile was assessed by determining the number of eggs in gravid animals (day 1 of adult) (SCHAFER; KENYON, 1995; WANG; ROURKE; RUVKUN, 2009). The number of eggs (egg production) in the uterus was determined by counting after individual lysis of the worms with bleaching solution. The experiments were performed at a temperature of 20 ${ }^{\circ} \mathrm{C} \pm 2$ and at least four times at different times.

\section{Statistical analyses}

The ImageJ program (NIH) was used for image analysis and densitometry. Statistical and graphical analyses were performed using GraphPad Prism $5 \circledR$ software. The significance of the difference between the means was verified through Student's t-test or analysis of variance (ANOVA) of one way followed by Bonferroni's test or two-way ANOVA when appropriate (GraphPad Scientific, San Diego, CA, USA).

\section{RESULTS}

\section{Survival (Cl50)}

After treating $C$. elegans with thallium acetate at different concentrations, the mortality rate was determined to determine the lethal concentration in $50 \%$ of the treated population. It was observed that there were no significant changes in the $50 \mu \mathrm{M}$ concentration. From the concentration of $100 \mu \mathrm{M}$ to $1000 \mu \mathrm{M}$, it was noted that there is a gradual and significant decrease in the number of surviving worms. The $\mathrm{LC}_{50}$ was determined at $222.708 \mu \mathrm{M}$ within 72 hours of treatment (Figure 1).

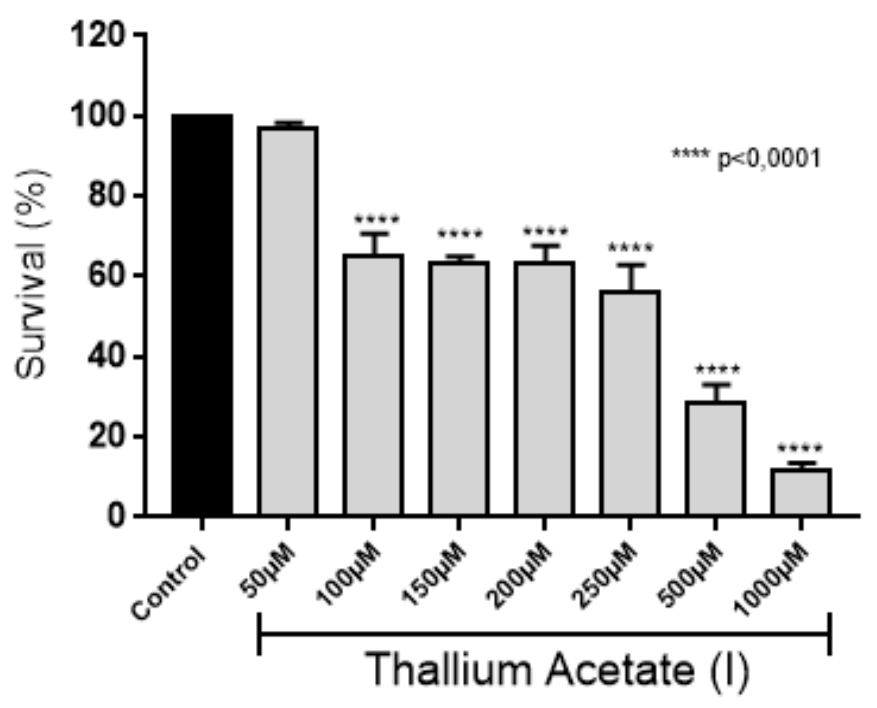

Figure 1: The values are displayed as $\%$ survival of total worms (mean \pm SEM) $(n=4$ independent experiments, with 10 nematodes classified by group). The worms were treated with thallium acetate solutions 
in concentrations ranging from $50 \mu \mathrm{M}-1000 \mu \mathrm{M}$ for 1 hour. After three washes in autoclaved distilled water, the worms were transferred to NGM plates sown with E. coli OP50 and survival to adulthood was assessed. **** The statistical significance $(\mathrm{p}<0.0001)$ in comparison to the ANOVA control group followed by a Bonferroni multiple comparison test was indicated.

The lethal dose of thallium ranges from 10 to $15 \mathrm{mg} \mathrm{kg}^{-1}$ for humans and chronic exposure can occur in the range 0.1 to $100 \mathrm{mg} \mathrm{kg}^{-1}$ ( $\mathrm{Li}$ et al., 2018). With these data, their high toxicity could be compared by other toxic metals, such as arsenic, mercury, cadmium, lead and copper. Thus, it was found through experiments that $\mathrm{Tl}^{+}$has high toxicity in low concentrations.

\section{DEVELOPMENT}

The exposure of $C$. elegans to thallium acetate affected its development. It was observed a significant delay in growth in parallel to the increase in thallium acetate concentration. After the treatment all the surviving worms were in stage L1 (Figure 2A), 24 hours after the treatment it is observed that there are still worms in stage L1 larval in at $100 \mu \mathrm{M}$ thallium acetate, it can be seen that there was a delay in the development of the animal (Figure 2B). Also, $48 \mathrm{~h}$ after, it was observed worm in stage L1 in worms exposed to $250 \mu \mathrm{M}$ (Figure $2 \mathrm{C}$ ) and after $72 \mathrm{~h}$ to 1000 $\mu \mathrm{M}$ thallium acetate (Figure 2D). It was not possible to observe many animals in concentrations of $500 \mu \mathrm{M}$ and $1000 \mu \mathrm{M}$ since the high toxicity which killed most of the worms. These data suggest that acute exposure to thallium acetate in C. elegans is capable of impairing the development of the animals, with, therefore, delay in larval growth in all stages.
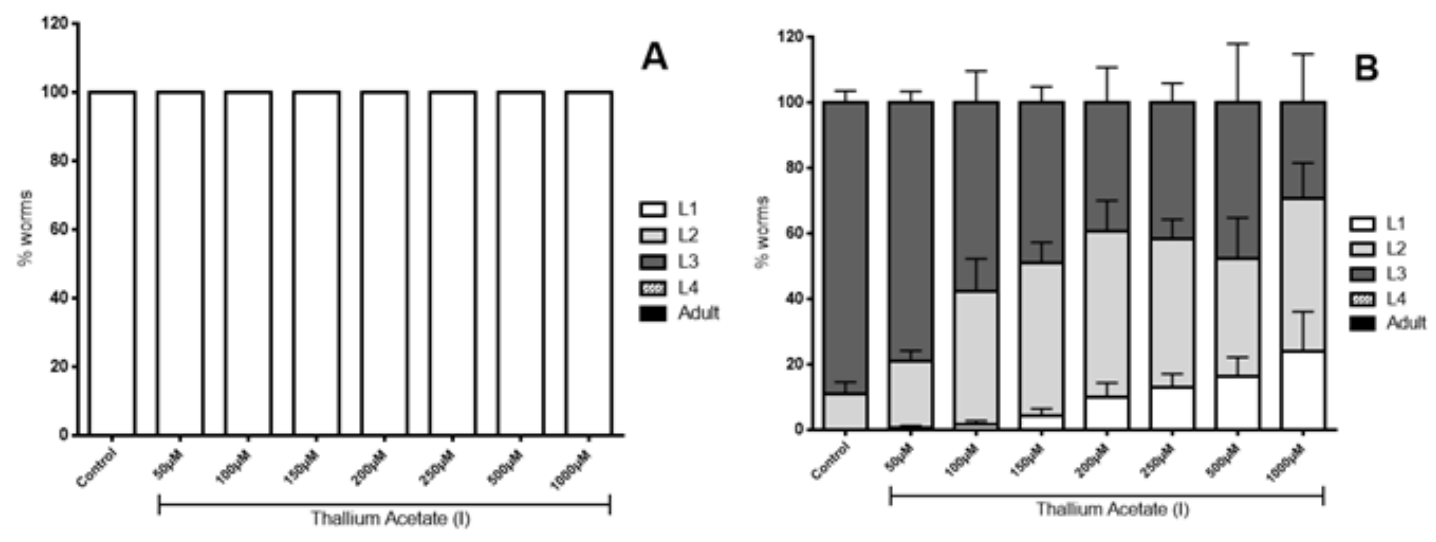

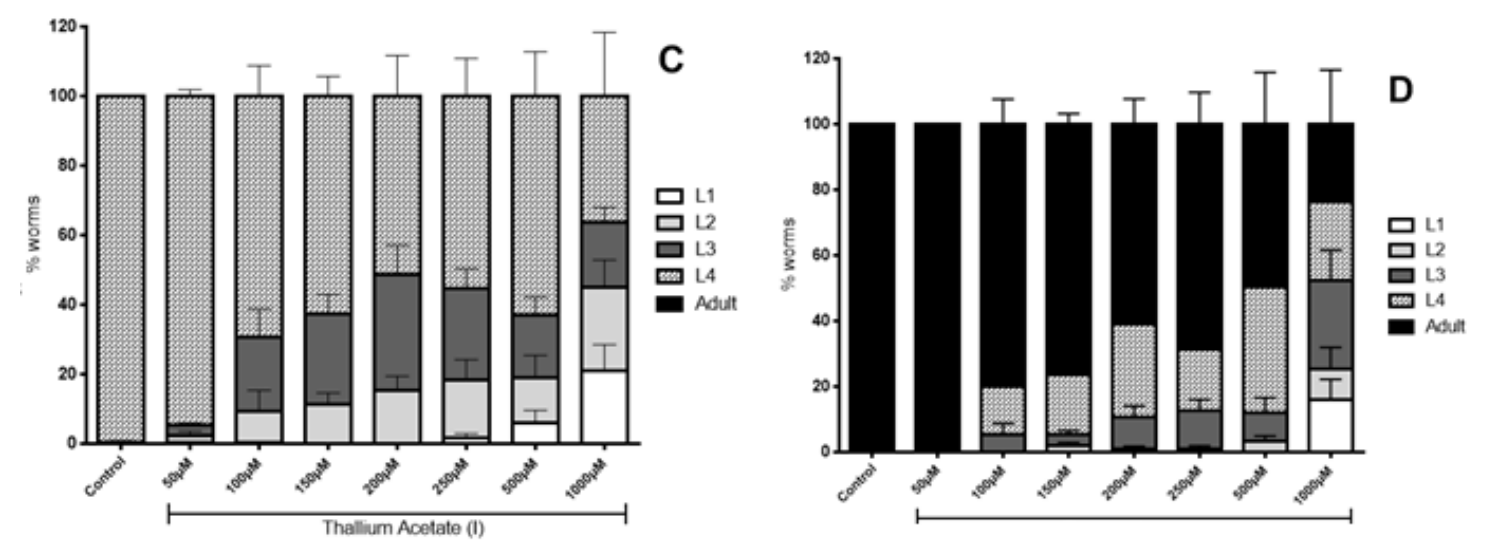

Figure 2: Larval development of $\mathbf{C}$. elegans nematode exposed to $\mathbf{T l}^{+}$. The worms were treated with different concentrations of larval stage thallium acetate solution and observed $1 \mathrm{~h}$ (A) $24 \mathrm{~h}$ (B) 48h (C) and 72h (D) after treatment. Values are displayed as the mean \pm SEM $(n=4$ independent experiments, with 10 nematodes classified by group in the behavioral test).

Studies show that the neurotoxic mechanisms of this metal can induce the formation of reactive oxygen species (ROS) and low production of cellular energy by mitochondria. Increased ROS generation and concomitant disruption of low energy production may block cell cycle progression. $\mathrm{Tl}^{+}$is also associated with inhibition of deoxyribonucleic acid replication and increased oxidative stress by inducing lipid peroxidation, which in turn leads to cellular apoptosis. This mechanism may slow the development of the worm gradually at non-lethal concentrations.

\section{Pharyngeal pumping and defecation cycle}

No significant differences were found in the pharyngeal beating behavior of the worms in all tested concentrations compared to the control group. A significant difference was observed defecation cycle at a concentration of $200 \mu \mathrm{M}$ thallium acetate $(* * \mathrm{p}<0.01)$ suggesting toxicity. No significant differences were found in the pharyngeal beating behavior of the worms in all tested concentrations compared to the control group. A significant difference was observed defecation cycle at a concentration of $200 \mu \mathrm{M}$ thallium acetate $(* * \mathrm{p}<0.01)$ suggesting toxicity. No significant differences were found in the pharyngeal beating behavior of the worms in all tested concentrations compared to the control group. A significant difference was observed defecation cycle at a concentration of $200 \mu \mathrm{M}$ thallium acetate $(* * \mathrm{p}<0.01)$ suggesting toxicity. 

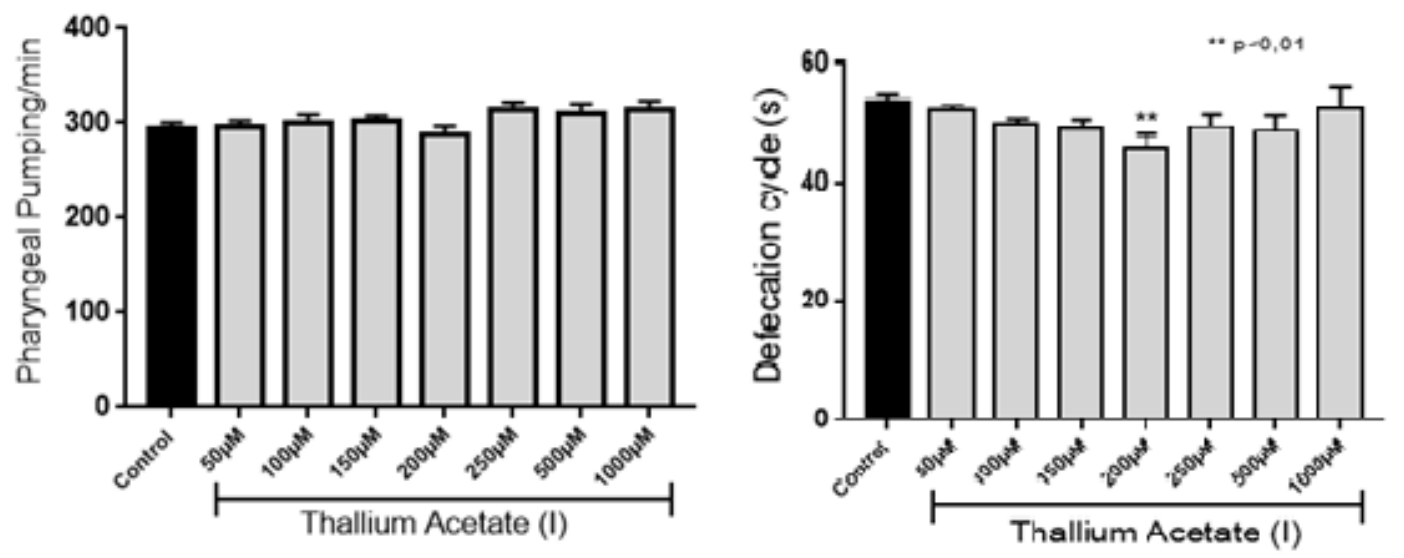

Figure 3: Evaluation of pharyngeal beating behavior in wild worms after being exposed to thallium acetate solution for 1 hour. The worms were observed for pharyngeal beating per minute. Treatment with thallium acetate solution $(50 \mu \mathrm{M}-1000 \mu \mathrm{M})$ started at the larval stage L1 and lasted 1 hour. After 48 hours, in the larval stage L4, the behaviors were determined. No significant differences were observed in the treated worms in relation to control. Values are displayed as mean \pm SEM ( $n=4$ independent experiments, with 10 nematodes classified per group in the behavior assay).

Figure 4: Duration of the defecation cycle in adult $C$. elegans worms after 1 hour of exposure to thallium acetate solution. Nematoids were evaluated in the larval stage L4 after exposure to T11+ in NGM plates sown with E.coli OP50. ** $\mathrm{p}<0.01$ indicates statistical significance compared to the control group by means of ANOVA followed by the Bonferroni Multiple Comparison Test. Values are displayed as mean \pm SEM ( $n=4$ independent experiments, with 10 nematodes classified per group in the behavior test).

\section{Reproduction}

There was a significant reduction in egg production with treatment from $100 \mu \mathrm{M}$ thallium acetate (**** $\mathrm{p}<0.0001$, figure 5). According to Mahoney et al. (2006), this reduction may indirectly indicate a rupture in the cholinergic system, so there may be damage to the nervous system. The results show the developmental delay also observed in worms exposed to thallium acetate. The $500 \mu \mathrm{M}$ and $1000 \mu \mathrm{M}$ groups had a high rate of dead animals or larval delay, so there were not enough worms for analysis, justifying the gap as zero egg production.Considering that the reproductive system is closely linked to longevity in C. elegans (WANG, D.; XING, 2008), we found that the shelf life was also reduced in worms exposed to $\mathrm{T}^{+}$when compared to controls. According to the literature, $\mathrm{Tl}^{+}$increased lipid peroxidation production, reduced shelf life and also affected reproduction. Notably, exposure to $\mathrm{Tl}^{+}$caused a reduction in the amount of eggs produced, indicating that cholinergic neurons may be affected by this metal. 


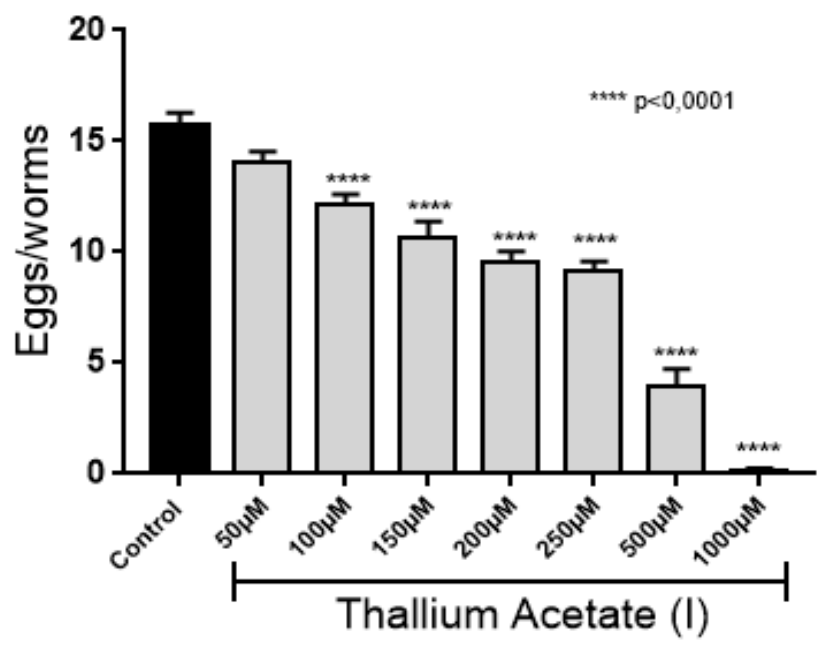

Figure 5: Evaluation of the reproductive behavior of $C$. elegans after exposure to thallium acetate for 1 hour. The production of eggs from worms in adult larval stage was observed after 72 hours of treatment with different concentrations of thallium acetate. The results represent the mean number of eggs inside the worms. ****The results were statistically different compared to the ANOVA control group followed by the Bonferroni test. The values are displayed as mean \pm SEM $(n=4$ independent experiments, with 10 nematodes classified per group in the behavior test).

\section{CONCLUSION}

The thallium acetate induced toxicity in C. elegans, which was evidenced by lethality, developmental impairment, and behavioral changes in the worm. The impacts are possibly related to neurotoxicity, and the next step of the present study will be investigating thallium acetate mechanisms behind the phenotypes observed.

\section{REFERENCES}

BRENNER, S. Genetics, v. 77, n. 1, p. 71-94, 1974.

K. Li et al., "Removal of thallium from wastewater by a combination of persulfate oxidation and iron coagulation," Process Saf. Environ. Prot., vol. 119, pp. 340-349, 2018

LIU, J et al. Environmental Pollution, v. 248, p. 906-915, 2019. Applied Geochemistry, v. 88, p. 239-246, 2018.

MARTIN, L. A.; et al. Geochimica et Cosmochimica Acta, v. 230, p. 1-16, 2018.

TATSI, K.; et al. Science of the Total Environment, v. 536, p. 382-390, 2015.

WANG, D.; XING, X. Assessment of locomotion behavioral defects induced by acute toxicity from heavy metal exposure in nematode Caenorhabditis elegans. J Environ Sci (China), v. 20, n. 9 , p. 1132-1137, 2008.

WANG, M. C.; et al. NIH Public Access. October, v. 322, n. 5903, p. 957-960, 2009. 


\title{
EFEITO DO NÚMERO CUMULATIVO DE CIGARROS FUMADOS SOBRE O PERFIL LIPÍDICO E CLASSES DE FOSFOLIPÍDIOS DE UMA POPULAÇÃO DE CARUARU-PERNAMBUCO
}

\section{EFECTO DEL NÚMERO ACUMULADO DE CIGARRILLOS FUMADOS EN EL PERFIL LIPIDO Y LAS CLASES DE FOSLÍPIDO DE UNA POBLACÍON DE CARUARU-PERNAMBUCO}

\section{EFFECT OF CUMULATIVE NUMBER OF SMOKED CIGARRTES ON LIPID PROFILE AND PHOSPOLIPID CLASSES OF A CARUARU-PERNAMBUCO POPULATION}

\begin{abstract}
Antonio Lopes Ferreira Neto ${ }^{1}$; Isabela Simões Alves ${ }^{2}$; Jeaninne Alexandra de Azevedo Silva ${ }^{3}$; Ana Carolina Bezerra Paz ${ }^{4}$; Bianka Santana dos Santos ${ }^{5}$
\end{abstract}

DOI: https://doi.org/10.31692/978-65-991061-9-4.94-99

\section{INTRODUÇÃO}

O tabagismo tem significativa participação na fisiopatologia de Doenças

Cardiovasculares Ateroscleróticas (DCVAs), que perpassam por alterações nos metabolismos lipídicos e glicídicos dos indivíduos fumantes. Porém, não há na literatura muitos registros de correlação entre o número cumulativo de cigarros fumados e o aumento quantitativo do perfil lipídico (LEE et al., 2011). Tem-se, por outro lado, o conhecimento de que a nicotina induz a secreção de catecolaminas, cortisol e hormônio do crescimento $(\mathrm{GH})$, o que acarreta em um aumento na concentração sanguínea de ácidos graxos livres capazes de estimularem a secreção hepática de lipoproteína de muito baixa densidade (VLDL), triglicerídeos (TG) e lipoproteínas de baixa densidade (LDL), e de inibirem a secreção de HDL-C (LI et al., 2018). Contudo, são pouco conhecidos, os mecanismos de aumento dos níveis de fosfolipídios plasmáticos através do uso crônico de cigarro (RAMOS et al., 2004).

Dessa forma, o presente projeto desperta a atenção para o fato de que, se houver alteração nas subclasses de fosfolipídios plasmáticos, pode-se encontrar um elo para a possível redução dos níveis de HDL com o uso cumulativo do cigarro, acrescentando enormemente para uma explicação fisiopatológica da relação causa-consequência entre tabagismo e DCVAs.

\footnotetext{
${ }^{1}$ Acadêmico de Medicina, Núcleo de Ciências da Vida - Universidade Federal de Pernambuco - Campus do Agreste, antonio.lopes.neto@hotmail.com

2 Acadêmica de Medicina, Núcleo de Ciências da Vida - Universidade Federal de Pernambuco - Campus do Agreste.

${ }^{3}$ Acadêmica de Medicina, Núcleo de Ciências da Vida - Universidade Federal de Pernambuco - Campus do Agreste, jeaninne.med@gmail.com

4 Acadêmica de Medicina, Núcleo de Ciências da Vida - Universidade Federal de Pernambuco - Campus do Agreste, ana-carolina-bezerra-paz@hotmail.com

${ }^{5}$ Doutora em Ciências Biológicas e Pós-Doutora em Bioquímica e Fisiologia, Docente do Curso de Medicina, Núcleo de Ciências da Vida - Campus do Agreste - Universidade Federal de Pernambuco, biankasantana@gmail.com
} 
Ademais, a nicotina tem ação sobre o sistema nervoso central, promovendo a liberação de inúmeros neurotransmissores e, em decorrência disso, provocando dependência, que pode ser avaliada através do Teste de Fagerström (VAN AMSTERDAM et al., 2019). Assim sendo, este estudo tem como objetivo principal estudar o efeito do número cumulativo de cigarros sobre o metabolismo lipídico, e avaliar, em paralelo, o processo tolerância-dependência à nicotina e suas confluências para a saúde caruaruense.

\section{FUNDAMENTAÇÃO TEÓRICA}

As doenças cardiovasculares figuram entre as primeiras causas de mortalidade mundial, com destaque especial para a Doença Arterial Coronariana (DAC) e doenças neurovasculares, como o Acidente Vascular Encefálico (AVE), seja ele isquêmico ou hemorrágico. Nesse sentido, os principais fatores de risco para altos índices de morbimortalidade por DCVAs são as dislipidemias, o tabagismo e o etilismo (PRÉCOMA et al., 2019).

O fumo do tabaco implica em uma inalação muito grande de nicotina e outros poluentes, que são responsáveis por indução de estresse oxidativo e resposta inflamatória nos vasos sanguíneos, além de inibirem a ativação de substâncias antioxidantes (MUNAKATA et al., 2018). Destarte, o uso crônico de cigarro, e consequente de nicotina por fumantes correntes, induzem uma maior produção de radicais livres de oxigênio, os quais atuam inibindo a formação de óxido nítrico e aumentando a sua degradação, o que acarreta em uma menor distensão vascular e maior vasoconstricção (TODA; TODA, 2010). Por conseguinte, há aumento da resistência vascular periférica, e, quando nos rins, esse processo constritor, diminui a perfusão das arteríolas eferentes, aumentando concomitantemente a pressão arterial (MANGAN; STOTT; DHANDA, 2018).

Paralelamente, o hábito tabagista é claramente relacionado ao aumento considerável de LDL, que pode corroborar com um diagnóstico de dislipidemia. O tempo de início do uso crônico de cigarros, bem como a quantidade diária fumada, relacionam-se positivamente ao crescimento quantitativo e qualitativo de LDL, assim, aqueles que fumam cerca de 20 cigarros ao dia por mais de 15 anos podem ter riscos de dislipidemias muito maiores que aqueles que fumam essa quantidade ou menos entre 1 e 5 anos (SHI et al., 2018). Não obstante, a nicotina induz uma resistência insulínica através da indução de liberação do hormônio do crescimento e cortisol e também do aumento na quantidade de lipídios plasmáticos (MORGAN et al., 2004).

Ademais, o uso do teste de Fagerström para dependência de nicotina faz-se imprescindível para o entendimento do consumo diário de cigarros e da dependência química deste, bem como método preditivo para as taxas de tendência ao hábito de fumar. A avaliação 
do número cumulativo de cigarros fumados, por sua vez, também é importante, pois este número traz à tona os efeitos que o cigarro provocou em pessoas que já cessaram o hábito tabágico, ou seja, os ex-fumantes, além de evidenciar as alterações ocorridas nos fumantes correntes (VAN AMSTERDAM et al., 2019).

\section{METODOLOGIA}

Desenho do Estudo e Determinações Bioquímicas. Estudo transversal foi conduzido com 500 voluntários, com idade $\geq 18$ anos, de Caruaru-PE, após aprovação por Comitê de Ética em Pesquisa ( $n^{\circ}$ CAAE 54688716.6.0000.5208). Após 12h em jejum, amostras sanguíneas foram obtidas para determinação de Colesterol Total, Triglicerídios, LDL-colesterol e HDLcolesterol, por metodologias enzimáticas, e dos fosfolipídios por cromatografia de camada delgada (FOLCH et al., 1957). Número Cumulativo de Cigarros Fumados e Dependência à Nicotina. Foram acessados, respectivamente, conforme Brinkman \& Coates (1963) e pelo Teste de Fagerström. Análise Estatística dos Dados. Teste de correlação e t de Student $(p<0,05)$.

\section{RESULTADOS E DISCUSSÕES}

Foi encontrada uma prevalência de $13 \%$ de fumantes correntes (FC) e de $14 \%$ de exfumantes (EF) na população deste estudo. Malta et al. (2010) verificaram uma prevalência de 16,1\% de tabagismo no Brasil e dados da jPNS (2013) e do MINISTÉRIO DA SAÚDE BRASIL (2017) mostraram uma prevalência de 15\% no Estado de Pernambuco. Outrossim, o presente estudo também mostrou que a maior parte de FC e EF foi de fumantes severos, seguidos por fumantes considerados moderados e, por fim, fumantes leves. Brinkman e Coates (1963) já mostravam a importância desta estratificação, quando criaram o Índice de Brinkman. O valor médio encontrado do Índice de Brinkman no presente estudo foi de 977,8 \pm EPM de 327,5 , evidenciando a maior presença de fumantes severos nessas pessoas de Caruaru-PE. O número cumulativo de cigarros fumados correlacionou-se positivamente, de maneira significativa, com os níveis séricos de Colesterol Total (CT), LDL-colesterol (LDL-C), Triglicerídeos (TG) e Glicose, conforme demonstrado na Tabela 1. FC tiveram significativamente menores níveis plasmáticos de Lisofosfatidilcolina e maiores níveis de Fosfatidilcolina do que Não Fumantes (NF), sem, no entanto, diferirem quanto às outras classes de fosfolipídios, como mostrado na Tabela 2. Dependência à nicotina também foi encontrada e classificada como grave. 
Tabela 1. Correlação (r) de Pearson entre valores de Índice de Brinkman, glicemia e níveis de lipídios séricos.

\begin{tabular}{ccc}
\hline $\begin{array}{c}\text { Parâmetros } \\
\text { Avaliados }\end{array}$ & $\mathbf{r}$ & $* \mathbf{p}$ \\
\hline TG (mg/dL) & 0,371 & $<0,001$ \\
HDL-C (mg/dL) & 0,402 & $<0,001$ \\
CT (mg/dL) & 0,425 & $<0,001$ \\
LDL-C (mg/dL) & $-0,432$ & $<0,001$ \\
Glicose (mg/dL) & 0,337 & $<0,001$ \\
\hline
\end{tabular}

\begin{tabular}{ccc}
\multicolumn{3}{c}{ Tabela 2. Valores de Fosfolipídios Plasmáticos em Fumantes e Não Fumantes de Caruaru-PE. } \\
\hline $\begin{array}{c}\text { Fosfolipídios }(\boldsymbol{\mu m o l} \text { de } \\
\text { Fósforo/mL) }\end{array}$ & $\begin{array}{c}\text { Média } \mathbf{E} \text { EP } \\
\text { NF }\end{array}$ & $\begin{array}{c}\text { Média } \pm \mathbf{E P} \\
\text { FC }\end{array}$ \\
\hline *Fosfatidilcolina $(\mathbf{P C})$ & $1,959 \pm 0,02$ & $3,014 \pm 0,02$ \\
& $0,635 \pm 0,01$ & $0,2141 \pm 0,02$ \\
*Lisofosfatidilcolina (LPC) & $0,355 \pm 0,2$ & $0,365 \pm 0,03$ \\
*Fosfatidiletanolamina (PE) & $0,404 \pm 0,01$ & $0,418 \pm 0,03$ \\
*Esfingomielina (SPH)
\end{tabular}

Teste $t$ de Student desemparelhado. Os valores estão expressos em média \pm EP (Erro Padrão da Média). *Valores de p (nível de significância) encontrados entre FC versus NF foram $<0,05$. **Valores de p (nível de significância) encontrados entre FC versus NF não foram significativos.

Destarte, ratifica-se uma forte correlação entre Colesterol Total e LDL-colesterol e o tempo de uso do cigarro. Shi et al. (2018) também encontraram uma forte correlação entre o tempo de tabagismo, os níveis de Triglicerídios e de Colesterol Total em Chineses, ocorrendo, por conseguinte, redução nos níveis de LDL-C. Kakamu et al. (2013) têm identificado um número cumulativo de cigarros fumados superior a 600 , como foi a média encontrada neste estudo $(977,8)$, como um marcador efetivo de risco para diabetes mellitus. Isto vem a somar com o alto dano que o tabaco pode ocasionar ao metabolismo lipídico e, consequentemente, ampliar o risco de doenças cardiovasculares. Os dados do presente estudo evidenciam uma possível menor esterificação do colesterol na HDL e, portanto, uma possível redução no transporte reverso do colesterol, que somado aos menores níveis de HDL-C, pode levar a uma maior probabilidade de DCVAs, como reportado por Shi et al. (2018). Kirchenchtejn e Chatkin (2004) ressaltaram a necessidade de se investigar não apenas o número de cigarros, mas também o processo de tolerância-dependência à nicotina, pois o estado de dependência é dinâmico e não seria justo classificar as pessoas apenas como dependentes ou não. Précoma et al. (2019) 
também relataram que o tabagismo é uma causa primária de DCVAs e é extremamente importante distinguir entre os fumantes o grau de dependência à nicotina. O presente estudo encontrou uma dependência à nicotina considerada como grave, com escore igual a 8. Isto mostra o quanto a população de Caruaru, Agreste de Pernambuco, pode estar susceptível a doenças crônicas não transmissíveis decorrentes do hábito tabagista e o quão difícil pode ser para aqueles que fazem uso do cigarro de forma corrente cessarem este hábito.

\section{CONCLUSÕES}

O tabagismo é uma condição prevalente em Caruaru, apesar da redução em nível nacional, com uma relação de dependência à nicotina considerada grave, e que está diretamente associado com a presença de condições biológicas de maior risco cardiovascular nesta população, em especial, correlacionando-se com alterações relevantes no metabolismo lipídico, e no sistema circulatório, propiciando não apenas dislipidemias quantitativas, mas também alterações qualitativas de extrema relevância, como o possível prejuízo no transporte reverso do colesterol realizado pela HDL, sugerido pela diminuição de lisofosfatidilcolina e elevação de fosfatidilcolina encontrados no estudo. Por isso, faz-se improtelável aplicação de esforços na redução do estilo de vida tabagista da população caruaruense, bem como faz-se imprescindível utilização dos princípios de prevenção à saúde da atenção primária em saúde para construir conhecimento popular sobre os benefícios de parar de fumar.

\section{REFERÊNCIAS}

BRASIL. Vigitel Brasil 2016 : vigilância de fatores de risco e proteção para doenças crônicas por inquérito telefônico. Brasília: Ministério da Saúde, 2017.

BRINKMAN, G. L.; COATES, JR., E. O. The Effect of Bronchitis, Smoking, and Occupation on Ventilation. The American Review of Respiratory Disease, [s.i], v. 87, p. 684-693. 1963.

DING, Ning et al. Cigarette smoking, smoking cessation, and long-term risk of 3 major atherosclerotic diseases. Journal of the American College of Cardiology, [s.i], v. 74, n. 4, p. 498-507, 2019.

FOLCH, J.; LEES, M.; STANLEY, G. H. S. A simple mehod for the isolation and purification of total lipides from animal tissues. The Journal Of Biological Chemistry, Boston, p. 497509. 23 ago. 1957.

KIRCHENCHTEJN, C.; CHATKIN, J. M. Dependência da nicotina. Jornal Brasileiro de Pneumologia. São Paulo, v. 30, n. 2, p. S11-S18, ago. 2004.

LI, X. X. et al. Effects of smoking and alcohol consumption on lipid profile in male adults in northwest rural China. Public health, [s.i], v. 157, p. 7-13, 2018. 
MANGAN, Clodagh; STOTT, Martyn C.; DHANDA, Raman. Renal physiology: blood flow, glomerular filtration and plasma clearance. Anaesthesia \& Intensive Care Medicine, v. 19, n. 5, p. 254-257, 2018.

MORGAN, Thomas M. et al. Acute effects of nicotine on serum glucose insulin growth hormone and cortisol in healthy smokers. Metabolism, [s.i[, v. 53, n. 5, p. 578-582, 2004.

MUNAKATA, Satoru et al. Oxidative stress responses in human bronchial epithelial cells exposed to cigarette smoke and vapor from tobacco-and nicotine-containing

PRÉCOMA, D. B. et al. (Orgs.), Sociedade Brasileira de Cardiologia. Atualização da Diretriz de Prevenção Cardiovascular da Sociedade Brasileira de Cardiologia. Arquivos Brasileiros de Cardiologia, [s.i], v. 113, n. 4, p.787-891, 2019.

SHI, Jikang et al. Classified status of smoking and quitting has different associations with dyslipidemia in residents in northeast China. Clinica Chimica Acta, [s.i], v. 486, p. 209-213, 2018.

TODA, Noboru; TODA, Hiroshi. Nitric oxide-mediated blood flow regulation as affected by smoking and nicotine. European journal of pharmacology, [s.i], v. 649, n. 1-3, p. 1-13, 2010.

VAN AMSTERDAM, Jan et al. Use of the Fagerström test to assess differences in the degree of nicotine dependence in smokers from five ethnic groups: The HELIUS study. Drug and alcohol dependence, [s.i], v. 194, p. 197-204, 2019. 


\title{
CONTRIBUIÇÕES DAS AÇÕES DE DESPERTAR VOCAÇÕES: O CASO DA VISITA GUIADA A UM CAMPUS AGRÍCOLA
}

\section{CONTRIBUCIONES DE LAS ACCIONES DE DESPERTAR VOCACIONES: EL CASO DE UN TOUR GUIADO A UN CAMPUS AGRÍCOLA}

\section{CONTRIBUTIONS OF AWAKENING VOCATIONS' ACTIONS: THE CASE OF A GUIDED TOUR TO AN AGRICULTURAL CAMPUS}

\author{
Karoliny Paula da Silva ${ }^{1}$; Erick Viana da Silva ${ }^{2}$
}

DOI: https://doi.org/10.31692/978-65-991061-9-4.100-103

\section{INTRODUÇÃO}

O Programa Despertando Vocações (PDV) é um projeto que integra ações de ensino, pesquisa, extensão e gestão proposto pelo IIDV (Instituto Internacional Descobrindo Vocações), que é subdividido em categorias que visam facilitar a integração dos discentes e docentes em suas áreas, são elas: Gestão e Tecnologia (PDVGT), Saúde (PDVS), Ciências Agrárias (PDVAgro) e Licenciaturas (PDVL).

O PDV tem como objetivo aproximar o discente do universo acadêmico, propondo como principal ponto o protagonismo acadêmico, ou seja, uma metodologia ativa na qual o discente promove primordialmente o seu processo educativo e o docente é concebido como um facilitador e mediador do conteúdo teórico, unindo-o com a realidade (MARCOS, 2018). Antes de atuar diretamente no PDV, o aluno passa por uma preparação acadêmica, para que ele desenvolva as competências necessárias para desempenhar as atividades propostas, essa formação é denominada de I9 PDV. Os cursos oferecidos durante esta capacitação não são voltados apenas para o programa em si, mas podem ser aproveitados durante toda a vida pessoal e acadêmica, tornando-se uma oportunidade do estudante conectar-se e cooperar com áreas distintas. Alguns dos cursos oferecidos são: Introdução à oratória, introdução à fotografia, marketing pessoal, planejamento acadêmico, introdução ao gerenciamento de projetos, gestão humanizada de pessoas, Arduíno, dentre outros.

A partir desse princípio, algumas atividades são fundamentais dentro do projeto, como minicursos ofertados pelos alunos que fazem parte da extensão, reuniões de troca de experiência acerca do programa, grupos de trabalho que tomam conta das partes funcionais e fundamentais do PDV e, dentre outras práticas, as visitas guiadas a outros campus. O último item é o que será retratado no presente documento, mais especificamente a visita guiada ao IFPE Campus Vitória,

\footnotetext{
${ }^{1}$ Graduanda em Psicologia, Universidade dos Guararapes, karolinypaula.pt@ gmail.com

${ }^{2}$ Mestre em Administração, IFPE - Campus Recife, erick.viana@ recife.ifpe.edu.br
} 
que foi ministrada pelo PDVAgro e teve por objetivo contextualizar os alunos com as atividades exercidas em um campus com enfoque nas ciências agrárias, em concomitância a fazer com que os alunos do PDVGT do IFPE Recife se apropriassem dos elementos necessários para o planejamento e execução de uma visita guiada, para que fosse posta em prática no campus de origem.

\section{RELATO DE EXPERIÊNCIA}

A visita técnica aconteceu no dia 06 de maio de 2019, nos reunimos no IFPE Campus Recife às sete manhã, e saímos às oito da manhã em direção ao Campus de Vitória de Santo Antão. Ao chegarmos em nosso destino, tivemos uma reunião com os professores do local, que explicaram um pouco mais acerca dos cursos ofertados e da influência do PDVL e do PDVAgro na escolha profissional dos jovens.

A instituição conta com os cursos de licenciatura em Química; bacharelado em Agronomia; subsequentes em Agricultura, Agroindústria e Zootecnia; Proeja em Manutenção e Suporte em Informática; e integrados em Agroindústria e Agropecuária. Os cursos são de extrema importância para a comunidade acadêmica, visto que a cidade de Vitória e as circunvizinhas tem sua economia movida a partir de atividades ligadas ao cultivo de animais e plantas para os mais diversos fins.

Durante a reunião primeira, foi falado que alguns moradores acham que o IFPE é uma escola particular de alto custo devido ao seu grande porte, as visitas guiadas entram nesse ponto também para desmistificar essa crença, além de cativar os futuros alunos a ingressarem nos cursos. Outra problemática que o Campus vinham enfrentando, que está sendo pauta em outros âmbitos da educação, é o contingenciamento de gastos proposto pelo Governo Federal, que coloca em risco a oferta de bolsas e até mesmo do restaurante do campus, elementos cruciais para que estudantes oriundos de famílias de baixa renda continuem nos seus cursos.

Após o momento de reflexão proposto, caminhamos para conhecer os cultivos do Campus, que tem um território enorme com diversos tipos de plantações e criações de animais, como coelhos, codornas, porcos, galinhas, peixes e camarões. A plantação cultivada é submetida a uma quantidade reduzida de agrotóxicos possíveis, havendo diversas amostras e pesquisas em andamento, o que demonstra uma preocupação com as questões de saúde, tanto do Campus, afinal tudo que é produzido serve para alimentar o restaurante interno, quanto de forma geral, afinal, as pesquisas podem ajudar na diminuição do uso desses produtos futuramente.

Vale ressaltar que as atividades acima foram propostas pelo PDVAgro, que são 
utilizadas geralmente para que o aluno em idade de decisão de sua trajetória laboral e acadêmica possa ter contato real com a área que o cerca constantemente, visando que ele entenda melhor o processo e permita-se ser cativado (ou não) pelos conhecimentos propostos.

Depois desse momento, houve uma pausa para o almoço e a continuidade dada ao momento pelo PDVL composto pelos licenciandos em Química, que fizeram vários experimentos dentro da área deles, contextualizando com o cotidiano dos alunos, com memes de conhecimento geral do público jovem e também com o "Passinho dos Malokas", ritmo atual que se popularizou no estado por meio das redes sociais. No final da apresentação do curso, houve uma conversa de saldo positivo e negativo e o que poderia ser proposto por cada curso do IFPE de Recife durante uma visita técnica para chamar a atenção do aluno para o curso. Foi de grande valia e cativou a todos, deixando a semente da reflexão para que pudesse germinar e ser frutífera.

No final houve um momento de maior descontração, apesar de que o saber acadêmico não foi deixado de lado. Conhecemos como era feito o processo para transformar a matéria prima nas comidas que compramos no supermercado, a partir do saber da Agroindústria. Foi possível ter acesso a iogurte produzido dentro do próprio Campus e pronto para consumo, tivemos acesso a como era produzida a farinha, queijos, licores, açúcar e outros produtos orgânicos. No final, ainda pudemos raspar cana para fazer o nosso próprio caldo de cana. $\mathrm{O}$ resultado foi positivo, todos os alunos saíram muito satisfeitos com a visita, foi impressionante como muitos dos estudantes que eram do integrado e, consequentemente, mais novos, nem sabiam como era moída a cana e nunca tinham visto uma moenda, mostrando a necessidade desse resgate de valores e cultura para os jovens.

\section{CONSIDERAÇÕES FINAIS}

Durante toda a visita, conseguimos perceber a importância de cativar o jovem para áreas do conhecimento que ele vê no cotidiano, mas talvez não entenda a fundo. Esse momento de escolha laboral resulta em um enorme estresse, o jovem precisa de influência da família, dos amigos, psicológica e de todos os âmbitos ao seu redor para poder lidar bem com o momento e escolher para qual direção ir. A iniciativa da visita técnica pode ajudar quem passa por essa situação a achar esse desejo interno e seguir sua profissão, minimizando a evasão dos cursos e aumentando a satisfação dos alunos.

Além disso, a forma próxima utilizada para passar o conteúdo, em concomitância com o planejamento, é uma tática para aproximar ainda mais o jovem do local, para que ele se perceba como parte integrante do ambiente, e não como externo. 
Enquanto estudante de psicologia, ao visitar um campus voltado majoritariamente para as ciências agrárias, pude constatar como o contato com a natureza, o campo e os fazeres laborais rurais podem servir como estratégia de combate para fatores estressores.

Não obstante, a visita foi importante para nós, que mesmo já estando, tecnicamente, seguindo uma carreira acadêmica, pudemos resgatar fatores primordiais da nossa cultura e conhecer os comportamentos e costumes de uma cidade que não a nossa, que mesmo sendo relativamente próxima, já traz consigo uma enorme quantidade de diferenças que pudemos conhecer e reconhecer.

\section{REFERÊNCIAS}

INSTITUTO IDV (Recife). Breve Histórico. 2019. Disponível em: <https://pdv.institutoidv.org/blog/quem-somos-nos/>. Acesso em: 20 jul. 2019.

MARCOS, L. Metodologias Ativas: O Protagonismo Acadêmico. Estácio Saúde, Santa Catarina, v. 7, n. 2, p.1-5, jul. 2018. Semestral. Disponível em: <http://periodicos.estacio.br/index.php/saudesantacatarina/article/view/5446/47964941>. Acesso em: 18 jul. 2019. 


\title{
A IMPORTÂNCIA DO TESTE DA LINGUINHA E DA INTERVENÇÃO DE UMA EQUIPE MULTIPROFISSIONAL EM CRIANÇAS COM ANQUILOGLOSSIA POR MEIO DO PROTOCOLO DE MARTINELLI
}

\section{LA IMPORTANCIA DE LA PRUEBA DE LENGUA Y DE LA INTERVENCIÓN DEL EQUIPE MULTIPROFISSIONAL EM NIÑOS COM ANQUILOGLOSIA A TRAVÉS DEL PROTOCOLO DE MARTINELLI}

\section{THE IMPORTANCE OF THE LITTLE TONGUE TEST AND THE INTERVENTION OF A MULTIPROFESSIONAL TEAM ON CHILDREN WITH ANKYLOGLOSSIA THROUGH THE MARTINELLI PROTOCOL}

\begin{abstract}
Danielle Pereira de Lima ${ }^{1}$; Alana Tainá Rodrigues Barbosa ${ }^{2}$; Eduardo Ramos da Silva ${ }^{3}$; Vytor Paulo Conserva Silva ${ }^{4}$; Artemísia Ruth Arruda Lucena Veras ${ }^{5}$
\end{abstract}

DOI: $\underline{\text { https://doi.org/10.31692/978-65-991061-9-4.104-106 }}$

\section{INTRODUÇÃO}

O teste da linguinha é um protocolo específico de avaliação do frênulo da língua em bebês para diagnóstico precoce da anquiloglossia, que podem comprometer algumas funções exercidas pela língua. É realizado uma avaliação anatomofuncional por meio do protocolo de Martinelli. O projeto de lei 4.832/12 aprovado em 20 de Junho do ano de 2014 (Brasil, 2014), obriga a realização do protocolo de avaliação do frênulo da língua em bebês, em todos os hospitais e maternidades do Brasil. Externamos a importância do teste, que por sua vez, permite ao bebê ser diagnosticado e na possibilidade de uma alteração, ser indicado ao tratamento precoce dos movimentos limitados da língua, ocasionados pela anquiloglossia, que pode comprometer as funções: sucção, deglutição, mastigação e fala.

\section{RELATO DE EXPERIÊNCIA}

Os projetos Língua Solta e Teste da Linguinha, são compostos por uma equipe multiprofissional, como Fonoaudiólogos, Psicólogos, Cirurgiões Dentistas, Nutricionista e graduandos nas áreas de Fonoaudiologia e Odontologia realizado na Universidade Federal de Pernambuco - UFPE. Em média são realizados 10 atendimentos por expediente, além desses atendimentos agendados, existe a demanda espontânea, a maioria dos casos são encaminhados ao projeto por médicos Pediatras. A avaliação é composta por história clínica, avaliação anatomofuncional, avaliação da sucção não nutritiva e nutritiva, a partir disso, o Fonoaudiólogo

\footnotetext{
${ }^{1}$ Fonoaudiologia, Centro Universitário São Miguel, fgadanielle@gmail.com

${ }^{2}$ Fonoaudiologia, Centro Universitário São Miguel, alana.taina@gmail.com

${ }^{3}$ Fonoaudiologia, Centro Universitário São Miguel, eduardo.ramos.fono@gmail.com

${ }^{4}$ Fonoaudiologia, Centro Universitário São Miguel, vytorpaulo78@gmail.com

${ }^{5}$ Mestre em Ciências da Linguagem, Centro Universitário São Miguel, artemisiaveras@ yahoo.com.br
} 
realiza o diagnóstico. Caso seja comprovada anquiloglossia e haja a necessidade de uma intervenção cirúrgica, onde é função exclusiva do cirurgião dentista, a cirurgia será redefinida após uma semana, ou por vezes mais de uma semana, já que atendemos um número considerável de pessoas carentes e algumas delas não possui as condições necessárias para ter um rápido resultado dos exames em mão, são eles: Hemograma, Coagulograma e Glicemia. Os bebês que ainda mamam, após a intervenção cirúrgica, são colocados no peito, pois se observa que além de acalmá-los o leite materno tem ação cicatrizante e diminui o fluxo na região. Os psicólogos são extremamente importantes dando suporte emocional a família, que em maioria desconhecem a técnica utilizada e que os profissionais são capacitados e habilitados na realização da frenotomia, também conhecida como "pique na língua". Entre Janeiro e Setembro foram atendidos 606 crianças, porém desses, entre a faixa etária de 0 a 2 foram atendidos 567 , sendo 350 do sexo masculino e 217 do sexo feminino. Crianças de 0 a 2 anos possuem uma vasta quantidade de células, águas e fibras colágenas no tecido epitelial contribuindo para esta cicatrização espontânea. Observamos que algumas mães conseguem notar a diferença positiva da pega ao peito, tornando a amamentação mais eficaz. É perceptível também uma melhoria na sucção e deglutição do bebê. Geralmente, a maioria das crianças encaminhadas ao projeto são lactentes, crianças acima de dois anos são minoria. Por vezes, o problema não é apenas a presença da anquiloglossia, mas também a falta de estímulo dos pais ou responsáveis, muitos casos a família têm dificuldade de acesso a orientação fonoaudiológica. Os que não são mais dependentes do leite materno recebem uma orientação nutricional.

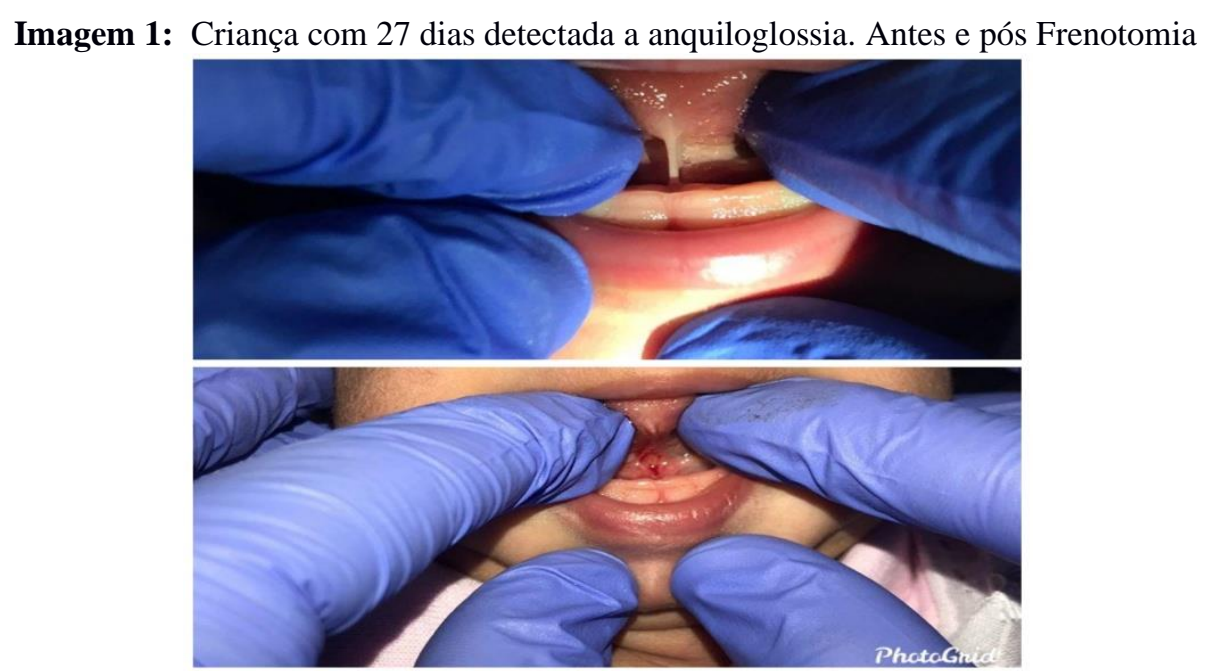

Fonte: Própria (2019)

\section{CONSIDERAÇÕES}

Podemos considerar que os projetos Língua Solta e Teste da Linguinha, é uma via de mão dupla, pois está nos permitindo crescer como estudantes de Fonoaudiologia, além de 
contribuir com a saúde pública promovendo qualidade de vida a população. Externamos nesse relato de experiência a importância da realização do teste da linguinha, não apenas pela sua obrigatoriedade definida pela legislação, mas em virtude da qualidade de vida de crianças e lactentes atendidos.

\section{REFERÊNCIAS}

BRASIL. PL 4832/2012, DE 20 DE JUNHO DO ANO DE 2014. Protocolo de avaliação do frênulo da língua em bebês recém-nascidos - "teste da linguinha", Brasíla, DF, jun 2014. Disponível em: <https://www.camara.leg.br/proposicoesWeb/fichadetramitacao?idProposicao=562681 >. Acesso em: 17 out. 2019.

MARTINELLI RLC, MARCHESAN IQ, BERRETIN-FELIX G Avaliação do frênulo lingual. Rev. CEFAC. 2013 Mai-Jun; 15(3):599-610.

MARTINELLI, ROBERTA LOPES DE CASTRO Validação do Protocolo de avaliação do frênulo da língua em bebês/ Roberta Lopes de Castro Martinelli. - Bauru, 2015. 104 p. :Il.; $30 \mathrm{~cm}$. 


\title{
SERVIÇO DE ATENDIMENTO INTERDISCIPLINAR A PACIENTES COM ALTERAÇÕES CRANIOMANDIBULARES
}

\section{SERVICIO DE ATENCIÓN INTERDISCIPLINARIA PARA PACIENTES CON CAMBIO CRANIOMANDIBULAR}

\section{INTERDISCIPLINARY CARE SERVICE FOR CRANIOMANDIBULAR CHANGE PATIENTS}

\begin{abstract}
Natália de Castro e Silva Martins ${ }^{1}$; Clarissa Evelyn Bandeira Paulino²; Giovanna Siqueira Faustino da Silva $^{3}$; Camilla Thalya da Silva Batista ${ }^{4}$ : Luciana Moraes Studart Pereira ${ }^{5}$
\end{abstract}

DOI: https://doi.org/10.31692/978-65-991061-9-4.107-110

\section{INTRODUÇÃO}

Alterações craniomandibulares podem relacionar-se às alterações na oclusão, lesões traumáticas ou degenerativas da articulação temporomandibular (ATM), além de problemas esqueléticos (SAUERESSIG; JAEGER; GRUNDLING, 2002). Essas desordens podem ser decorrentes de traumas na face, desproporções maxilomandibulares associadas à má-oclusão, problemas posturais e funcionais, disfunção da ATM e musculatura mastigatória (RIZATTIBARBOSA et al., 1997). São condições que demandam adaptações do sistema estomatognático e que, quando ocorrem interligadas, promovem desequilíbrio e comprometimento no desempenho das funções orais (PEREIRA; BIANCHINI, 2011).

Nesse sentido, a Fonoaudiologia, atua colaborando com a reorganização neuromuscular e a reabilitação das funções estomatognáticas (ALÉSSIO; MEZZOMO; KORBES, 2007), podendo contribuir no restabelecimento da respiração, mastigação, deglutição e fala, visando um equilíbrio miofuncional, uma vez que qualquer alteração óssea ou dentária pode interferir nessas funções (CARDOSO, 2009).

A atuação do profissional da Fonoaudiologia em conjunto com a Odontologia pode iniciar no processo de avaliação, possibilitando a identificação das adaptações funcionais decorrentes das desproporções, traumas e/ou dores orofaciais e, sobretudo, auxiliando no direcionamento da terapêutica (STUDART, 2013). No tocante à reabilitação, o trabalho interdisciplinar, visa impedir complicações que possam comprometer a recuperação do paciente e o restabelecimento das funções orais abreviando, dessa forma, o retorno do paciente às

\footnotetext{
${ }^{1}$ Fonoaudióloga Graduada pela Universidade Federal de Pernambuco, natcsmartins@gmail.com

${ }^{2}$ Fonoaudióloga Graduada pela Universidade Federal de Pernambuco, clarissa.bandeirap@gmail.com

${ }^{3}$ Graduanda em Odontologia pela Universidade Federal de Pernambuco, giovsfs@ gmail.com

${ }^{4}$ Fonoaudióloga Graduada pela Universidade Federal de Pernambuco, camillathalyasb@ hotmail.com

${ }^{5}$ Docente do Curso de Fonoaudiologia da Universidade Federal de Pernambuco, luciana.studart@uol.com.br
} 
atividades diárias (STUDART, 2013; CONSTANTINO, 2011).

Nesse sentido, a realização desse projeto possibilita a implementação de atuação interdisciplinar tão necessária à assistência desse grupo de pacientes. O projeto propõe oferecer à comunidade, um serviço de atendimento interdisciplinar a pacientes com alterações craniomandibulares. Além disso, se propõe a realizar avaliação e tratamento em pacientes com deformidades dentofaciais, vítima de trauma de face, dor orofacial e apneia obstrutiva do sono, promover discussão de casos clínicos e favorecer o vínculo interdisciplinar entre as especialidades envolvidas.

\section{RELATO DE EXPERIÊNCIA}

Trata-se de um serviço vinculado a um projeto de extensão, desenvolvido há mais de três anos, ofertado gratuitamente à comunidade, onde são realizados atendimentos interdisciplinares nas áreas de Fonoaudiologia e Odontologia da Universidade Federal de Pernambuco, bem como campanhas públicas. Compõem a equipe: professores e alunos do departamento de Fonoaudiologia, discentes do Curso de Odontologia, além de colaboradores externos - fonoaudiólogos e odontólogos vinculados a serviços de referência na área de cirurgia e traumatologia bucomaxilofacial e dor orofacial.

A participação e atribuições dos estudantes nesse tipo de projeto em conjunto com profissionais e professores nas extensões são de suma importância para sua formação crítica dentro do ambiente acadêmico. Isso porque, a extensão universitária visa uma relação teoriaprática, entre a universidade e sociedade através da prestação de serviços assistencialistas, como oportunidade de troca de saberes (JEZINE, 2004).

A intervenção fonoaudiológica ocorre em uma clínica escola de Fonoaudiologia, em ciclos de 12 sessões, sempre com a presença de estudantes e profissionais das referidas áreas. O público alvo atendido é composto por crianças, adolescentes e adultos vítimas de trauma de face; com desproporções maxilomandibulares, pré e/ou pós cirurgia ortognática; sujeitos com queixa de ronco e/ou apneia obstrutiva do sono; pacientes com dor orofacial e/ou diagnóstico de disfunção temporomandibular e participantes das campanhas de domínio público.

No primeiro contato com o paciente, é realizada uma triagem, onde são coletados os dados pessoais, realizada uma anamnese e a assinatura dos termos de autorização para registros de imagem e compromisso. Os pacientes com demandas urgenciais são encaixados durante os turnos de atendimento e os demais são realocados para a lista de espera. Assim que algum paciente encerra seu ciclo de 12 sessões, os que foram triados são chamados para a primeira sessão. A terapia fonoaudiológica nesses casos visa à adequação das estruturas e funções do 
sistema estomatognático, ocorrendo por meio de exercícios, manobras e orientações específicas para cada indivíduo, trazendo uma repercussão imediata na evolução desses pacientes, com duração média de 40min.

Ao final dos atendimentos ocorrem discussões dos casos clínicos, com vistas na análise dos dados de avaliação e planejamento terapêutico para cada paciente, bem como na formação dos graduandos. É importante destacar que se necessário, são realizados encaminhamentos a outras especialidades. Com o objetivo de se manter o serviço em constante avaliação, os pacientes são convidados a preencher questionário de satisfação por volta da quarta sessão.

O projeto atinge um grande quantitativo de público-alvo, atendendo cerca de 90 pacientes e aproximadamente 450 atendimentos ambulatoriais por ano. Além disso, existem outros produtos, como por exemplo, as apresentações de trabalhos em congressos nacionais com publicação em anais e premiação de alguns trabalhos publicados (TABELA1). Nesse sentido, o Plano Nacional de Extensão afirma que a extensão universitária, que articula o ensino com a pesquisa, facilita a comunicação e divulga a ciência, levando à sociedade o saber desenvolvido e acumulado, decodificando-o para o público (NUNES; SILVA, 2011).

Tabela 1. Ações desenvolvidas no projeto de extensão Craniomandibular Inter

\begin{tabular}{lc}
\hline \multicolumn{1}{c}{ Produtos } & Quantidade \\
\hline Organização de campanhas & 05 \\
Apresentações em eventos científicos & 28 \\
Publicações em anais ou revistas científicas & 04 \\
Premiações em eventos científicos & 04 \\
Trabalhos de conclusão de curso (graduação) & 04 \\
Trabalhos de conclusão de curso (especialização) & 01 \\
Projetos de extensão vinculados & 03 \\
Projetos de iniciação científica & 04 \\
\hline
\end{tabular}

\section{CONSIDERAÇÕES}

Considera-se que a atuação fonoaudiológica em parceria com as referidas especialidades proporciona melhor entendimento sobre os problemas craniomandibulares e a reabilitação dos pacientes relacionada às performances das funções estomatognáticas. No que concerne à assistência, o projeto vem atingindo todos os objetivos, pois se observa repercussão imediata na evolução dos pacientes atendidos, identificada por meio de avaliações clínicas específicas e relatos dos próprios usuários. Além disso, o projeto oportuniza, aos graduandos, o aprendizado sobre a importância do trabalho interdisciplinar.

\section{REFERÊNCIAS}

ALÉSSIO, C.V; MEZZOMO, C.L; KORBES, D. Intervenção fonoaudiológica nos casos de 
pacientes classe III com indicação à cirurgia ortognática. Arquivos em Odontologia. v. 43, n. 3, p. 102-110, 2007.

CARDOSO, R.M. Cirurgia Ortognática: Orientações Ortodônticas. Recife: Int J Dent. v. 8, n. 2, p. 94-97, 2009.

CONSTANTINO, D.R et al. Possibilidade de atuação do fonoaudiólogo nos Traumas de face. In: Santos-Coluchi GG, Viana RS, Souza LBR (org.). Ortodontia e Fonoaudiologia na prática clínica. Rio de Janeiro: Revinter. 2011.

JEZINE, E. As Práticas Curriculares e a Extensão Universitária. Anais do $\mathbf{2}^{\circ}$ Congresso Brasileiro de Extensão Universitária. 2004.

NUNES, A.L.P.F; SILVA, M.B.C. A extensão universitária no ensino superior e a sociedade. Mal-Estar e Sociedade - Ano IV. Barbacena - julho/dezembro, 2011. n. 7, p. 119-133.

PEREIRA, J.B.A; BIANCHINI, E.M.G. Características das funções estomatognáticas e disfunções temporomandibulares pré e pós-cirurgia ortognática e reabilitação fonoaudiológica da deformidade dentofacial classe II esquelética. Rev. CEFAC. v.13, n. 6, p.1086-1094, 2011.

RIZATTI-BARBOSA, C.M. et al. Disfunções Craniomandibulares: Tratamento, Interdisciplinar Desenvolvido na Faculdade de Odontologia de Piracicaba/Unicamp. Rev. Bras. Fisiot. v. 2, n. 2, p. 67-70, 1997.

STUDART, L. Avaliação fonoaudiológica na cirurgia ortognática. In: Klein D, Justino H, Marchesan, I, Andrade, I, Brasil L, Pinto M, Tessitore A (org.) Avaliação em motricidade orofacial: discussão de casos clínicos. São José dos Campos: Pulso. p.157-72, 2013. 


\title{
USO DE DROGAS LÍCITAS E ILÍCITAS NA GRAVIDEZ: A IMPORTÂNCIA DOS ESCLARECIMENTOS DOS RISCOS AS GESTANTES
}

\author{
USO DE DROGAS LICITAS E ILICITAS EN EL EMBARAZO: LA IMPORTANCIA \\ DE ACLARAR LOS RIESGOS PARA LAS MUJERES EMBARAZADAS
}

\section{USE OF LICIT AND ILLICIT DRUGS IN PREGNANCY: THE IMPORTANCE OF RISK CLAIMS AS PREGNANT}

\author{
Larissa Tainá ${ }^{1}$; Deyse Aíla ${ }^{2}$; Alessandra Alves ${ }^{3}$; Laniedja Jacó ${ }^{4}$; Robervam Pedroza ${ }^{5}$
}

DOI: https://doi.org/10.31692/978-65-991061-9-4.111-114

\section{INTRODUÇÃO}

O período gestacional é caracterizado como fase de diversas transformações físicas e psicológicas na mulher. Segundo Leitão (1998) a gravidez requer um esforço suplementar de síntese e de reorganização da estabilidade, do qual pode resultar um acréscimo de vulnerabilidade, capaz de constituir um fator de risco para a saúde mental da mulher. Alguns fatores adversos como gravidez não planejada, situação econômica frágil, família desestruturada podem levar essas mulheres a procurarem as drogas como forma de fugir da realidade. As drogas são caracterizadas como qualquer substância que ao ser introduzida no organismo causa uma alteração no mesmo.

O projeto buscou conhecer melhor as drogas lícitas e ilícitas e suas implicações do uso durante a gravidez, a partir do estudo das propriedades dessas substâncias, o perfil socioeconômico demográfico dessas mulheres, bem como o acompanhamento dos processos do parto, nascimento e no crescimento e desenvolvimento da criança. Sendo assim, a pesquisa trouxe possibilidades de lidar com essas mulheres nas situações que visam à promoção da saúde e prevenção de agravos, através de ações educativas, com a perspectiva de sensibilização quanto aos riscos que o álcool e as outras drogas podem causar ao binômio mãe-filho.

É de extrema importância que esse público obtenha informações e acompanhamento adequado para redução de danos e o uso seja desestimulado e minimizado, evitando assim complicações, tanto na gravidez quanto no parto e puerpério. A cidade onde foi desenvolvida a pesquisa ainda não possui na sua rede serviços de saúde voltados para a promoção, prevenção e reabilitação para o uso de substâncias psicoativas (álcool e outras drogas ilícitas), nem tampouco a modalidade de Centro de Atenção Psicossocial voltado para álcool e outras drogas

\footnotetext{
${ }^{1}$ Bacharelado em Enfermagem, IFPE, LALAPERFA29@gmail.com

2 Bacharelado em Enfermagem, IFPE, deyramalho99@gmail.com

${ }^{3}$ Bacharelado em Enfermagem, IFPE, alessandraalveslins14@gmail.com

${ }^{4}$ Bacharelado em Enfermagem, IFPE, lanypocao@gmail.com

${ }^{5}$ Mestre em Saúde da Família, IFPE, robervam@pesqueira.ifpe.edu.br
} 
(CAPS-AD). Por conseguinte, essa população fica em situação de vulnerabilidade, dada a escassez de serviços na rede, bem como as limitações das equipes de saúde da família em suprir a atenção necessária a todas as mulheres envolvidas. O público-alvo foram as gestantes que fazem uso de drogas lícitas e ilícitas, com finalidade de identificar e analisar as condições de saúde materno- filial associado aos riscos do uso das drogas durante a gravidez. O estudo foi desenvolvido na cidade de Pesqueira, Pernambuco, na Unidade Básica de Saúde (UBS), localizada no bairro São Francisco.

\section{RELATO DE EXPERIÊNCIA}

A pesquisa foi classificada como descritiva e exploratória desenvolvida na Unidade Básica de Saúde São Francisco no período de fevereiro a dezembro de 2018, localizada na cidade de Pesqueira em Pernambuco.

O projeto foi apresentado na Secretaria de Saúde de Pesqueira, na qual foram identificadas as potenciais gestantes da UBS. A partir de então, foi feita a apresentação para as enfermeiras e toda a equipe da UBS. Com o intuito de uma melhor organização da pesquisa foi estabelecido como critério de inclusão no estudo: ser gestante cadastrada na Unidade Básica de Saúde (UBS) São Francisco e que fizesse uso de drogas lícitas ou ilícitas no período gestacional ou puerperal. Assim como critério de exclusão ser gestante que não estivessem cadastradas na Unidade Básica de Saúde (UBS) São Francisco.

A partir do primeiro contato com as gestantes, público-alvo do projeto de extensão, percebeu-se as dificuldades de acesso. Diante dessa situação fez-se necessário estabelecer vínculos, com as gestantes, primeiro apresentando o projeto e depois através de ações educativas de saúde, como oficinas de musicoterapias, rodas de conversas apresentando quais os riscos e agravos que as drogas podem causar, tirando dúvidas apresentadas por elas, troca de saberes, oficina sobre manobras de primeiros socorros em bebês, abordando sobre alimentação saudável, além de outros temas relacionados à gravidez. Para fins de consolidação das atividades e para otimizar o registro, as atividades eram resumidas em um diário de campo, com base nas rodas de conversa e nas demais atividades desenvolvidas entre os extensionistas, profissionais e as gestantes.

Através de rodas de conversa com as gestantes cadastradas na UBS São Francisco foram identificadas as necessidades de esclarecimentos sobre os riscos e consequências para binômio mãe-filho que o uso de drogas lícitas e ilícitas ocasionaria.

Com o apoio da equipe foram realizadas ações educativas com ênfase na prevenção do uso de drogas lícitas e ilícitas, além de enfatizar a importância do acompanhamento regular no 
pré-natal.

\section{CONSIDERAÇÕES}

O uso de drogas lícitas e ilícitas no período gestacional ainda é um grave problema de saúde pública, precisa ser averiguado desde o pré-natal para que os profissionais de saúde possam informar as mães, pais e familiares sobre os riscos e consequências para binômio. Assim faz-se necessário o embasamento de estratégias especificas de repasse de informações, qualificação de profissionais, ações conjuntas de equipes multiprofissionais com o mesmo intuito, bem como, a correlação com a literatura que faz alusão à temática e dessa forma possam ser amenizados os efeitos nocivos, de modo a garantir uma boa qualidade de vida para o bebê, a mãe e sua família.

Quanto ao município onde foi o cenário do trabalho, é importante que a gestão municipal aborde mais o tema e o difunda nas demais unidades, haja vista que a problemática uma dimensão sistêmica e não pontual. Dessa forma, uma estratégia importante seria uma política de educação e promoção à saúde mais abrangente para que a temática fosse articulada em todas as unidades.

Há de se considerar que o município não possui nenhum serviço especializado de saúde que atenda essa demanda, ficando a cargo das unidades de saúde da família o acompanhamento dessas usuárias do serviço com todas as fragilidades que a rede já possui, sobretudo para os indivíduos que fazem uso inadequado de álcool e outras substâncias psicoativas.

A instituição de ensino, no exercício do seu papel de educar e formar, tem se inserido no contexto dos serviços, aproximando da realidade dos serviços para fortalecer o SUS municipal. Dessa forma pode colaborar com a gestão municipal na elaboração de políticas que melhore a qualidade de vida dos cidadãos, e em especial, as gestantes que fazem uso dessas substâncias, através das atividades de ensino, de pesquisa e de extensão.

\section{REFERÊNCIAS}

ANGELUCCI, Mateus A. Exposição ao álcool na gestação e sintomas psiquiátricos na idade escolar. 2010. 85p. Dissertação (Mestrado) - Universidade de São Paulo - Faculdade de Ciências Farmacêuticas, Ribeirão Preto, 2010. Disponível em: file://C:/Users/2351691/Downloads/dissertacao_original\%20(2).pdf. Acesso em: 08/12/2018.

BRASIL. Ministério da Saúde. Secretaria de Atenção à Saúde. Pré-Natal e Puerpério: atenção qualificada e humanizada: manual técnico. Brasília, 2006. Disponível em: http://bvsms.saude.gov.br/bvs/publicacoes/manual_pre_natal_puerperio_3ed.pdf. Acesso em: $10 / 12 / 2018$. 
BRASIL. Ministério da Saúde. Secretaria de Vigilância em Saúde. Plano emergencial de combate ao uso nocivo de álcool e outras drogas. Brasília, DF; 2010. Disponível em: http://bvsms.saude.gov.br/bvs/sus/pdf/junho/MS_plano_emergencial_combate_uso_alcool_dr ogas_0406.pdf. Acesso em 11/10/2018.

CERVO, Amado L. Metodologia Científica. São Paulo: Pearson Prentice Hall, 2007.

LEITÃO, M. L. H. A Gravidez de Alto Risco Genético: contributo para a compreensão dos fenómenos psicológicos envolvidos. 1998. Tese de Mestrado em Psicologia Clínica do Desenvolvimento não publicada, Faculdade de Psicologia e de Ciências da Educação da Universidade de Coimbra.

McDERMOTT, R.; CAMPBEL, S.; LI, M.; McCULLOCH, B. The health and 4. nutrition of young indigenous women in north Queensland - intergenerational implications of poor food quality, obesity, diabetes, tobacco smoking and alcohol use. Public Health Nutr. v.11, n.6, p.1-7, 2009.

SEGRE, C. A.M. Efeitos do álcool na gestante, no feto e no recém-nascido. São Paulo: Sociedade de Pediatria de São Paulo, 2010.

YAMAGUCHI, Eduardo T.; CARDOSO, Monica M. S. C.; TORRES, Marcelo L. A.; ANDRADE, Arthur G. Drogas de Abuso e Gravidez. Revista de Psiquiatria Clínica, São Paulo, v. 35, 2008. Disponível em: http://www.scielo.br/scielo.php?script=sci_arttext\&pid= S0101-60832008000700010. Acesso em: 08/12/2018. 


\title{
PLANTAS MEDICINAIS UTILIZADAS NO NORDESTE DO BRASIL: UMA REVISÃO DE LITERATURA
}

\author{
PLANTAS MEDICINALES UTILIZADAS EN EL NORESTE DE BRASIL: UNA \\ REVISIÓN DE LA LITERATURA
}

\section{MEDICINAL PLANTS USED IN NORTHEASTERN BRAZIL: A LITERATURE REVIEW}

\author{
Zion Nascimento de Souza'; Bárbara Rafaela da Silva Barros²; Kaline Soares da Silva ${ }^{3}$; Ricardo Sérgio da \\ Silva ${ }^{4}$; Cristiane Moutinho Lagos de Melo ${ }^{5}$.
}

DOI: https://doi.org/10.31692/978-65-991061-9-4.115-132

\begin{abstract}
RESUMO
A região Nordeste do Brasil possui uma extensão de aproximadamente $1.558 .000 \mathrm{~km}^{2}$ de território, destacando-se a sua vasta diversidade de espécies vegetais, climas e hábitats. A diversidade florística dessa região, tem proporcionado uma grande variedade de plantas que são utilizadas por diversos grupos, como: ribeirinhos, pescadores, agricultores, indígenas e comunidades rurais, para o tratamento e prevenção de diversas doenças. Esse conhecimento da medicina popular, tem chamado a atenção de diversos pesquisadores em todo o mundo, a fim de testarem a eficácia e a veracidade por trás dos benefícios aparentemente verídicos, no tratamento dessas doenças. Dessa forma, o presente estudo tem como objetivo a análise e discussão a respeito das plantas medicinais mais utilizadas no Nordeste brasileiro. E para isso, foi realizada uma análise qualitativa, quanto a importância e uso de tais plantas, na região Nordeste do Brasil. Através da análise de 104 artigos das plataformas Scielo, Pubmed e Google Acadêmico, datados entre 2009 e 2019. Como resultado, foram identificadas 20 espécies de plantas pertencentes a 17 famílias e as informações a respeito do seu uso medicinal foram relatadas em todas as regiões. Também é importante destacar a grande importância e potencial de aplicação das plantas medicinais do Nordeste do Brasil para o tratamento de enfermidades com seu uso popular e sua utilização para a produção de fármacos, aliado às futuras investigações biológicas voltadas aos benefícios e ao controle de segurança necessário para os devidos usos.
\end{abstract}

Palavras-Chave: Etnofarmacologia; plantas medicinais; potencial terapêutico; região nordeste.

\section{RESUMEN}

La región Nordeste de Brasil tiene una extensión aproximada de 1,558,000km² de territorio, destacando su gran diversidad de especies vegetales, climas y hábitats. La diversidad florística de esta región ha proporcionado una amplia variedad de plantas que son utilizadas por diferentes grupos, tales como: ribereños, pescadores, agricultores, indígenas y comunidades rurales, para el tratamiento y prevención de diversas enfermedades. Este conocimiento de la medicina popular ha llamado la atención de varios investigadores alrededor del mundo, con el fin de probar la efectividad y veracidad detrás de los aparentemente verdaderos beneficios, en el tratamiento de estas enfermedades. Así, el presente estudio tiene como objetivo analizar y discutir las plantas medicinales más utilizadas en el noreste de Brasil. Y para eso, se realizó un

\footnotetext{
${ }^{1}$ Bacharelado em Biomedicina, UFPE, zionnascimento@ hotmail.com

${ }^{2}$ Mestranda em Ciências Biológicas, UFPE, barbarabarrosbio@ gmail.com

${ }^{3}$ Bacharelado em Agronomia, INACAP/ IFPE, kalis.soares8@gmail.com

${ }^{4}$ Mestre em Morfotecnologia, UFPE, profricardosergio.bio@gmail.com

${ }^{5}$ Doutora em Ciências Biológicas, UFPE, cristianemout@gmail.com
} 
análisis cualitativo, sobre la importancia y uso de tales plantas, en la región Nordeste de Brasil. Mediante el análisis de 104 artículos de las plataformas Scielo, Pubmed y Google Acadêmico, fechados entre 2009 y 2019. Como resultado, se identificaron 20 especies de plantas pertenecientes a 17 familias y se reportó información sobre su uso medicinal en todas las regiones. También es importante resaltar la gran importancia y potencial de la aplicación de plantas medicinales en el noreste de Brasil para el tratamiento de enfermedades con su uso popular y su uso en la producción de medicamentos, combinado con futuras investigaciones biológicas dirigidas a los beneficios y el control de seguridad necesario. para usos adecuados.

Palabras clave: Etnofarmacología; plantas medicinales; potencial terapéutico; región nordeste.

\section{ABSTRACT}

The Northeast region of Brazil has an extension of approximately 1,558,000 $\mathrm{km}^{2}$ of territory, highlighting its vast diversity of plant species, climates and habitats. The floristic diversity of this region has provided a wide variety of plants that are used by several groups, such as: Riverside, fishermen, farmers, indigenous people and rural communities, for the treatment and prevention of various diseases. This knowledge of popular medicine has called the attention of several researchers around the world, in order to test the efficacy and truthfulness behind the seemingly true benefits in the treatment of these diseases. This way, the present study aims to analyze and discuss the most used medicinal plants in northeastern Brazil. In order to do this, a qualitative analysis was performed regarding the importance and use of such plants in the northeast region of Brazil. Through the analysis of 104 articles of the platforms Scielo, Pubmed and Scholar Google, dated between 2009 and 2019. As a result, 20 species of plants belonging to 17 families were identified and information about their medicinal use was reported in all regions. It is also important to highlight the great importance and potential application of medicinal plants in northeastern Brazil for the treatment of diseases with their popular use and their use for the production of drugs, allied to future biological investigations to the benefits and safety control required for proper uses.

Keywords: Ethnopharmacology; medicinal plants; northeast region; therapeutic potential.

\section{Introdução}

O Brasil é o país mais rico do mundo em biodiversidade terrestre, pois abriga cerca de 20\% das espécies animais, vegetais e de microrganismos do planeta (Nogueira et al., 2010).

A região Nordeste do país é marcada por um intenso uso etnofarmacológico de diferentes plantas por populações de comunidades locais. Esse conhecimento tradicional é passado através das gerações e observa-se que existe um amplo conhecimento sobre métodos alternativos usados para curar ou aliviar sintomas de algumas doenças (Baptistel et al. 2014). A interação entre conhecimento tradicional e indústria farmacêutica originou a fitoterapia, entendida como o tratamento com plantas medicinais ou com seus derivados farmacológicos (Firmo et al., 2011).

Segundo a Organização Mundial da Saúde (OMS), planta medicinal é considerada todo e qualquer vegetal que possui, em um ou mais órgãos, substâncias que podem ser utilizadas para fins terapêuticos ou que sejam precursores de fármacos semissintéticos. O emprego de plantas medicinais para a manutenção e a recuperação da saúde tem ocorrido ao longo dos 
tempos utilizando-se formas simples de administração, como chás, decocções, infusões e macerados. A possibilidade de desvendar a estrutura e o funcionamento dessas moléculas bioativas desperta o interesse de diversas áreas da pesquisa (Lana et al., 2010).

De fato, no Brasil, estima-se que $25 \%$ do faturamento da indústria farmacêutica são originados de medicamentos derivados de plantas (Brasil, 2016).

Os seres humanos têm usado as plantas para fins medicinais devido ao vasto rol de compostos químicos sintetizados pelas mesmas (Petrovska, 2012), dentre eles, estão os metabólitos secundários, estes compostos são geralmente sintetizados pelas plantas de acordo com as suas necessidades específicas, que incluem as condições ambientais, as interações com outras plantas e a proteção contra predadores (Savithramma et al., 2011). No entanto, na vida humana, estes compostos podem ser utilizados como medicamentos (princípios ativos ou excipientes), aromatizantes ou corantes. Esses metabólitos possuem atividades biológicas marcantes e, diferentemente dos metabólitos primários, apresentam-se em baixas concentrações. Embora muitos dados científicos afirmem que os metabolitos secundários não desempenham um papel crucial para o crescimento, desenvolvimento e reprodução das células vivas, eles são fundamentais na defesa e proteção da planta contra qualquer dano ecológico (Samuni-Blank et al., 2012). De uma maneira geral os principais metabólitos encontrados e estudados são os compostos fenólicos (ácidos fenólicos, taninos e flavonoides), alcalóides, terpenóides e compostos nitrogenados (Ferreira,2012).

Baseado nas propriedades citadas anteriormente e na importância do uso das plantas medicinais pela população da região nordeste, o presente estudo visa expor os benefícios e potenciais usos das mesmas. Com isso, é possível promover o uso correto e apresentar a relação dessas plantas com os estados da região nordeste e sua real importância para com a promoção da saúde.

\section{Fundamentação Teórica}

Os metabólitos secundários extraídos das plantas são subdivididos em três classes principais: terpenoides, alcalóides e compostos fenólicos, os quais apresentam atividade farmacológica interessante (Pal et al., 2014; Pereira et al., 2016; Savithramma et al., 2011). Além disso, alguns estudos têm demonstrado que esses metabólitos possuem também ações anti-inflamatória, antimicrobiana, cicatrizante e antitumoral (Kowalski et al., 2005; Bankeu et al., 2017; Smiljkovic et al., 2017; Zhao et al., 2017).

Embora muitas plantas tenham seu valor medicinal reconhecido, que está em constante comprovação científica, a cultura popular colabora com o uso indiscriminado de plantas 
medicinais no contexto da automedicação, exigindo o estudo de seus constituintes, o mecanismo de ação terapêutica e a identificação de princípios ativos responsáveis pelas diversas atividades biológicas relatadas pela população (Ford et al., 2014). Nesse sentido, o objetivo deste estudo foi identificar as principais plantas medicinais utilizadas na região Nordeste do Brasil e suas propriedades biológicas cientificamente comprovadas.

\section{Metodologia}

A pesquisa é de natureza qualitativa e foi realizada durante o primeiro semestre de 2019. O campo de pesquisa foi constituído por análises de artigos localizados na plataforma Google Acadêmico, Plataforma PubMed e Scielo, com o objetivo de reunir dados sobre as Plantas Medicinais mais utilizadas na medicina popular da Região Nordeste do Brasil. Além disso, ainda foram consultados dados do Ministério da Saúde do Brasil e das Secretarias de Saúde dos nove estados da região estudada- Alagoas, Bahia, Ceará, Maranhão, Paraíba, Pernambuco, Piaú́, Rio Grande do Norte e Sergipe- com o intuito de enumerar e confirmar a presença e utilização das plantas em cada localidade e seu impacto nas respectivas populações.

Foram realizadas diversas pesquisas nas plataformas acadêmicas para a aquisição de informações, posteriormente foram montadas tabelas para a análise do material coletado. Os critérios de inclusão foram voltados aos artigos publicados nos últimos 10 anos (entre 2009 e 2019), onde foram utilizadas palavras chave como: plantas medicinais, Nordeste do Brasil, etnofarmacologia, fitoterápicos e doenças tratadas por plantas. Artigos publicados fora da margem dos 10 anos escolhidos, além dos que incluíam discussão sobre a utilização das mesmas plantas em outras regiões do país, não foram considerados para a pesquisa.

A região inserida para a análise, possui uma extensão de aproximadamente 1.558 .000 $\mathrm{km}^{2}$ de território e uma população 53.081.950, segundo dados do Instituto Brasileiro de Geografia e Estatística (IBGE) e compreende nove estados, sendo eles: Alagoas, Bahia, Ceará, Maranhão, Paraíba, Pernambuco, Piauí, Rio Grande do Norte e Sergipe. Além disso, ainda é válido ressaltar a grande variedade de vegetações e clima na região analisada no presente estudo, o que reflete na grande diversidade de plantas e características das mesmas. 
Figura 1: Metodologia aplicada durante o processo de seleção dos artigos incluídos no trabalho.

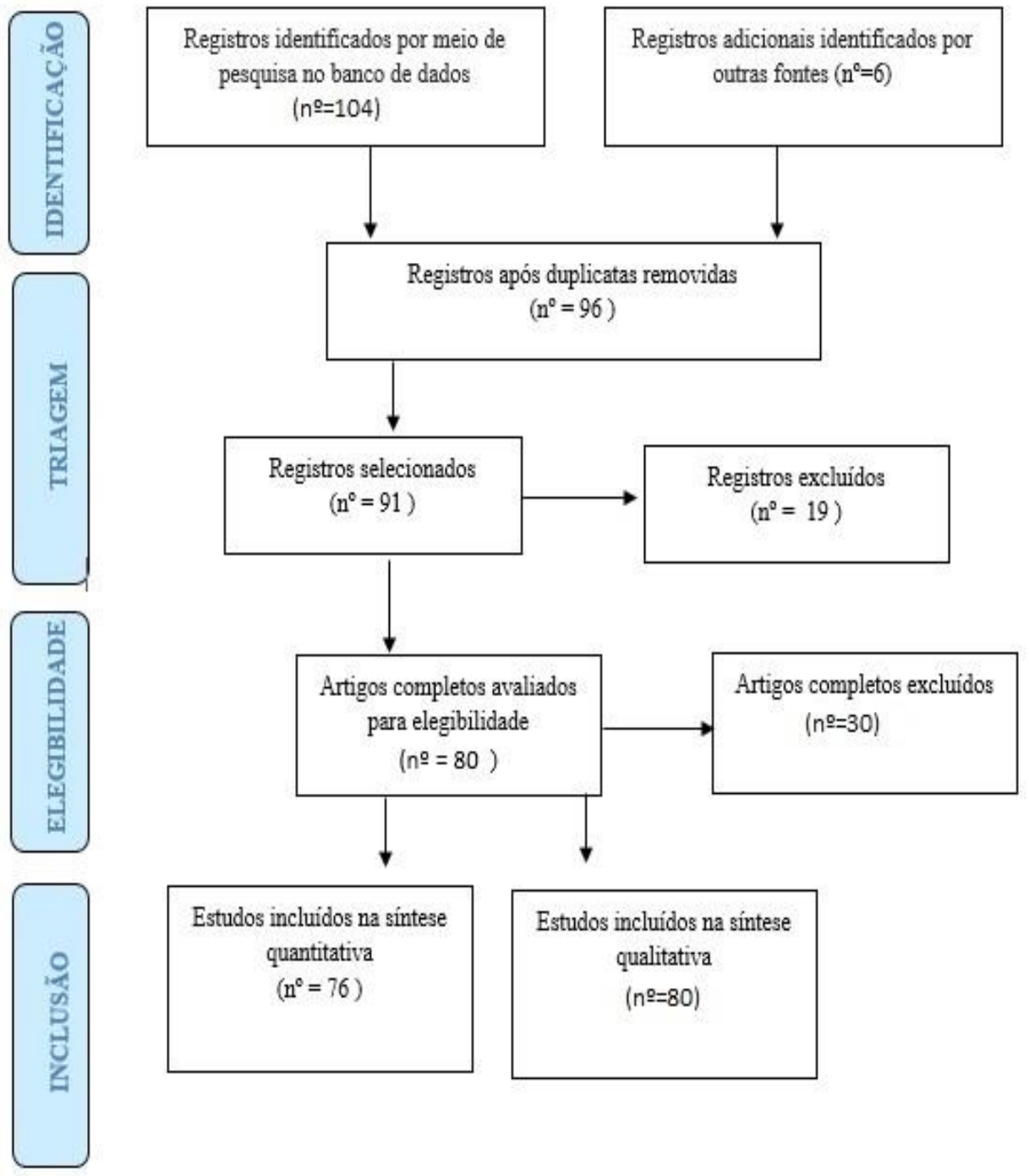

Fonte: Própria

\section{Resultados e discussão}

De acordo com a pesquisa realizada foi possível confirmar as plantas mais utilizadas no tratamento de doenças por comunidades localizadas na Região Nordeste do Brasil (Tabela 1).

Tabela 1: Plantas medicinais utilizadas nos estados da Região Nordeste

\begin{tabular}{|c|c|c|c|c|c|}
\hline $\begin{array}{c}\text { NOME } \\
\text { POPULAR }\end{array}$ & $\begin{array}{c}\text { NOME } \\
\text { CIENTÍFICO }\end{array}$ & $\begin{array}{c}\text { UTILIZAÇÃO } \\
\text { POPULAR }\end{array}$ & FAMÍLIA & $\begin{array}{c}\text { PARTE } \\
\text { UTILIZADA }\end{array}$ & AUTOR \\
\hline Erva cidreira & Lippia alba & $\begin{array}{l}\text { Calmante, cólicas } \\
\text { intestinais, febre. }\end{array}$ & Verbenaceae & Folhas & $\begin{array}{l}\text { Lima, et al } \\
\text { (2016) }\end{array}$ \\
\hline Romã & Punica granatum $L$ & $\begin{array}{l}\text { Gastrite, garganta } \\
\text { inflamada, tosse. }\end{array}$ & Lythraceae & $\begin{array}{l}\text { Semente } \\
\text { e casca }\end{array}$ & $\begin{array}{c}\text { Nascimento } \\
\text {, et. al } \\
\text { (2013) }\end{array}$ \\
\hline
\end{tabular}




$\begin{array}{cc}\text { Jatobá } & \begin{array}{c}\text { Hymenaea courbaril } \\ \text { L. }\end{array} \\ \text { Eucalipto } & \begin{array}{c}\text { Eucalyptus } \\ \text { globulus }\end{array} \\ \text { Capim-Santo } & \begin{array}{c}\text { Cymbopogon } \\ \text { citratus }\end{array} \\ \text { Mastruz } & \begin{array}{c}\text { Chenopodium } \\ \text { ambrosioides L }\end{array} \\ \text { Babosa } & \begin{array}{c}\text { Aloe vera } \\ \text { Arruda }\end{array} \\ \text { Aroeira } & \begin{array}{c}\text { Muta graveolens } \\ \text { urundeuva }\end{array} \\ \text { Alecrim } & \begin{array}{c}\text { Rosmarinus } \\ \text { officinalis L. }\end{array}\end{array}$

Camomila Matricaria recutita

Catuaba Anemopaegma sp

$\begin{array}{cc}\text { Quebra- } & \text { Phyllanthus niruri } \\ \text { pedra } & L\end{array}$

Cumaru

Macaíba

Alfavaca
Tosse, aumenta o sangue, gripe, anemia.

Febre, garganta

inflamada, asma, gripe, congestão nasal.

Dor abdominal e reumática, alteração digestiva, calmante, febre, tosse e dor de cabeça.

Gripe, doenças respiratórias, vasculares, gastrointestinais, endócrinas. Cicatrizante, antibacteriana, antifúngica e antivirótica.

Cólicas e problemas oculares.

Cicatrizante, antiinflamatória, dor de dente.

Calmante, reumatismo, prisão de ventre, bronquite, gripe, coração.

Anti-inflamatória, espasmolítica, sedativa, antibacteriana e antifúngica.

Tônica, estimulante energética,

antioxidante, antiinflamatória e antimicrobiana. Pedras nos rins e pedras na vesícula, alívio da azia, antiviral, diminuição do açúcar no sangue, proteção do fígado.

Cardiotônica, antiespasmódica, antiasmático,antiinflamatória,

Analgésica, bronco dilatadora.

Expectorante, suplemento alimentar.

Adstringente, antioxidante, antimutagênico, antibacteriano, antiinflamatório e antiviral.

Folhas
Fabaceae

Casca

Nascimento

, et. al

Myrtaceae

Folhas, casca e

Oliveira, et. caule al (2015)

Poaceae

Folhas

Santos, et al (2009)

Amaranthaceae

Folhas

Silva, et al (2015)

Bach;

Xanthorrhoeaceae Folhas

Lopes

Rutaceae

Folhas

Barbosa et al (2000)

Anacardiaceae Folhas

Brandão et al (2008)

Folhas, caule e raiz

Wang et al (2008)

Mazokopak is et al (2005)

Bignoniaceae Folhas e flores

Zanolari et al (2005)

Euphorbiaceae

Marques et al (2010)

Fabaceae

Sementes, flores e

Silveira cascas (2003)

Arecaceae

Fruto

Rocha et al. (2008)

Abdeslam

Lamiaceae

Folhas e flores gratissimum $L$

et al., (2007) 


\begin{tabular}{|c|c|c|c|c|c|}
\hline Açafrão & Crocus sp & $\begin{array}{l}\text { Anti-inflamatório, } \\
\text { antioxidante, antiviral, } \\
\text { antibacteriana e } \\
\text { antifúngica. }\end{array}$ & Iridaceae & Raiz & $\begin{array}{l}\text { He et al. } \\
(2015)\end{array}$ \\
\hline Canela & $\begin{array}{c}\text { Cinnamomum } \\
\text { zeylanicum Blume }\end{array}$ & $\begin{array}{c}\text { Antibacteriana, } \\
\text { antiviral, antifúngica e } \\
\text { antioxidante. }\end{array}$ & Lauraceae & Casca & $\begin{array}{c}\text { Guerra et al } \\
\text { (2012) }\end{array}$ \\
\hline Louro & Laurus nobilis L. & $\begin{array}{c}\text { Desobstruente, } \\
\text { estimulante, } \\
\text { expectorante, hepática. }\end{array}$ & Lauraceae & Folhas & $\begin{array}{l}\text { Sellami et } \\
\text { al (2011) }\end{array}$ \\
\hline Boldo & $\begin{array}{l}\text { Peumus boldus } \\
\text { Mol. }\end{array}$ & $\begin{array}{c}\text { Diurética, } \\
\text { antiespasmódica, anti- } \\
\text { séptica, antibacteriana, } \\
\text { anti-inflamatória, } \\
\text { antioxidante, } \\
\text { desintoxicante, } \\
\text { vermífuga. }\end{array}$ & Monimiaceae & Folhas & $\begin{array}{c}\text { Quezada et } \\
\text { al (2004) }\end{array}$ \\
\hline
\end{tabular}

Fonte: Própria

Com a análise das informações do Ministério da Saúde e das Secretarias de Saúde dos estados incluídos na pesquisa, foram destacadas as plantas estudadas e a sua distribuição pela região Nordeste, com isso, foi possível relacionar os estados com as respectivas plantas comumente presentes e mais utilizadas para fins terapêuticos em todos os Estados da Região Nordeste, como é exposto na tabela 2.

Tabela 2: Relação da incidência das Plantas Medicinais nos estados nordestinos.

\begin{tabular}{|c|c|c|}
\hline ESTADO & $\begin{array}{l}N^{\circ} \text { DE PLANTAS } \\
\text { ENCONTRADAS }\end{array}$ & PLANTAS ENCONTRADAS \\
\hline Alagoas & 7 & $\begin{array}{c}\text { Eucalipto, Mastruz, Babosa, Arruda, Aroeira, } \\
\text { Alecrim, Quebra-Pedra. }\end{array}$ \\
\hline Bahia & 7 & $\begin{array}{l}\text { Erva-Cidreira, Capim-Santo, Mastruz, } \\
\text { Aroeira, Quebra-Pedra, Alfavaca, Canela. }\end{array}$ \\
\hline Ceará & 12 & $\begin{array}{l}\text { Erva-Cidreira, Romã, Eucalipto, Capim- } \\
\text { Santo, Mastruz, Babosa, Aroeira, Alecrim, } \\
\text { Quebra-Pedra, Cumaru, Alfavaca, Açafrão. }\end{array}$ \\
\hline Maranhão & 13 & $\begin{array}{c}\text { Erva-Cidreira, Aroeira, Romã, Eucalipto, } \\
\text { Capim-Santo, Mastruz, Babosa, Arruda, } \\
\text { Camomila, Quebra-Pedra, Alfavaca, Canela, } \\
\text { Boldo. }\end{array}$ \\
\hline
\end{tabular}


Piauí

9

Pernambuco

16

Paraíba

9

Rio Grande do Norte

Sergipe

Erva-Cidreira, Romã, Eucalipto, Mastruz, Babosa, Aroeira, Arruda, Quebra-Pedra, Boldo.

Erva-Cidreira, Romã, Jatobá, Capim-Santo, Mastruz, Babosa, Arruda, Aroeira, Alecrim, Camomila, Quebra-Pedra, Macaíba, Alfavaca, Canela, Louro, Boldo.

Erva-Cidreira, Romã, Capim-Santo, Mastruz, Aroeira, Camomila, Quebra-Pedra, Cumaru, Boldo.

Erva-Cidreira, Mastruz, Camomila, Arruda, Aroeira, Eucalipto, Babosa, Arruda, QuebraPedra, Alfavaca, Canela, Louro, Boldo, Romã.

Erva-Cidreira, Romã, Eucalipto, CapimSanto, Babosa, Arruda, Aroeira, Alecrim, Catuaba, Quebra-Pedra, Canela, Louro, Boldo.

Fonte: Própria

Entre as plantas relatadas com uso medicinal na Região Nordeste do Brasil, destacamse as que possuem relatos de utilização em todos os estados estudados. São elas: Aroeira (Myracrodruon urundeuva), Mastruz (Chenopodium ambrosioides L.) e Quebra-pedra (Phyllanthus amarus Schumach.), sendo estas utilizadas popularmente para o tratamento algumas enfermidades como processos inflamatórios, problemas respiratórios, gripe, úlcera, dor no fígado e pedra nos rins respectivamente.

As folhas de Myracrodruon urundeuva (aroeira) são muito utilizados na medicina popular em forma de chá para problemas de natureza inflamatória, além disso, o chá é também muito utilizado para lavagem de feridas, para a cicatrização (Brandão et al., 2008). Há também alguns relatos na literatura, que afirmam o potencial efeito cicatrizante e analgésico da $M$. urundeuva em problemas odontológicos, confirmando os usos da planta para o mesmo fim, nas comunidades (Machado e Oliveira, 2014).

Além disso, Alves et al. (2009) avaliaram in vitro a atividade antimicrobiana, antifúngica e antiaderente da $M$. urundeuva sobre microrganismos do biofilme dental e candidiose oral, como alternativa terapêutica odontológica. Observaram-se também atividade antifúngica do extrato de $M$. urundeuva sobre cepas de Cândida albicans, Cândida [122] 
tropicalis e Cândida krusei. Outros autores também descreveram a ação antifúngica do extrato de aroeira (folhas) sob os fungos Colletotrichum gloeosporioides e Corynespora cassiicola (Naruzawa \& Papa, 2011).

Segundo Machado e colaboradores (2014), um dos efeitos biológicos mais conhecidos sobre a M. urundeuva é o seu efeito antimicrobiano, que pode estar associado com os resultados aferidos na medicina popular, sobre a eficácia na cicatrização de ferimentos. Diversos trabalhos na literatura têm testado o extrato da aroeira na inibição do crescimento bacteriano. Bianco (2004) constatou a capacidade de inibir o crescimento bacteriano do extrato vegetal aquoso e hidroalcoólico das folhas da M. urundeuva.

Alves (2009) testou o extrato hidroalcoólico in vitro da M. urundeuva e observou que esta apresentou atividade bactericida e bacteriostática sobre algumas espécies de bactérias como: S. mutans, S. mitis, S. sobrinus, S. sanguis e L. casei; bem como também a ação antifúngica sobre C. albicans, C. tropicalis e C. krusei.

A Chenopodium ambrosioides $L$ popularmente conhecida na região Nordeste do Brasil como Mastruz, possui diversos estudos voltados para o seu potencial antioxidante, inseticida e em especial, antimicrobiano (Abdel-Aziz et al., 2014; Chu et al., 2011). O que tem sido bastante estudado até o momento, são os achados científicos de ações antiparasitárias, antibacterianas e antioxidantes de óleos essenciais extraídos das folhas do mastruz (Monzote et al., 2014).

Embora os alvos terapêuticos na medicina popular, sejam aplicados para o tratamento de doenças respiratórias, pouco se sabe sobre a ação dos extratos e componentes bioquímicos das folhas da $C$. ambrosioides sobre esses tipos de ação. Esse quadro destaca mais uma vez sobre a necessidade de investigações mais especificas da comunidade científica, focando nos alvos terapêuticos populares, para uma melhor confirmação e conhecimento da medicina alternativa.

A terceira planta mais utilizada no NE do Brasil, é a Phyllanthus amarus Schumach, popularmente conhecida como Quebra-pedra, por ser bastante conhecida na medicina popular pelo chá das folhas dessa espécie, supostamente possuir um potencial de desfragmentação de vesículas ou pedras na vesícula e rins, além de ser bastante utilizada também no tratamento de hiperglicemia e inflamações no fígado (Marques et al., 2010).

Embora os seus efeitos ainda não sejam totalmente comprovados cientificamente, na literatura é possível observar alguns trabalhos como os de Faremi et al. (2008) e Srirama et al. (2011), onde foram testados extratos das folhas de Phyllanthus amarus a fim de confirmar o seu efeito hepatoprotetor, obtendo ambos os grupos, resultados significativos tanto na utilização do extrato da referida espécie, como de espécies da mesma família Euphorbiaceae. 
As espécies menos utilizadas são a None (Morinda citrifolia), Confrei (Symphytum officinale), Vinagreira-roxa (Hibiscus sabdariffa), Pau-ferro (Caesalpinia ferrea Mart), Cumaru (Amburana cearenses), Carambola (Averrhoa carambola L.), Tipi (Petiveria alliacea L.) e Malva-branca (Sida cordifolia L.) sendo essas, algumas que foram citadas apenas em um estado nordestino. Entre as plantas encontradas, as famílias botânicas mais representativas foram Fabaceae, Lamiaceae, e Rubiaceae, e esse resultado é confirmado ao observar um número significativo de indivíduos das espécies que foram selecionadas para a revisão.

Nos artigos avaliados também foi possível observar uma maior utilização das folhas das plantas, para fins terapêuticos, em comparação aos demais órgãos. Segundo Cunha et.al. (2015) essa grande utilização se dá pela facilidade da coleta e disponibilidade das folhas, já que elas ficam expostas e estão presas à planta por mais tempo, durante todo o ano, além de concentrarem a maior parte dos princípios ativos necessários para o uso terapêutico.

Nas publicações selecionadas, foi possível observar que a maioria das pessoas que utilizam plantas como método terapêutico nessas regiões, refletem sobre a importância da informação desses conhecimentos na comunidade, incluindo as práticas terapêuticas tradicionais, bem como o caráter familiar da comercialização dos seus recursos.

De acordo com Rodrigues \& Carvalho (2011), essas regiões abrigam grandes grupos de comunidades indígenas, quilombolas, ribeirinhos, pescadores, pequenos produtores rurais e extrativistas, que possuem e fazem uso de um vasto conhecimento sobre a utilização de plantas na medicina popular. E esse conhecimento tem sido passado de gerado a geração, fazendo parte da cultura e costumes dessas comunidades (Giraldi \& Hanazaki 2010). Entretanto, a população tem o habito de usar indiscriminadamente as plantas em geral, em diversas preparações como chás, infusões, pomadas de macerados e extrações alcóolicas dentro do contexto da automedicação (Giraldi \& Hanazaki 2010).

\section{CONCLUSÃO}

Os estudos dos constituintes dessas plantas, bem como seus mecanismos de ação terapêutica, são de grande importância para correlacionar o uso etnofarmacológico com os achados científicos.

Diante da diversidade e do uso de plantas como terapia de doenças, praticados na região do Nordeste do Brasil nos últimos 10 anos, esse estudo serve de estímulo para futuras e promissoras investigações científicas, que possam ratificar e correlacionar os usos populares, com seus constituintes bioquímicos, além de conferir a eficácia dos mesmos sobre as doençasalvo relatadas pelas comunidades e grupos populares, bem como aferir a segurança biológica 
sobre a potencial toxicidade desses compostos.

\section{Referências}

ABDEL-AZIZ, M.S.; SHAHEEN, M.S.; EL-NEKEETY, A.A.; ABDEL-WAHHAB, M.A. Antioxidant and antibacterial activity of silver nanoparticles biosynthesized using Chenopodium murale leaf extract. King Saud University.Journal of Saudi Chemical Society.

ABUAJAH, C.I.; OGBONNA, A.C.; OSUJI, C.M. Functional components and medicinal properties of food: a review. Journal of Food Science and Technology.v.52, n.5, p.25222529, 2015.

AGRA, M.F; DE FREITAS, P.F; FILHO, J.M.B. Sinopse das plantas conhecidas como medicinais e venenosas no Nordeste do Brasil. Revista Brasileira de Farmacognosia Jan./Mar.2007.

ALMEIDA, C.B.R; FÁTIMA, C.; ALBUQUERQUE, U.P. Uso e conservação de plantas e animais medicinais no Estado de Pernambuco (Nordeste do Brasil): um estudo de caso. Interciencia, vol. 27, núm. 6, junio, 2002, pp. 276-285 Asociación Interciencia Caracas, Venezuela.

ALVES, P.M.; QUEIROZ, L.M.G.; PEREIRA, J.V.; PEREIRA, M.S.V. Atividade antimicrobiana, antiaderente e antifúngica in vitro de plantas medicinais brasileiras sobre microrganismos do biofilme dental e cepas do gênero. Rev. Soc. Bras. Med. Trop. vol.42 no.2 Uberaba Mar./Apr. 2009.

ARANTES, E. M.; CREMON, C.; LUIZ, M.A.C. Alterações dos atributos químicos do solo cultivado no sistema orgânico com plantio direto sob diferentes coberturas vegetais. Revista Agraria. nISSN: 1984-2538. Dourados, v.5, n.15, p.47-54, 2012.

ARAÚJO, C.R.F.; SANTIAGO, F.G.; PEIXOTO, M.I.; OLIVEIRA, J.O.D.; COUTINHO, M.S. Use of medicinal plants with teratogenic and abortive effects by pregnant women in a city in Northeastern Brazil. Rev. Bras. Ginecol. Obstet, v.38, p. 127-131, 2016.

ARNOUS, A.H; SANTOS, A.S; BEINNER, R.P.C. Plantas medicinais de uso caseiroConhecimento popular e interesse por cultivo comunitário. Revista Espaço para a Saúde, Londrina, v.6, n.2, p.1-6, jun. 2005.

AZEVEDO, C.F.; QUIRINO, Z.G.M.; BRUNO, R. L. A. Estudo farmacobotânico de partes aéreas vegetativas de aroeira-vermelha. Rev. bras. plantas medicinais. vol.17 no.1 Botucatu Jan./Mar. 2015.

BANKEU, K.J.J.; DIETAGOUM, M.S.; KUMAR, R.; ALI, M.S.; LENTA, N.B.; YOUSUF, S. Crystal structure and Hirshfeld surface analysis of 3-oxours-12-ene-27a,28-dioic acid (quafrinoicacid). Acta Crystallographica Section. E: Crystallographic Communications, v.73, n. 5, p. 763-766, 2017. 
BAPTISTEL, A.C.; COUTINHO, J.M.C.P.; LINS, E.M.F.N.; MONTEIRO, J.M. Plantas medicinais utilizadas na Comunidade Santo Antônio, Currais, Sul do Piauí: um enfoque etnobotânico. Revista Brasileira de Plantas Medicinais, Bom Jesus-PI, v. 16, n.2, p.406425,2014 .

BARROS, B.R.S. Caracterização estrutural e fitoquímica e investigação das atividades antioxidante, antimicrobiana, citotóxica e imunomoduladora promovidas pelo extrato salino das folhas de Malpighia emarginata d.c. (Aceroleira). Monografia apresentada ao Curso de Licenciatura Plena em Ciências Biológicas/UFRPE.

BATISTA, A.A.M.; OLIVEIRA, C.R.M. Plantas utilizadas como medicinais em uma comunidade do semiárido baiano: Saberes tradicionais e a conservação ambiental. Enciclopédia Biosfera, Centro Científico Conhecer- GO, v.10, n.18, p.74, 2014.

BERG, J. M. T. e LUBERT, J. (2008), Bioquímica. 6.Ed. Rio de Janeiro: Guanabara Koogan, 545p.

BRANDÃO, H. N.; NASCIMENTO, J.A.P.; COUTO, R.D.; DAVID, J. P.; DAVID, J.M. Química e Farmacologia de Quimioterápicos antineoplásicos derivados de plantas. Química Nova, v.33, n.6, p.1359-1369, 2010.

CAMPOS, S.C.; SILVA, C.G.; CAMPANA, P.R.V.; ALMEIDA, V.L. Toxicidade de espécies vegetais. Rev. Bras. Pl. Med., Campinas, v.18, n.1.

CARVALHO, J.S.B.; MARTINS, J.D.L.; MENDONÇA, M.C.S.; LIMA, L.D. Uso popular das plantas medicinais na comunidade da Várzea, Garanhuns-PE. Revista de biologia e ciências da terra, v.13, n. 2, 2013.

CHAVES, E.M.F., BARROS, R.F.M. Diversidade e uso de recursos medicinais do carrasco na APA da Serra da IIbiapaba, Piauí, Nordeste do Brasil. Revista Brasileira de Plantas Medicinais, v.14,n.3, 2012.

CHU, S.S; HU, J.F; LIU, Z.L. Composition of essential oil of Chinese Chenopodium ambrosioides and insecticidal activity against maize weevil, Sitophilus zeamais. Published online inWiley Online Library: 24 February 2011.Ciência agrotécnica, v. 25, p. 102-123, 2011.

CONCEIÇÃO, G. M.; RUGGIERI, A. C.; ARAUJO, M. F. V.; CONCEIÇÃO, T. T. M. M.; CONCEIÇÃO, M. A. M. M. Plantas do cerrado: comercialização, uso e indicação terapêutica fornecida pelos raizeiros e vendedores, Teresina, Piauí. Scientia Plena, v.7, n.12, 2011.

CORREA, N.; SOARES, M.C.F.; BAISCH, A.L.M. Conhecimento do tema plantas medicinais e fitoterápicos como instrumento tecnológico na formação dos acadêmicos de enfermagem. Journal Of Health Sciences, v.30, n.2, 2018.

CUNHA, A. L.; MOURA, K. S; BARBOSA, J. C; SANTOS, A. F. Os metabólitos secundários e sua importância para o organismo. DIVERSITAS JOURNAL. Santana do Ipanema/AL. vol 1, n. 2, p.175-181, mai./ago. 2016.

CUNHA, M.M.C.;GONDIM, R.S.D.; BONFIM, B.F.; JUNIOR, N.J.P.B.; BARROSO, W.A.; 
VILANOVA, C.M. Perfil etnobotânico de plantas medicinais comercializadas em feiras livres de São Luís, Maranhão, Brasil. Scientia Plena, v.11, n.12, 2015.

DA CRUZ, P.R., SOUSA, H.A., COELHO, G.P.B., ARAÚJO, M.F.N., VICTOR,P. Riqueza e importância das plantas medicinais do Rio Grande do Norte. Revista de Biologia e

Ciências da Terra, v.11, n.1,p.157-168, 2011.

DAVID, M.; PASA, M.C.; As plantas medicinais e a etnobotânica em Várzea Grande, MT, Brasil. Interações. Campo Grande, v.16, n.1, p.97-108, jan/jun.,2015.

DE MORAIS, S.M; DANTAS, J.D.P; DA SILVA, A.R.A; MAGALHÃES, E.F. Plantas medicinais usadas pelos índios Tapebas do Ceará. Revista Brasileira de Farmacognosia ,Abr./Jun. 2005.

DE SÁ, C.G; DE BARROS, S.O; GOMES, A. P; SILVA FILHO, F. A; TEIXEIRA, K.S.S. Plantas medicinais usadas na região nordeste: revisão integrativa. Rev. bras. plantas med. vol.16 no.4 Botucatu Oct./Dec. 2014.

FAREMI, T.Y.; SURU, S.M; FAFUNSO, M.A.; OBIOHA, U.E. Hepatoprotective potentials of Phyllanthus amarus against ethanol-induced oxidative stress in rats. www.elsevier.com/ locate/foodchemtox.

FEIJÓ, E.V.R.S.; PEREIRA, A.S.; SOUZA; L.R.; SILVA, L.A.M.; COSTA, L.C.B. Levantamento preliminar sobre plantas medicinais utilizadas no bairro Salobrinho no município de Ilhéus, Bahia. Revista Brasileira de Plantas Medicinais, v.15, n.4, p.595-604, 2013.

FERREIRA, R.O.; CARVALHO, M.G.; SILVA, T.M.S. Ocorrência de Biflavonoides em Clusiaceae: Aspectos Químicos e Farmacológicos. Química Nova, v.35, n.11, p.2271-2277, 2012.

FIRMO, W. C. A. et al. Contexto histórico, uso popular e concepção científica sobre plantas medicinais. Caderno de Pesquisa, v. 18, n. especial, p. 90-95, 2011.

FORD, J.B.; SUTTER, M.E.; OWEN, K.; ALBERTSON, T.E. Volatile Substance Misure: An Updated Review of Toxicity and Treatment. Clin. Reviews in Allergy \& Immunology, v. 46, p. 19-33, 2014.

FRANÇA, E.; VASCONCELLOS, A.G. Patentes de fitoterápicos no Brasil: uma análise do andamento dos pedidos no período de 1995-2017. Cadernos de Ciência \& Tecnologia, Brasília, v. 35, n. 3, p. 329-359, set./dez. 2018.

FREITAS, A.V.L.; COELHO, M.F.B.; PEREIRA, Y.B.; NETO, E.C.F.; AZEVEDO, R.A.B. Diversidade e usos de plantas medicinais nos quintais da comunidade de São João da Varzea, Mossoró-RN. Revista Brasileira de Plantas Medicinais, v. 17, n. 4, Botocatu, 2015.

FREITAS, V.S.;RODRIGUES, R.A.F.; GASPI, F.O.G. Propriedades farmacológicas da Aloe vera (L.) Burm. f. Revista Brasileira de Plantas Medicinais, v.16,n.2, p.299-307, 2014.

GIRALDI, M.; HANAZAKI, N. Uso e conhecimento tradicional de plantas medicinais no 
Sertão do Ribeirão, Florianópolis, SC,Brasil. Acta bot. Bras., v.24, n.2, p.395-406, 2010.

GOMES, T.B.; BANDEIRA, F.P.S.F. Uso e diversidade de plantas medicinais em uma comunidade quilombola no Raso da Catarina, Bahia. Acta bot.Bras., v.26, n.4, p.796-809, 2012.

GUERRA, P. M.; NODARI, O. R.; SIMÕES, M. O. Biodiversidade: aspectos biológicos, geográficos, legais e éticos. In: et al. Farmacognosia: da planta ao medicamento. 3. ed. Porto Alegre: UFRGS; Florianópolis: UFSC, 2001. p.15.

ISHAQ, N.;BILAL,M.; IQBAL,H.M.N. Medicinal Potentialities of Plants Defensins: A Review with Applied Perspectives. Medicines, fev, 2019.

KOWALKI, J.; SAMOJEDNY, A.; PAUL, M.; PIETSZ, G.; WILCZOK, T. 2005. Effect of apigenin, kaempferol and resveratrol on the expression of interleukin-1beta and tumor necrosisfactor-alpha genes in J774.2 macrophages. Rep. Pharmacol. 57(3), 390-394, 2005.

KUMAR, B.M.; NAIR, P.K.R. The enigma of tropical home gardens. Agroforestry systens, vol. 19, p. 195-207, 2004.

LANA, S. L. B. et al. Design de biojoias: desenvolvimento de produtos com perfil sustentável. In: ENCONTRO NACIONAL DA ANPPAS, 5., 2010, Florianópolis. Resumos... Florianópolis: ANPPAS, 2010. p. 1-13.

LEMOS, J.R.; ARAÚJO, J.L. Estudo etnobotânico sobre plantas medicinais na comunidade de Curral Velho, Luís Correia, Piauí, Brasil. Biotemas, UFSC, v.28, n.2, 2015.

LIMA, I.E.O.; NASCIMENTO, L.A.M.; SILVA, M.S. Comercialização de Plantas Medicinais no Município de Arapiraca-AL. Revista Brasileira de Plantas Medicinais, v.18, n.2, p.462-472, 2016.

LINHARES, J.F.P.; HORTEGAL, E.V.; RODRIGUES, M.I.A.; SILVA, P.S.S. Etnobotânica das principais plantas medicinais comercializadas em feiras e mercados de São Luís, Estado do Maranhão,Brasil. Revista Pan-Amazônica de Saúde, v.5, n.3,set, 2014.

LOPES, R.M.; OLIVEIRA, T.D.; NAGEM, T.J.; PINTO, A.D.S. Flavonóides. Biotecnologia Ciência \& Desenvolvimento. 2010;3(14).

MACHADO, A.C.; OLIVEIRA, R.C. Medicamentos Fitoterápicos na odontologia: evidências e perspectivas sobre o uso da aroeirado-sertão (Myracrodruon urundeuva Allemão). Rev. bras. plantas med. vol.16 no.2 Botucatu Apr./June 2014.

MACIEL, M.A.M.; PINTO, A.C.; JUNIOR, V.F.V. Plantas Medicinais: A Necessidade de Estudos Multidisciplinares. Química Nova, v.25, n.3,p.429-438,2002.

MAIA-ALMEIDA, C.I.; MING, L.C.; MARQUES, M.O.M.; MAGALHÃES, P.M.; QUEIROZ, S.C.N.; SCRAMIM, S.; MISCHAN, M.M.; MONTANARI-JR,; PEREIRA, B.;FERREIRA, M.I. Densidade de plantio e idade de colheita de quebra-pedra [Phyllanthus amarus (Schumach. \& Thonning) genótipo Unicamp-CPQBA 14] na produtividade de filantina. Rev. Bras. Pl. Med., Botucatu, v.13, especial, p.633-641, 2011. 
MANETTI, L.M.; TURRA, A.F.; TAKEMURA, O.S.; SVIDZINSKI, T.I.E.; LAVERDE, J.A. Avaliação das atividades antimicrobiana, citotóxica, moluscicida e antioxidante de Bromelia antiacantha Bertol. (Bromeliaceae). Revista Brasileira de Plantas Medicinais, Botucatu, v.12, n.4, p.406-413,2010.

MARINHO, M.G., ANDRADE, L.H.C. Levantamento etnobotânico de plantas medicinais em área de caatinga no município de São José de Espinharas, Paraíba, Brasil. Revista Brasileira de Plantas Medicinais, v.13, n.2, p.170-182, 2011.

MINISTÉRIO DA SAÚDE. Secretaria de Ciência, Tecnologia e Insumos Estratégicos Departamento de Assistência Farmacêutica e Insumos Estratégicos. Política e Programa Nacional de Plantas Medicinais e Fitoterápicos. Brasília - DF 2016.

MONZOTE, L.; PASTOR, J.; SCULL, R.; GILLE, L. (2014). Antileishmanial activity of essential oil from Chenopodium ambrosioides and its main components against experimental cutaneous leishmaniasis in BALB/c mice. Phytomedicine 21(8-9):1048-52.

MORAIS, S.M; LIMA, K.S.B.; SIQUEIRA, S.M.C.; CAVALCANTI, E.S.B. ; SOUZA, M.S.T. ; MENEZES, J.E.S.A.; TREVISAN, M.T.S. Correlação entre as atividades antiradical, antiacetilcolinesterase e teor de fenóis totais de extratos de plantas medicinais de farmácias vivas. Revista Brasileira de Plantas Medicinais, v.15, n.4, p.575-582,2013.

NARUZAWA, E.S.; PAPA, M.F.S. Antifungal activity of extracts from brazilian Cerrado plants on Colletotrichum gloeosporioides and Corynespora cassiicola. Rev. Bras. Pl. Med., Botucatu, v.13, n.4, p.408-412, 2011.

NASCIMENTO, W. M.C.; MELO, O.F.; SILVA, I.F.; SOUZA, F.L. Plantas medicinais e sua utilização pelas comunidades do município de Sobral, Ceará. v.2,n.1, 2013.

NETO, F.R.G.; ALMEIDA, G.S.S.A.; JESUS, N.G.; FONSECA, M.R. Estudo etnobotânico de plantas medicinais utilizadas pela comunidade do Sisal no município de Catu, Bahia, Brasil. Revista Brasileira de Plantas Medicinais, v.16, n.4, p.856-865, 2014.

NOGUEIRA, R.C.; CERQUEIRA, H.F. de; SOARES, M.B.P. Patenting bioactive molecules from biodiversity: the Brazilian experience. Expert Opinion on Therapeutic Patents, v.20, p.1-13, 2010. DOI: 10.1517/13543770903555221.

OLIVEIRA, D.M.S.; LUCENA, E.M.P. O uso de plantas medicinais por moradores de Quixadá-Ceará. Revista Brasileira de Plantas Medicinais, v.17, n.3, p. 407-412, 2015.

OLIVEIRA, D.R.; JÚNIOR, F.E.B.; SAMPAIO, L.A.; TORRES, J.C.; RAMOS, A.G.B.; NUNES, A.A. Ethnopharmacological usage of medicinal plants in genitourinary infections by residentes of Chapada do Araripe, Crato, Ceará, Brazil. Revista Brasileira de Promoção à Saúde, v.25, n.3, 2012.

PAL, A. et. al. (2014). Bioactive Compounds and Properties of Seaweeds - A Review. Open Access Library Journal, 1, pp. 752-769.

PEREIRA, P.S; RUYZ, L.L; DE PAULA, J. Ações terapêuticas do capim-santo: uma revisão 
de literatura. Revista Saúde em Foco - Edição nº 10 - Ano: 2018.

PEREIRA, R. J.; CARDOSO, M.G. Metabólitos secundários vegetais e benefícios antioxidantes. J. Biotec. Biodivers. v. 3, N.4: pp. 146-152, Nov. 2012.

PETROVSKA, B. B. (2012). Historical Review of Medicinal Plants Usage. Pharmacog. Rev., 6 (11), pp. 1-5.

RAMOS, E.S.; DAMASCENA, R.S. Avaliação do uso de plantas medicinais na academia da saúde do município de Rio de Contas/BA. Revista Multidisciplinar e de Psicologia, v.12, n. $42,2018$.

REIS,S.G. Levantamento do uso de Plantas Medicinais por agricultores de municípios de Sergipe. Trabalho de Conclusão de Curso, UFS, 2018.

RIBEIRO, D.A.; MACÊDO, D.G.; OLIVEIRA, L.G.S.; SARAIVA, M.E.; OLIVEIRA, S.F.;SOUZA, M.M.A.; MENEZES, I.R.A. Potencial Terapêutico e uso de plantas medicinais em uma área de Caatinga no estado do Ceará, nordeste do Brasil. Revista Brasileira de Plantas Medicinais, Campinas, v.16, p.912-930, 2014.

ROCHA, F. A. G.; ARAÚJO, L. S. G.; LIMA, T. G. D.; SILVA, E. R.; SILVA, P. A.;GUNDIM, M. K. M.; ARAÚJO, M. F. F.; COSTA,N. D. L. Características do comércio informal de plantas medicinais no município de Lagoa Nova/RN. Holos, v.5, 2013.

ROCHA, L.L.; SOUSA L. S.; CAETANO, T. S. Importância do metabolismo secundário para as plantas. Universidade Federal do Amazonas. Manaus-AM 2018.

RODRIGUES, V.E.G.; CARVALHO, D.A. Levantamento Etnobotânico De Plantas Medicinais Do Domínio Cerrado Na Região Do Alto Rio Grande, Minas Gerais. Rev. Bras. Pl. Med., Botucatu, v.9, n.2, p.17-35, 2007.

ROQUE, A.A.; ROCHA, A.M.; LOIOLA, M.I.B.; Uso e diversidade de plantas medicinais da Caatinga na comunidade rural de Laginhas, município de Caicó, Rio Grande do Norte (nordeste do Brasil). Revista Brasileira de Plantas medicinais, Botucatu-SP, v.12, n.1, p.31$42,2010$.

ROSSATO, M.B.; DENARDIN, M.L.B.; SILVA, F.M.; RESSEL, L.B. Plantas Medicinais: o saber sustentado na prática do cotidiano popular. Revista de Enfermagem, v. 15, n.1, janmar, p.132-139, UFRJ, 2011.

SAMUNI-BLANK, M. et. al. (2012). Intraspecific directed deterrence by the mustard oil bomb in a desert plant. Current Biol., 22 (13), pp. 1218-1220.

SANTOS, E. O.; LIMA, L. S.; DAVID, J. M., MARTINS, L. C.; GUEDES, M. L. S.; DAVID, J.P.; Nat. Prod. Res. 2010. Bioactive Oleanane, Lupane and Ursane Triterpene Acid Derivatives. DO - 10.3390/molecules 171012197. Molecules Journal.

SANTOS, S.L.D.X; ALVES, R.R.N.; SANTOS, S.L.D.X.; BARBOSA, J.A.A.; BRASILEIRO, T.F. Plantas utilizadas como medicinais em uma comunidade rural do semiárido da Paraíba, Nordeste do Brasil. Revista Brasileira de Farmácia, 2011. 
SANTOS-LIMA, T.M.; SANTOS, D.R.V.; SOUZA, R.M.; BASTOS, N.G.; SANTOS, M.A.V.; NUNES, E.S.; LIMA, A.G.D. Plantas Medicinais com Ação Antiparasitária: conhecimento tradicional na etnia Kantaruré, aldeia Baixa das Pedras, Bahia, Brasil. Revista Brasileira de Plantas Medicinais, v.18, n.1, p.240-247, 2016.

SAVITHRAMMA, N. et. al. (2011). Screening of medicinal plants for secondary metabolites. Middle-East J. Sci. Res., 8, pp. 579-584.

SILVA, C.G.; MARINHO, M.G.V.; LUCENA, M.F.A.; COSTA, J.G.M. Levantamento etnobotânico de plantas medicinais em área de Caatinga na comunidade do Sítio Nazaré município de Milagres, Ceará, Brasil. Revista Brasileira de Plantas Medicinais, v.17, n.1, p. 133-142, 2015.

SILVA, N.; LUCENA, R.F.P.; LIMA, J.R.F.; LIMA, G.D.S.; CARVALHO, T.K.N.; JÚNIOR, S.P.S.; ALVES, C.A.B. Conhecimento e uso da vegetação nativa da Caatinga em uma Comunidade Rural da Paraíba, Nordeste do Brasil. Bol. Mus. Biol. Mello Leitão, abr, 2014.

SILVA, N.C.B.; REGIS, A.C.D.; ESQUIBEL, M.A.; SANTOS, J.E.S.; ALMEIDA, M.Z. Uso de Plantas Medicinais na comunidade quilombola da Barra II-Bahia, Brasil. Bol Latinoam Caribe Plant Med Aromat,p.435-453, 2012.

SILVA, T.S.S.; MARISCO, G. Conhecimento etnobotânico dos alunos de uma escola pública no município de Vitória da Conquista/BA sobre plantas medicinais. Biofar, Campina GrandePB, v.9,n.2, p.62-73, jun/ago, 2013.

SIMÕES, C. M. O.; SCHENKEL, E. P.; GOSMAN, G.; MELLO, J. C. P.; MENTZ, L. A.; PETROVICK, P. R. (2007). Farmacognosia: da planta ao medicamento. Florianópolis: Editora da UFSC, 1102p.

SIMPLICIO, F.G.; PEREIRA, M.M. Aspectos Químicos e Farmacológicos de Byrsonima (Malpighiaceae). Química Nova, v.34, n.6,p.1032-1041,2011.

SMILJKOVIC, M.; STANISAVLJEVIC, D.; STOKKOVIC, D.; PETROVIC, I.; VICENTIC, J.M.; GRDADOLNIK, S.G.; MARKOVIC, D.; SANKOVIC-BABICE, S.; GLAMOCLIJA, J.; STEVANOVIC, M.; SOKOVIC, M. Apigenin-7-O-glucoside versus apigenin: Insight into the modes of anticandidal and cytotoxic actions. Excli journal., v, 16, p. 795-807, 2017.

SOBRINHO, O.P.L.; PEREIRA, A.I.S.; CANTANHEDE, E.K.P.; XAVIER, R.S.; OLIVEIRA, L.S.; PEREIRA, A.G.S.; CRUZ, C.H.G. Estudo etnobotânico de plantas medicinais e indicações terapêuticas no povoado Fomento, município de Codó, Maranhão, Brasil. Revista Cubana de Plantas Medicinales,v.23, n. 1, 2018.

SOUZA, M.Z.S.; ANDRADE, L.R.S.; FERNANDES, M.S.M. Levantamento sobre plantas medicinais comercializadas na feira livre da cidade de esperança- PB. Revista de biologia e farmácia, v.5,n.1, 2011.

SRIRAMA, R.; DEEPAK, H. B.; SENTHILKUMAR, U.; RAVIKANTH, G.; GURUMURTHY, B.R.; SHIVANNA, M. B. Hepatoprotective activity of Indian Phyllanthus. 
Pharmaceutical Biology Journal.Volume 50, 2012 - Issue 8.

VIEIRA,L.S.; SOUSA, R.S.; LEMOS, J.R. Plantas Medicinais conhecidas por especialistas locais de uma comunidade rural maranhense. Revista Brasileira de Plantas Medicinais, v.17, n.4, p. 1061-1068, 2015.

YAMAGUCHI, K.K.L.; PEREIRA, C.V.L.; LIMA, E.S.; JUNIOR, V.F.V. Química e Farmacologia do Bacuri (Platonia insignis). Scientia Amazonia, v.3, n.2, p.39-46, 2014.

ZHAO, H.; LIU, Q.; WANG, S.; DAI, F.; CHENG, X.; CHEN, W.; ZHANG, M.; CHEN, D. In vitro additive antitumor effects of Dimethoxycurcumin and 5-fluorouracil in colon câncer cells. Cancer medicine, v. 6, n. 7, p. 1698-1706, 2017. 


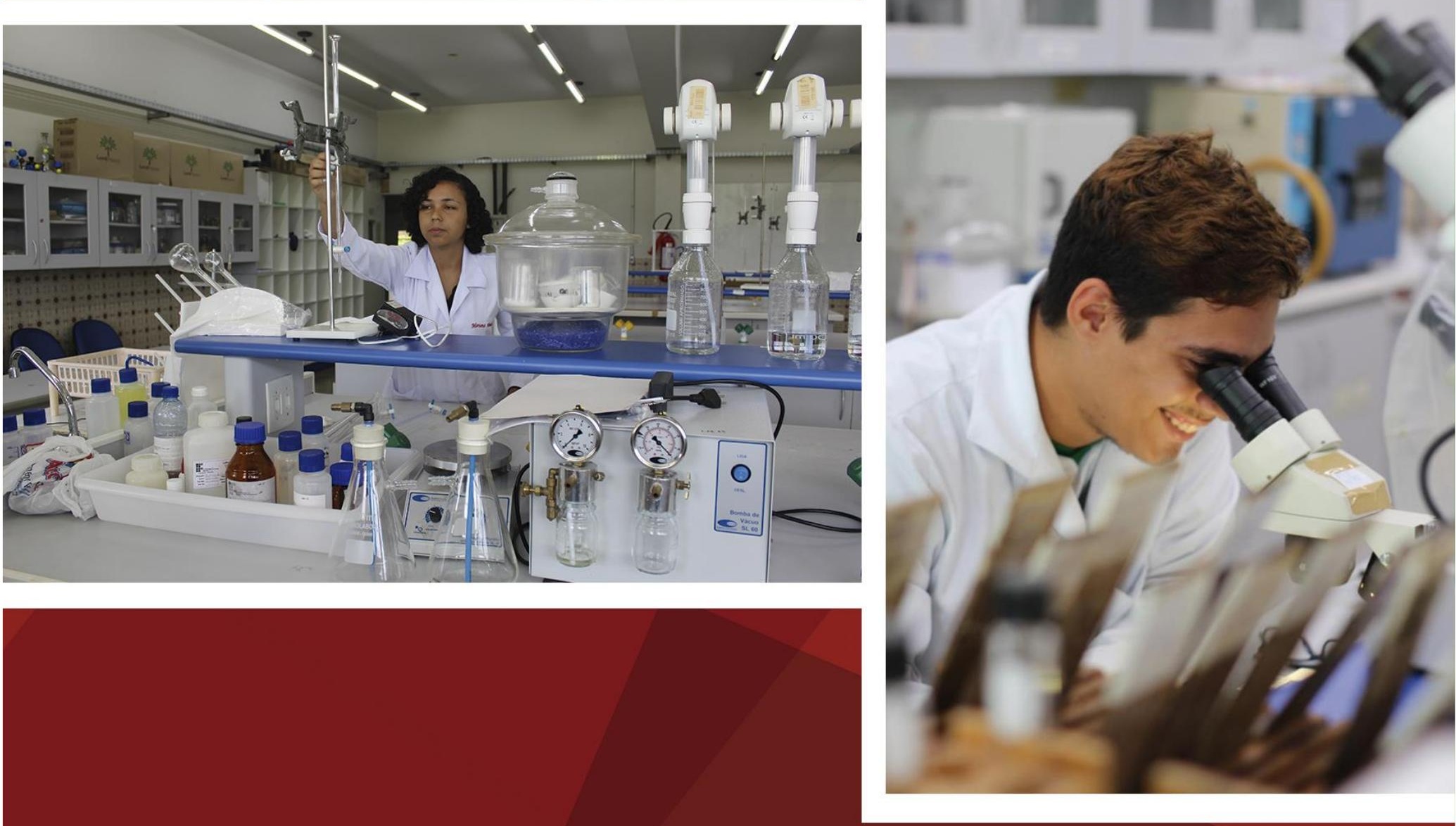

